La Mirada en êl Horizonte de las Cièncias de la Complejidad Rẹvista Digital Internacionàl de Psicología y Ciencia Social

Volumen 1| Nümero 2| Dicienore 2015

- The Glance on the horizon of Complexity science. International Digital Journal
of Psycholgy \& Social Science International Digital Journal
of Psycholgy \& Social Science

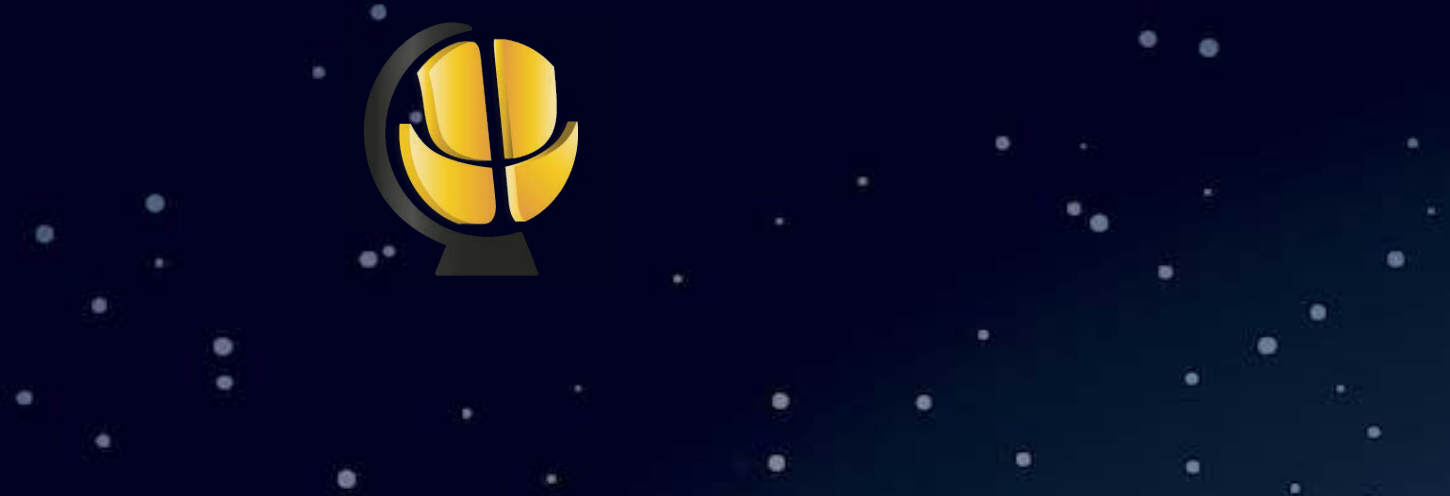
a (1) 


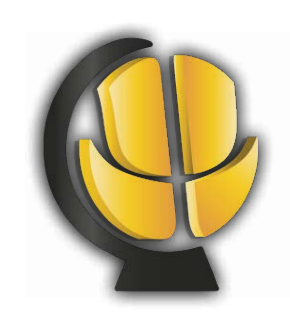

La Mirada en el Horizonte de las Ciencias de la Complejidad

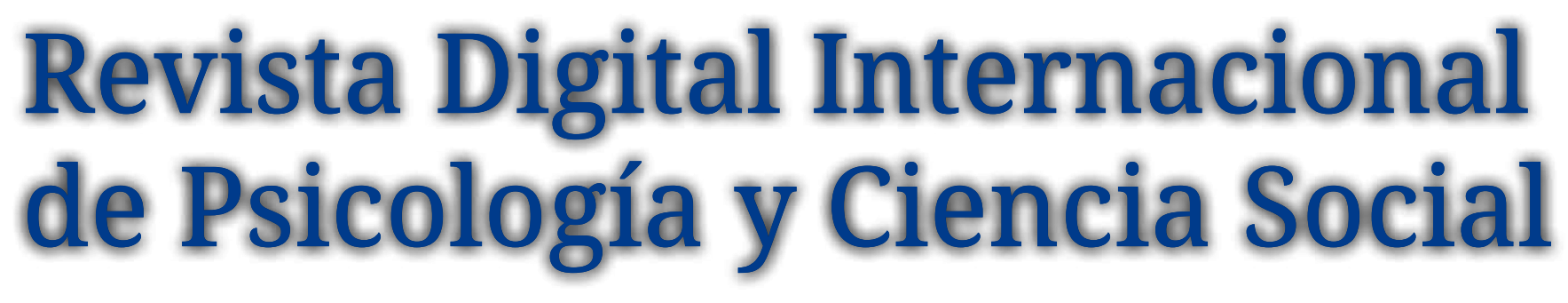

\section{Volumen $1 \mid$ Número 2 | Diciembre 2015}

The Glance on the horizon of Complexity Sciences

\section{International Digital Journal of Psycholgy \& Social Science}


El fin de la ciencia especulativa es la verdad, y el fin de la ciencia práctica es la acción

\section{ARISTÓTELES}




\section{D.R. @ Universidad Nacional Autónoma de México}

Facultad de Estudios Superiores Iztacala

Av. de los Barrios No. 1, Los Reyes Iztacala

C.P. 54090, Tlalnepantla, Edo. de México

\section{Diseño Editorial}

Laboratorio de Evaluación y Educación Digital

UNAM, FES-Iztacala

Tel. (+52) - (55) -56231333 ext. \# 39707

\section{Publicación Periódica a Cargo}

Universidad Nacional Autónoma de México www.unam.mx

Facultad de Estudios Superiores Iztacala www.iztacala.unam.mx/

Corporativo Universitario Virtual de Educación a Distancia (CUVED) www.cuved.unam.mx

El Colegio de Académicos de Psicología de la UNAM, FES-Iztacala (CAPSI)

Asociación de Profesionales e Investigadores en Ciencias de la Educación a Distancia (APICED) www.cuved.unam.mx/apiced

Grupo de Investigación en Procesos Psicológicos y Sociales (GIPPS) www.gipps.org/

\section{Editor General de la Revista}

Arturo Silva Rodríguez

\section{Corrección de Estilo}

Esther López González

Rubén Cortez Aguilar

\section{Composición y MaQuetación de La Revista Mirna Elizabeth Quezada}

Edición Diciembre, 2015

La edición en formato electrónico fue realizada en la Editorial LEED del Laboratorio de Evaluación y Educación Digital<smiles>B</smiles>

Las imágenes de la cubierta, portada, portadillas, secciones y cubiertas de los artículos de la revista fueron cortesia de Freepik

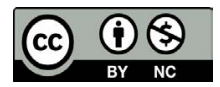

Copyright: @ 2015 Revista Digital Internacional de Psicología y Ciencia Social

Esta es una revista de acceso abierto distribuida bajo los términos de la licencia Creative Commons Reconocimiento-NoComercial 4.0 Internacional, por lo que su contenido gráfico y escrito se puede compartir, copiar y redistribuir total o parcialmente sin necesidad de permiso expreso de sus creadores con la única condición de que no se puede usar con fines directamente comerciales y los términos legales de cualquier trabajo derivado deben ser los mismos que se expresan en la presente declaración. La única condición es que se cite la fuente con referencia a la Revista Digital Internacional de Psicología y Ciencia Social y a sus creadores.

Revista Digital Internacional de Psicología y Ciencia Social 2015, es una una publicación semestral editada por la Universidad Nacional Autónoma de México, tercer piso del edificio B de la of. admin. ext. de la Zona Cultural, Ciudad Universitaria, Coyoacán, C.P. 04510, Distrito Federal, Tel. (55) 5623-1333, Ext. \#39707, http://cuved.unam.mx/rdipycs, rdipycs@gmail.com. Editor Responsable: Arturo Silva Rodríguez. Reserva de Derechos al Uso Exclusivo No. 04-2016-012514394300-203, ISSN: (en trámite), ambos otorgados por el Instituto Nacional del Derecho de Autor. Responsable de la última actualización de este número, Laboratorio de Evaluación y Educación Digital de la Universidad Nacional Autónoma de México (UNAM), Facultad de Estudios Superiores Iztacala, Lic. José Manuel Sánchez Sordo, Av. de los Barrios \#1, Los Reyes Iztacala, Tlalnepantla Edo. de México. C.P. 54090, fecha de última modificación, 25 de enero de 2016. La difusión y soporte digital a cargo del Laboratorio de Evaluación y Educación Digital de la Universidad Nacional Autónoma de México (UNAM), Facultad de Estudios Superiores Iztacala. Las opiniones expresadas por los autores no necesariamente reflejan la postura del editor de la publicación. 


\section{Arturo Silva Rodríguez \\ Editor General \\ Mirna Elizabeth Quezada \\ Editora EJecutiva \\ Abigail Galván Arista \\ EdITORA TÉCNICA}

Consejo Editorial

José Eduardo López Peralta

Directora del Ấrea de las Ciencias Físico_Matemáticas
Adriana García Silva

Directora del Área de las Ciencias Económico-Administrativas

Claudia Lucy Saucedo Ramos

Directora del Ấrea de la Ciencias Sociales

Miguel Ángel Tellez Jardínez

Director del Área de LAS INGenierías

José Manuel Sánchez Sordo

Director del Área de las Humanidades y las Artes
Juan Manuel Mancilla Díaz

Editor General

Época Revista de Psicología y Ciencia Social

Período 2000 a 2005

Jaime Montalvo Reyna

Editor General

É́poca Revista de Psicología y Ciencia Social

Período 2005 a 2009
Rosario Espinosa Salcido

Editora General

É́poca Revista de Psicología y Ciencia Social

Período 2009 a 2014

Rafael Palacios Abreu

Editor de Proyectos

É́poca Revista de Psicología y Ciencia Social

Período 2000 a 2014 
Universidad Nacional Autónoma de México

\section{Facultad de Ciencias Políticas y Sociales}

Ismene Ithai Bras Ruíz Relaciones Internacionales
Alma Adriana Becerril Ramírez

Ciencias de la Comunicación

\section{Universidad Nacional Autónoma de México}

\section{Facultad de Estudios Superiores Acatlán}

José Eduardo López Peralta Matemáticas Aplicadas | Computación
Luis Daniel Vilchiz Alcántara

Matemáticas Aplicadas | Computación

\section{Universidad Nacional Autónoma de México}

\section{Facultad de Estudios Superiores Iztacala}

Laura Edna Aragón Borja

Evaluación Psicológica | Dislexia | Métodos Cuantitativos

María Leticia Bautista Díaz

Psicología de la Salud | Metodología de la Investigación

Enrique Berra Ruíz

Psicología de la Salud | Psicología Clínica

María de los Angeles Campos Huichán Psicología Cultural | Terapia Gestalt

Margarita Chávez Becerra Psicología Educativa | Métodos Cuantitativos

Norma Coffin Cabrera Psicológica Clínica | Psicología de la Salud

Ana Elena del Bosque Fuentes Entornos Virtuales de Aprendizaje | Psicología Educativa

María Guadalupe de los Milagros Damián Díaz Desarrollo Psicológico | Estimulación Temprana

David Javier Enríquez Negrete SUAyED Psicológica | Psicología Clínica y de la Salud

Estela Flores Ortiz Psicología Social | Desempeño Escolar
Gisel Gómez Escobar

Procesos Psicologógicos Básicos | Metodología

Esperanza Guarneros Reyes

SUAyED Psicología | Psicología del Desarrollo Infanti

Jorge Guerrero Barrios

Psicología Experimental | Psicología Educativa

Gilberto Hernández TzinTzun

Ciencias de la Salud | Sociología

Edilberta Joselina Ibáñez Reyes

Psicología Experimental

Omar Moreno Almazán

SUAyED Psicología | Psicología Clínica y de la Salud

Juan Manuel Montiel Génova

SUAyED Psicología | Terapia Familiar

Oscar Iván Negrete Rodríguez

SUAyED Psicología | Métodos Cuantitativos

Rafael Palacio Abreú

Psicología Educativa

Gilberto Pérez Campos

Psicología Cultural | Historia de la Psicología 
Mirna Elizabeth Quezada Gestión Organizacional | Educación Digital

Leticia Nayelli Ramírez Ramírez Psicología Educativa | Diseño curricular

Ma. Refugio Ríos Saldaña Psicología del Adolescente | Habilidades Sociales

David Ruíz Méndez Psicología Experimental | Psicología Organizacional

Ricardo Sánchez Medina SUAyED Psicológica | Psicología Clínica y de la Salud José Manuel Sánchez Sordo Experto en Tecnologías de la Información | Psicología
Christian Sandoval Espinosa

SUAyED Psicología | Terapia Familiar

Claudia Lucy Saucedo Ramos

Psicología Cultural | Psicología Escolar

Aura Silva Aragón

SUAyED Psicológica | Terapia Familiar

José de Jesús Vargas Flores

Editor de la Revista Electrónica de Psicología Iztacala

Cynthia Zaira Vega Valero

Psicología Organizacional | Psicología Clínica y de la Salud

Luis Zarzosa Escobedo

Psicológica Experimental | Psicología Educativa

\section{Universidad Nacional Autónoma de México}

Facultad de Estudios Superiores Zaragoza

Luz María Flores Herrera Psicológica Ambiental | Comportamiento Humano
Juan Jíménez Flores

Psicología de la Salud | Psicología Comunitaria

\section{Universidad Nacional Autónoma de México}

\section{Facultad de Psicología}

German Álvarez Díaz de León Historia de la Psicología | Criminología en México

Nestor Fernández Sánchez

Entornos Virtuales de Aprendizaje | Psicopedagogía
Javier Urbina Soria

Psicología Ambiental | Educación Ambiental
Instituto Politécnico Nacional

José Gonzalo Amador Salinas Psicología Educativa | Tecnología Educativa
Virginia González Rivera

Rendimiento Escolar | Metodología de la Investigación

\section{Universidad Autónoma de Aguascalientes}

Pedro Palacios Salas

Desarrollo Psicológico | Infancia 
Universidad Autónoma de Querétaro

Sonia Sujell Velez Baez Psicología Clínica | Psicoterapia

Universidad Autónoma del Estado de Hidalgo

Rebeca María Elena Guzmán Saldaña Psicología de la Salud | Trastornos Alimentarios

David Jiménez Rodríguez

Psicología de la Salud | Psicología Educativa

Universidad Autónoma del Estado de México

Reyna Amador Velázquez Psicología de la Salud | Adolescencia

Hugo Alberto Yam Chalé Psicología Aplicada | Criminología

Universidad De Guadalajara

Jorge Arauz Contreras

Psicología de la Salud | Gestión Educativa

Universidad de Sonora

Julio Alfonso Piña López

Psicología de la Salud | Gestión Educativa

Universidad JuÁrez Autónoma de Tabasco

Alba Cerino Soberanes

Psicología Educativa | Psicología del Desarrollo

Universidad JuÁrez de Durango

Patricia Lorena Martínez Martínez Psicología Educativa | Psicología Clínica 
Universidad Michoacana de San Nicolás de Hidalgo

Fabiola González Betanzos Psicología de la Salud | Metodología Científica

Juan Torres Melgoza

Psicologia de la Salud | Metodologia Clentifica

Marisol Morales Rodríguez Psicología | Educación Psicología | Educación

Alehtia Dánea Vargas Silva Psicología | Educación

\section{Comité Editorial}

Pontificia Universidad Católica Argentina

Analía Verónica Losada Abuso Sexual Infantil | Patologías Alimentarias

Universidad Católica de Nuestra Señora de la Asunción Paraguay

Norma Coppari González de Vera

Editora de la Revista Eureka

Universidad Federal Fluminense de Brasil

Marialia Etienne Arruguy

Psicología de la Salud | Metodología Científica

Fabiola Arellano Jiménez Terapia Familiar | Consultorio Particular

Silvia Alicia Cabrera Torres Psicología Educativa | Tecnología Educativa

Yu Hing Valeria Chuey Rosas Terapia Familiar | Consultorio Particular
María Fernanda Rodríguez Abello Terapia Familiar | Consultorio Particular

Alondra Belem Medina Luna

Terapia Familiar | Consultorio Particular 


\section{\begin{tabular}{l|l|l} 
Volumen 1 & Número 2015
\end{tabular}}

Jorge Arauz Contreras Psicología de la Salud | Gestión Educativa

Fabiola Arellano Jiménez Terapia Familiar | Consultorio Particular

Grever María Ávila Sansores Psicología de la Salud | Metodología de la Investigación

María Leticia Bautista Díaz Psicología de la Salud | Metodología de la Investigación

Silvia Alicia Cabrera Torres Psicología Educativa | Tecnología Educativa

María de los Ángeles Campos-Huichán Psicología Cultural | Historia de la Psicología

Yu Hing Valeria Chuey Rosas Terapia Familiar | Consultorio Particular

María Teresa Dávalos Romo Psicología del Desarrollo | Infancia
Abigail Galván Arista

Desarrollo Psicológico | Evaluación psicológica

Alondra Belem Medina Luna

Terapia Familiar | Consultorio Particular

Juan Manuel Montiel Génova SUAyED Psicología | Terapia Familiar

María Fernanda Rodríguez Abello Terapia Familiar | Consultorio Particular

Christian Sandoval Espinosa SUAyED Psicología | Terapia Familiar

Aura Silva Aragón SUAyED Psicológica | Terapia Familiar

Hugo Alberto Yam-Chalé Psicología Aplicada | Criminología 


\section{VOLUMEN 1 | NúMERO 2 | DiCIEMBRE 2015 La Mirada en el HorizONTE DE LAS Ciencias de la Complejidad}

Presentación del número, 184

EDITORIAL

193

Racionalidad, Posmodernidad, Complejidad e Investigación Científica. Nuestro

Rumbo, 194

Arturo Silva-Rodríguez

ARTí́culos EMPÍRICOS

Impacto del trabajo Multidisciplinario en Niños con Necesidades Educativas

Especiales, 208

Andrea Lorena Ramos-Ramírez

Propiedades Psicométricas del Cuestionario de Autoeficacia Profesional (AU-10)

en jóvenes mexicanos que estudian y trabajan, 228

Andrés Valdez-Estrella, Edgar Jimenez-Hernandez y Fabiola Itzel Villa-George

La tesis de licenciatura: Imposibilidad por falta de habilidades redactoras, 244

Jorge Daniel Fabila-Cervantes y Alberto Hurtado-Páramo

ESTUDIOS DE CASO

Relación entre nivel de ansiedad y funcionamiento familiar, 263

Lourdes Remigio-Mondragón y Angélica Pérez-Arredondo

RESEÑA DE LIBROS

Familia y Psicología, 286

Nélida Padilla-Gámez

Psicología y Salud, 292

Sandra Ivonne Muñoz-Maldonado 


\section{Q}

La Mirada en el Horizonte délá ciencici Rèvista Digital Internacional de Psicología y Ciencia Social

Volumen 1 | Número 2 | Diciembre 2015 The Glance on the horizon of science. International Digital Journal of Psycholgy \& Social Science 
[Presentación del Número]

Suscribirse a la revista

http://dx.doi.org/10.22402/j.rdipycs.unam.1.2.2015.19.185-192

\section{Presentación del Número de la Revista}

| Volumen 1 | Número 2 | Diciembre 2015 |

\section{TABLA DE CONTENIDO}

INTRODUCCIÓN

ESQUEMA EDITORIAL

ANÁLISIS DE LOS DICTÁMENES DE LOS REVISORES

Perfil de evaluación entre pares, 187

Introducción, 187

Método, 187

Resultados , 188

Todos los apartados, 188

Calificación Promedio de los artículos, 188

Índice de concordancia, 189

Correlograma, 189

Deacuerdo entre revisores, 189

El MATERIAL CIENTÍfICO PUBLICADO

190

REFERENCIAS

191 


\section{INTRODUCCIÓN}

$\mathrm{E}$ ste segundo numero de 2015 de la Revista Digital Internacional de Psicología y Ciencia Social (RDIPyCS) representa un cumulo de esfuerzos para el equipo editorial que involucraron por un lado, el rediseño de la revista para que se ajustará mejor a los parámetros de los motores de búsqueda de Internet; y por otro, la automatización de todo el proceso editorial a través del Open Journal Sytem (OJS), puesto que históricamente en la revista se había utilizado esta herramienta, prácticamente sólo como repositorio de artículos.

Estos esfuerzos tomaron como punto de referencia las mejores prácticas mundiales en la edición de revistas científicas, en consecuencia, nuestra revista se publica ahora en diferentes formatos; en el clásico PDF, en el dinámico e interactivo HTML, en Epub y en mp3.

El formato Epub permitirá que nuestra revista pueda ser leída a través de múltiples dispositivos como serían tablets, móviles, videoconsolas, lectores de libros electrónicos, etc. De igual manera, los documentos publicados podrán adaptarse a distintos tamaños de letra y pantalla, además nuestros lectores contarán con herramientas que les permitirán marcar los pasajes de los materiales publicados que les parezcan más interesantes y compartirlos con sus colegas o pares.

Finalmente, siguiendo una política editorial de inclusión social los artículos científicos se publicarán también en formato mp3, con la finalidad de que sirvan como herramientas de apoyo para personas débiles visuales o ciegas.

\section{ESQUEMA EDITORIAL}

Continuando con su vocación de transparentar las decisiones científico-editoriales, este número de la RDIPyCS muestra al mundo todos los procesos que utiliza para transferir y difundir la ciencia.

Estos procesos se desarrollarán en un esquema editorial que será usado en todos los artículos que se publiquen y consiste en:

1. Portada. Está constituida por título, el resumen en español e inglés de artículo, las palabras claves y la forma de citar de acuerdo a las reglas establecidas por el American Psychological Association (APA).

2. Bitácora. Conformada por el título del artículo, los tiempos editoriales (cuándo se recibió, cuándo fue aceptado para su publicación y la fecha en que fue publicado); las imágenes iconográficas de los dos primeros autores/as del artículo, en caso de que sean más; las secciones de resúmenes curriculares; las contribuciones que hicieron cada uno de los autores/as en la elaboración del artículo; los agradecimientos y los datos de afiliación de las autores/as.

3. Índice. Es una serie de vínculos que permitirán al lector navegar en forma libre por el cuerpo del artículo, lo que evitará una lectura secuencial del material científico publicado.

4. Cuerpo. Consiste en el artículo propiamente. Los apartados en que se desarrolle el material científico dependerán del tipo de estudio que se esté reportando. Si desea conocer los que se aceptan en esta revista diríjase al siguiente vínculo.

5. Meta-análisis del artículo. Está constituido por procedimientos meta-analíticos en donde se presentan cuantitativamente las opiniones que emitieron los evaluadores sobre el artículo. Esta sección del artículo tiene dos dimensiones: la primera es la cuantitativa, constituida por tres partes, (i) el perfil en donde se presentan las opiniones que emitieron los revisores en cuanto a la calidad de la introducción, la metodología, los resultados y todos los apartados del artículo. (ii) La segunda parte presenta la figura de concordancia que existió entre las opiniones de los revisores, construida utilizando el método de Bland y Altman (1986). Finalmente, (iii) la tercera muestra el nivel de acuerdo que se dio entre los revisores al calificar todos los apartados del material científico. La otra dimensión es la cualitativa del meta-análisis en donde se presentan los juicios emitidos por los revisores sobre el manuscrito científico evaluado.

6. Historia del proceso editorial. En él hay dos vínculos, uno permite el acceso al meta-análisis en línea, y en el otro se puede consultar todo el proceso editorial del artículo, que incluye las conversaciones entre los autores y los revisores, es decir, el intercambio dialógico entre los actores científicos.

\section{ANÁlisis de LOS DICTÁMENES de lOS REVISORES}

En esta sección se presenta un análisis global de los dictámenes que los revisores hicieron de todos los artículos publicados en este número de la revista. Podría decirse que es una especie de radiografía en conjunto que nos 
habla de la opinión que los revisores se formaron de los materiales científicos publicados.

Con esto se busca que el lector tome como punto de referencia la opinión de los revisores, que son gente de la comunidad científica; la contraste con su opinión y saque sus propias conclusiones sobre la calidad, relevancia e impacto de lo que se publicó en este número.

De esta manera se irá formando una opinión pública fundamentada en la transparencia de las decisiones que se toman para transmitir el conocimiento científico; es decir, una opinión pública informada producto del entendimiento personal que tiene cada revisor/a y de la valoración que hagan los lectores del material científico divulgado.

Al igual que en cada artículo, en este apartado de la revista se presenta el meta-análisis, pero a diferencia de aquel, aquí se muestra el resultado de la opinión que emitieron los revisores/as en su conjunto de los artículos publicados. Las secciones son: el perfil de evaluación entre pares, la calificación promedio otorgada a cada uno de los artículos, el índice de concordancia, el correlograma y el índice de desacuerdo entre revisores/as.

Es importante mencionar que aunque se habla de los revisores/as, esto no significa que cada uno de ellos haya evaluado todos los artículos publicados en la revista, sino más bien para este meta-análisis se consideró a cada revisor como una unidad de análisis y cada artículo como si fuera uno mismo, es decir, el conjunto de dictámenes se tomó a manera de una unidad replicativa, ya que cada dictamen fue hecho por diferentes revisores/as.

Si bien como lo señalan Glass, Wilson, y Gottman (1975); Yin (1984); Menard (1991) y Silva-Rodríguez (2004), los análisis que se basan en unidades replicativas son más propensos a verse afectados por fuentes de invalidez, debido a la alteración de la naturaleza de los individuos (en nuestro caso diferentes revisores/as) que componen la unidad de observación, puesto que es probable confundir el efecto de los juicios de los revisores/ as con cambios abruptos en la composición de dicha unidad. Sin embargo, la unidad replicativa está menos sujeta a efectos de información y reactividad, puesto que si fueran los mismos revisores/es de todos los artículos que se publican en un determinado número de la revista acarrearían su sesgo en todos los artículos evaluados.

Tomando en consideración lo anterior, el algoritmo que se utilizó para calcular el perfil de la revista, los índices de concordancia y acuerdo, así como el correlograma y la calificación otorgada a los artículos de este número fue el siguiente:

$$
\text { Opinión }=\frac{\left(a_{11}+a_{21}\right)+\left(a_{32}+a_{42}\right)+\ldots+\left(a_{i j}+a_{1 j}\right)}{n}
$$

En donde:

$a$ es la opinión de la revisión i del artículo j iésima revisión $=1,2, \ldots$, hasta $\boldsymbol{n}$, y

jésimo artículo $=1,2, \ldots$, hasta $\boldsymbol{k}$

Que para el caso de este número de la revista $\boldsymbol{n}$ es igual a 8 revisores y $\boldsymbol{k}$ igual a 4 artículos.

\section{Perfil de evaluación entre pares}

Por su parte el perfil evalúa la apreciación que le asignaron los revisores a las partes más amplias que constituyen el reporte de la literatura científica como son la introducción, el método, los resultados y todos los apartados del artículo.

\section{Introducción}

En la figura 1 se muestra la opinión que emitieron respecto a la introducción de todos los artículos. Como se puede observar en esa figura, los revisores opinaron que la definición de variables fue satisfactoriamente baja; debido a que hubieron algunos detalles que se omitieron, por lo que le asignaron la calificación de 2.05 de una calificación máxima de 4.

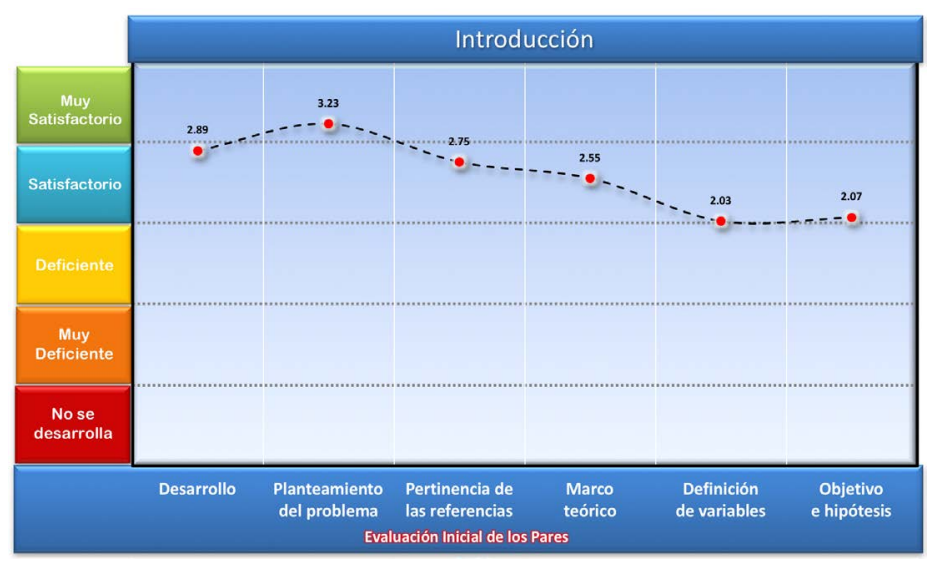

Figura 1.

Perfil de la opinión de los revisores sobre cada uno de los componentes de la introducción de los artículos.

Por otro lado, la opinión más favorable fue en el planteamiento del problema al conceder una puntuación de 3.23 de una de 4. Finalmente, al observar a lo largo de todo el patrón de opinión, los revisores consideraron que los artículos en cuanto a introducción eran muy satisfactorios, ya que el desarrollo, el planteamiento del problema, la pertinencia de las referencias, el marco teórico y el objetivo e hipótesis fueron calificados dentro de esa categoría. 


\section{Método}

Según los revisores, los artículos muestran una variabilidad considerable en el método, como se observa en la figura 2. Ellos consideraron que el desarrollo de las cuestiones éticas relacionadas con las temáticas abordadas por los artículos fue deficiente, puesto que la calificación que le otorgaron fue apenas de 1 de 4.

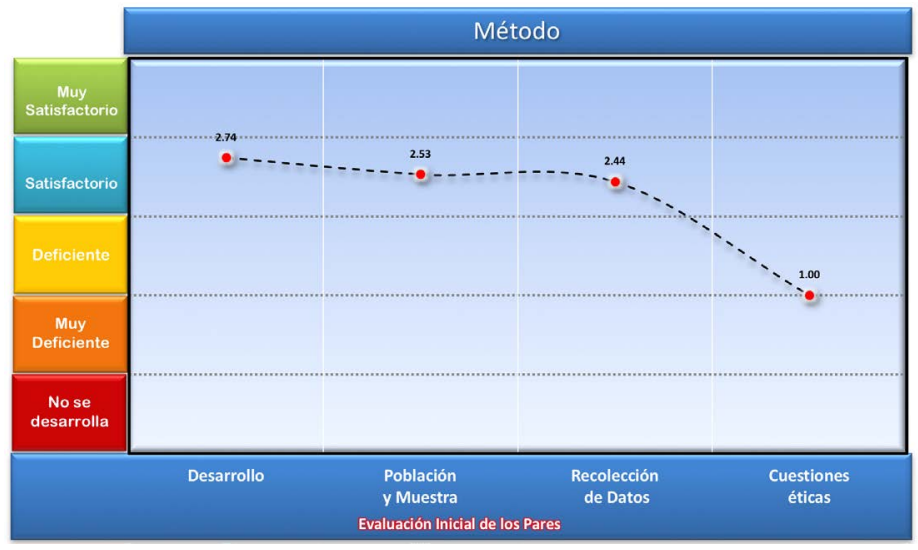

Figura 2.

Perfil de la opinión de los revisores sobre cada uno de los componentes del método de los artículos.

La opinión más favorable fue para los aspectos relacionados con la recolección de la información de los estudios, así como para la forma en que se desarrolló, se identificó a la población y se seleccionó la muestra, ya que todas éstas fueron consideradas como satisfactorias.

\section{Resultados}

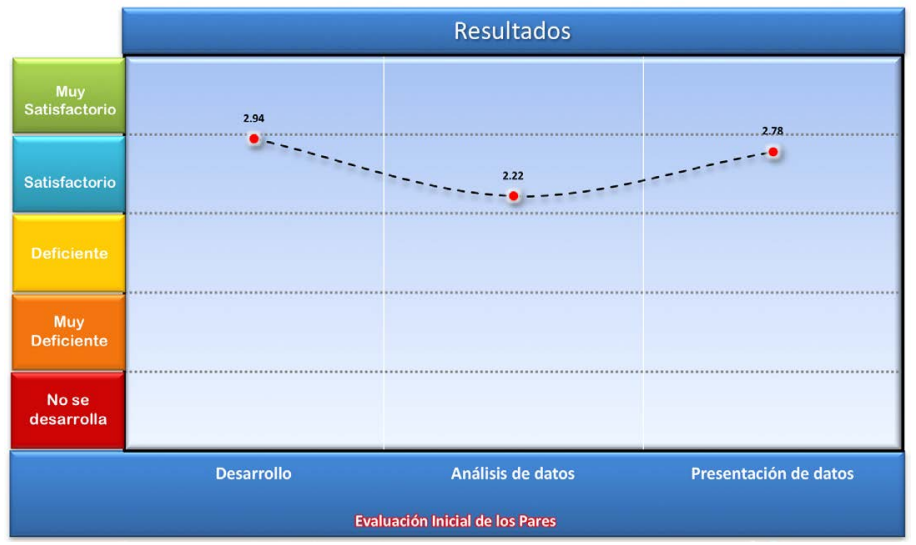

Figura 3.

Perfil de la opinión de los revisores sobre cada uno de los componentes de los resultados de los artículos.

En cuanto a la presentación de resultados (véase figura 3) las opiniones fueron más estables, ya que los revisores consideraron que la forma en que se desarrolló este apartado fue satisfactoria con una calificación de 2.94 de 4. Además consideraron que el análisis de datos Ilevado a cabo en los artículos fue satisfactoria.

Finalmente la presentación de los datos mediante tablas y gráficas fue considerada satisfactoria, alcanzando una calificación de 2.78 .

\section{Todos los apartados}

En la figura 4 se muestra la opinión emitida sobre todos los apartados. Como se puede ver en esa figura, los revisores le otorgaron a las conclusiones una calificación de 2.33, que las colocan en una calidad de satisfactorias en todos los artículos que se publican en este número.

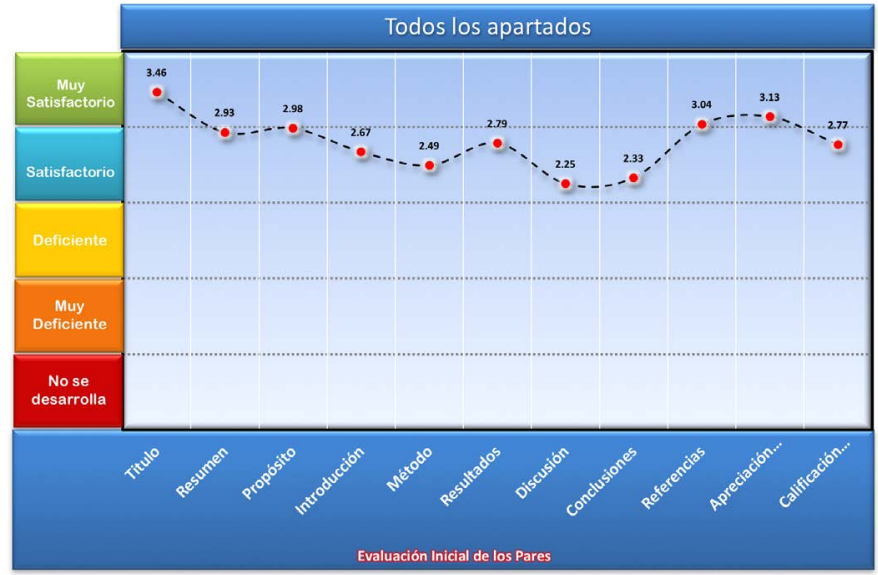

Figura 4.

Perfil de la opinión de los revisores en todos los apartados de los artículos.

Los otros apartados, como son el título, la referencias y sus apreciaciones, los consideraron muy satisfactorios; mientras que el resumen, propósito, introducción, método, resultados y la discusión las consideraron satisfactorias.

Por último, la calificación promedio otorgada a los artículos fue de 2.72, con lo cual puede decirse que los revisores opinaron que su calidad fue satisfactoria, ya que su apreciación cae levemente en esa categoría de la escala.

\section{Calificación Promedio de los artículos}

En la figura 5 se presenta la calificación promedio otorgada por los evaluadores al artículo que revisaron. En dicha figura puede observarse que la calificación otorgada a los artículos varió entre 88.39 y 57.31 , en una escala del 0 al 100, que corresponde al artículo escrito por la autora Ramos Ramírez y al escrito por Fabila y Hurtado, respectivamente.

Como se puede ver, la mayoría de los artículos obtuvieron una calificación variada el de Remigio y Pérez con un 59.19; y el de Valdez Jiménez y Villa con 71.97. 


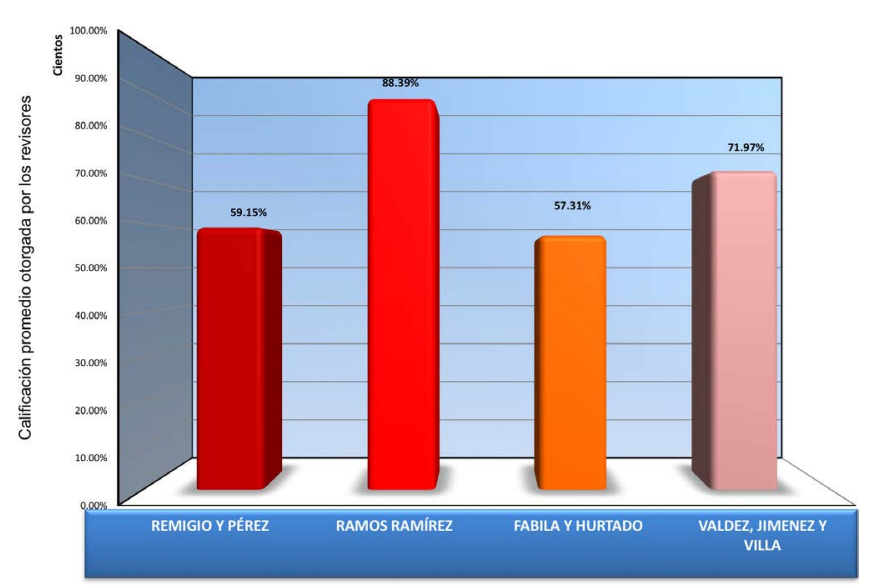

Figura 5.

Calificación promedio otorgada por los revisores al artículo.

\section{Índice de concordancia}

Este índice indica el acercamiento que hubo en los juicios de los revisores; es decir, la magnitud en que éstos reportan resultados iguales; mide por lo tanto la variabilidad entre sus opiniones o juicios con respecto a los dictámenes que emitieron del artículo.

Para construir la figura 6, se tomó la calificación promedio de los juicios que los revisores asignaron a las nueve partes del artículo, como fueron título, resumen, propósito, introducción, método, resultados, discusión, conclusiones y referencias.

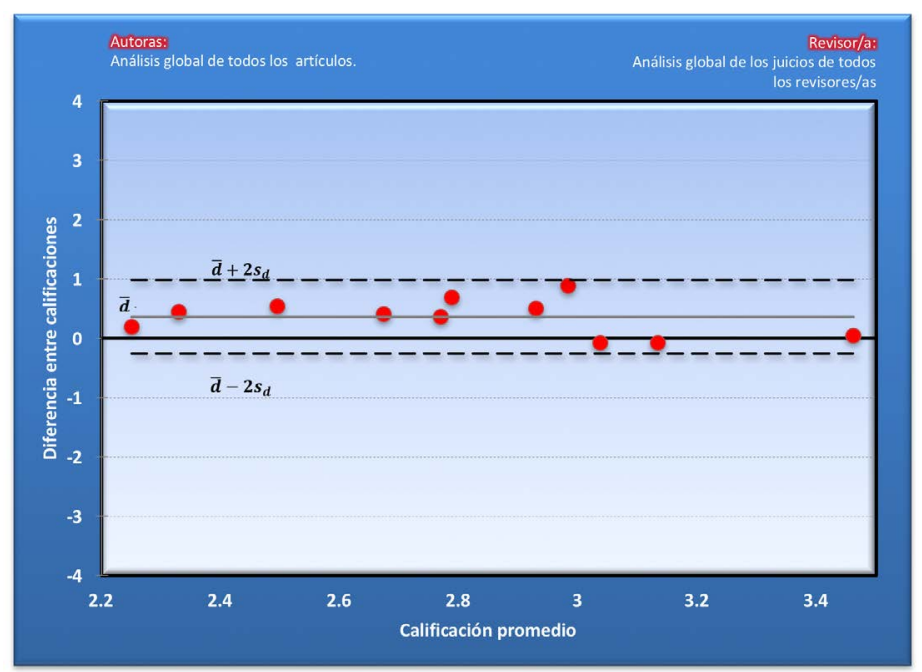

\section{Figura 6.}

Indice de concordancia en los juicios de los revisores.

En dicha figura se observa que la concordancia entre los revisores fue grande, ya que la diferencia entre ellos no superó el límite de las desviaciones estándar de las diferencias; solamente en el apartado de referencias la diferencia estuvo a punto de superar ese límite al obte- nerse una diferencia de 0.95 cuando el límite superior fue de 1.00 .

\section{Correlograma}

En la figura 7 se muestra el correlograma de los juicios que emitieron los revisores, es una figura construida a partir de calcular los índices de correlación entre las opiniones emitidas.

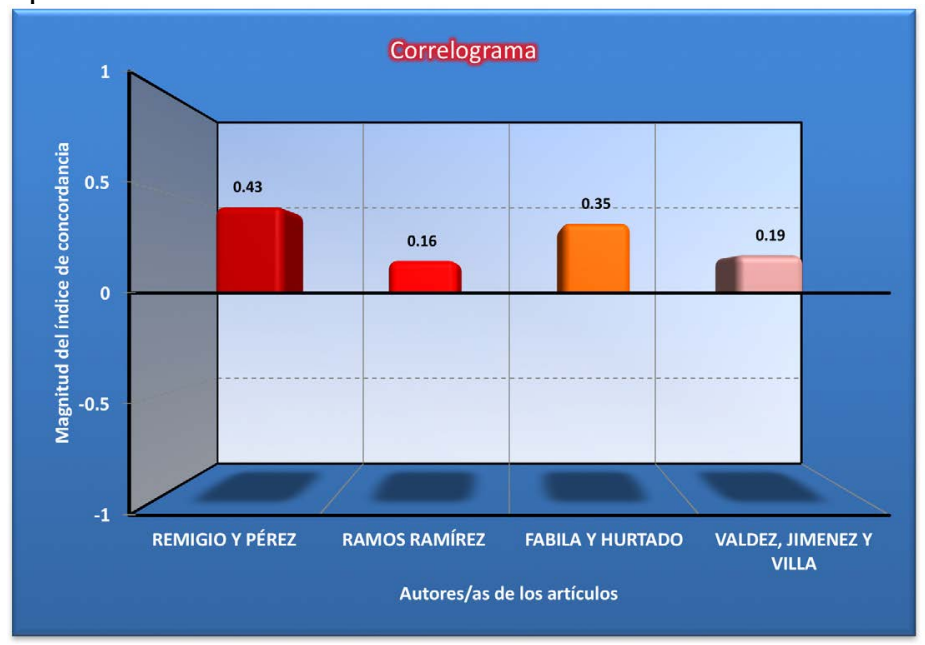

Figura 7.

Correlación entre los juicios de revisores.

Los juicios de los revisores que se correlacionaron en el mismo sentido y con una magnitud moderada fueron los que revisaron el artículo de Remigio y Pérez con un índice de 0.43 , después el de Fabila y Hurtado, con 0.35.

Las opiniones de los revisores que no se correlacionaron fueron los que dictaminaron el artículo de Ramos con 0.16, igualmente los que revisaron el artículo de Valdez, Jiménez y Villa sus juicios estuvieron contrapuesto debido a la magnitud de la correlación también fue baja, de 0.19, 3 décimas que el de Ramos.

\section{Desacuerdo entre revisores}

Finalmente la figura 8 muestra el desacuerdo entre los revisores, independientemente de su sentido, puesto que sólo evalúa la magnitud de la diferencia de opinión.

Los revisores que menos desacuerdos tuvieron fueron los que dictaminaron el artículo de Fabila y Hurtado, al otorgarle uno de ellos una calificación de 57.42 y el otro de 57.20.

Por otro lado, los desacuerdos más grandes en la opinión de los revisores se encontraron en los que dictaminaron el artículo de Váldez, Jiménez y Villa que fue de 32.74 puntos porcentuales, uno le otorgó la calificación de 88.44 mientras que el otro le designó un valor de 55.50.

También se observó una variabilidad muy grande en las opiniones de quienes dictaminaron el artículo de Remigio y Pérez, en donde la diferencia de la calificación entre 
ellos fue de 20.29 puntos porcentuales, uno le asignó un valor de 49.01 y el otro de 69.30. Igualmente la diferencia de opinión fue grande entre los revisores del artículo de Ramos, la cual alcanzo la magnitud de 17.22 puntos porcentuales, uno le asignó 97 puntos y el otro 79.78 .

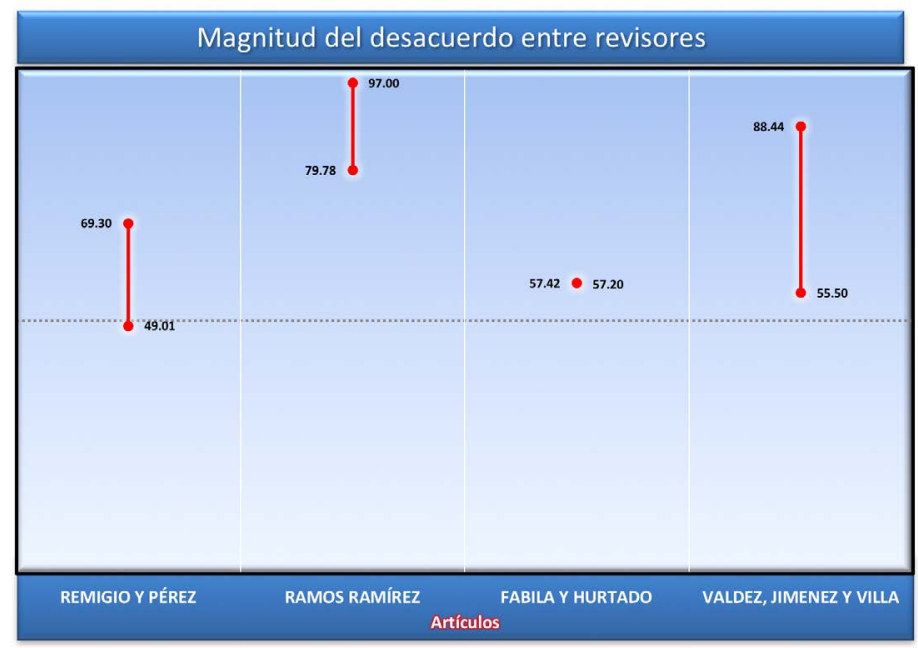

Figura 8.

Desacuerdo entre revisores.

Como se podría esperar por estos resultados la diferencia de opinión entre los revisores fue la regla más que la excepción. Esto confirma que los criterios utilizados son muy diversos y que no coinciden en sus apreciaciones sobre la calidad de un artículo.

Estas discrepancias en la apreciación de la calidad de los artículos son valoraciones que los revisores las perciben subjetivamente, lo relevante de todo esto es encontrar el punto en donde las diversas subjetividades, principalmente de los revisores, coincidan para así tener una revista que facilite la comunicación científica, no obstante que sea una realidad artificial producto de los múltiples significados y sentidos que los revisores le asignen al material científico revisado.

\section{El material CIENTífico Publicado}

En el mundo científico se está viviendo en esta época posmoderna cambios vertiginosos que han producido rupturas epistemológicas que tienen que ver con la racionalidad que se sigue para realizar la investigación científica. En este entorno de cambio, las revistas que difunden el quehacer científico necesitan alinear sus políticas editoriales para convertirse en un factor de cambio hacia una nueva forma de hacer y validar el conocimiento que generen las comunidades de científicos.

Es innegable que cada día que pasa se están interrelacionando distintos movimientos científicos y disci- plinarios, los cuales han dado origen al florecimiento de un pensamiento unificado alrededor en las ciencias de la complejidad.

Ante este panorama, en la Revista Digital Internacional de Psicología y Ciencia Social se decidió publicar artículos en un amplio rango de campos científicos, puesto que se pretende difundir los avances de la producción científica y tecnológica en los campos de la psicología, las ciencias sociales, de la salud, las ingenierías y las humanidades para fomentar, generar y desarroIlar el conocimiento transdisciplinario entre las distintas disciplinas que comprenden al campo de estudio de las ciencias sociales y de la salud, de las ingenierías y de las humanidades.

Precisamente, el artículo editorial de este número tiene el propósito de guiar y orientar a sus autores y lectores acerca del enfoque y las líneas editoriales que se siguen en la revista. Para lograr este objetivo, en primer término en el artículo editorial se aborda el sentido del concepto de racionalidad, que es el principio que organiza todas las acciones encaminadas a la generación de conocimiento científico; en seguida se examina el papel que tiene la racionalidad en la investigación científica; a continuación se analiza la relación entre racionalidad y verdad; posteriormente se aborda la maneras en que el pensamiento complejo ha cambiado el modo de hacer investigación científica en nuestro tiempo; el artículo finaliza concluyendo que la adopción del enfoque de la complejidad en la investigación científica conlleva un cambio en la mentalidad de la sociedad y se revolucionen las decisiones de poder entre los diferentes niveles de decisión de la comunidad científica.

El artículo de Ramos presenta de una manera clara y concisa el impacto que tienen las intervenciones multidisciplinarias en un centro de desarrollo educativo comunitario que atiende a niños con necesidades educativas especiales.

Los hallazgos mostraron que una atención médica primaria propició la detección y atención temprana de diversos padecimientos y el control del niño sano. El estudio demuestra además cómo el trabajo de múltiples disciplinas tiene efectos positivos, ya que las indicaciones de los optómetras y médicos permitieron un trabajo integral con los niños en el ámbito psicológico.

La autora concluye que el trabajo multidisciplinario impactó favorablemente, puesto que hubo avances en todos los ámbitos de intervención, los niños mostraron una mejoría notable en habilidades sociales, motrices y de autocuidado, gracias al múltiple trabajo de las disciplinas implicadas, cada una de ellas contribuyendo en su ámbito de la salud. 
El siguiente estudio aborda el tema de la autoeficacia que en los últimos años ha tenido un auge importante en la investigación científica, varios de estos estudios se han enfocado a construir instrumentos para medirla. El estudio de Valdez, Jiménez y Villa se centra en evaluar la autoeficacia en el ámbito laboral midiéndola desde una perspectiva contextual, con la finalidad de analizar las propiedades psicométricas del cuestionario de Autoeficacia Profesional (AU-10) en mexicanos que estudian y trabajan.

Los resultados del análisis de confiabilidad y de validez concurrente realizado, mostraron que el cuestionario es confiable y en cuanto a la validez concurrente se encontró una correlación positiva, así como una relación significativamente positiva con las subescalas del Inventario de Desempeño Laboral.

Los autores concluyen que el cuestionario de Autoeficacia Profesional (AU-10) cuenta con adecuadas propiedades psicométricas de confiabilidad y validez, por lo que sugieren que puede utilizarse en investigaciones relacionadas con la autoeficacia en el ámbito laboral en población mexicana.

En el artículo de Remigio y Pérez se reporta un estudio de caso clínico sobre ansiedad y funcionamiento familiar, en el cual se muestra que la influencia de este último puede afectar positiva o negativamente en la salud de los miembros de la familia.

Tomando como base esta idea las autoras idearon su plan terapéutico para el caso clínico bajo la hipótesis de que la relación funcional de la familia se veía influida por la ansiedad que presentaba la madre, y que posiblemente era producto de un conflicto encubierto en el holón conyugal y el síntoma era exteriorizado por los hijos.

Las autoras describen como durante el proceso terapéutico se logró abrir el conflicto que limitaba el funcionamiento familiar, apoyándonos en el enfoque centrado en soluciones y la hipnosis ericksoniana. Además reportan cómo la sujeto después del tiempo de seguimiento continuaba manteniéndose tranquila y su familia también tomando ya decisiones con sus hijos adolescentes.

En el artículo final de este número de la revista, Fabila y Hurtado analizan el problema de la poca atención que recibe en la educación básica el establecimiento de habilidades redactoras, lo cual repercute en las dificultades que muestran la mayoría de los alumnos de educación superior para redactar su tesis. Esta dificultad se convierte en un gran obstáculo al momento del egreso de la licenciatura manifestándose en una incapacidad para elaborar la tesis, ya que al no saber redactar, no hay forma de reflejar el pensamiento, y al tener dificultades para plasmar el pensamiento, se tienen problemas de análisis y reflexión; así como de las habilidades fundamentales para desarrollar cualquier tema académico.

De acuerdo con esto, Fabila y Hurtado plantean la necesidad de identificar el nivel de habilidades de redacción en estudiantes universitarios para observar de qué manera éstas influyen en la elaboración de una tesis de licenciatura. El estudio realizado fue de naturaleza cualitativa realizándose entrevistas estructuradas a 34 alumnos, además a otros 15 alumnos se le requirió que elaborarán un ensayo en el que se les pidió que reflexionarán sobre la manera de transmitir conocimiento.

Los resultados encontrados mostraron que el 93\% de los escritos tenían problemas de ortografía, puntuación, sintaxis y en general mala redacción. Respecto a los entrevistados, el $62 \%$ argumentó que no le gusta hacer investigación, debido a la complejidad de buscar, interpretar y citar la información consultada.

Este segundo número finaliza con dos reseñas de libros, uno es de la autora Analía Verónica Lozada, el otro es de Julio Alfonso Piña López. El primero lleva por título "Familia y Psicología", publicado por la Editorial Dunken en 2015, en él la autora nos habla de la familia, pero no de aquella armoniosa que transmite en la televisión, sino aquella que recibe las complicaciones sociales y que pasa por transiciones, dificultades y fortalezas las cuales marcan su devenir histórico.

Nelida Padilla Gámez hace una reseña amena de este libro y describe las ideas principales que la autora desarrolla a lo largo de su obra, principalmente aqueIlas que tienen que ver con las diversas configuraciones afectivas que hoy conocemos como familia y como la autora toca el tema de las familias reconstruidas, familias homoparentales, las conformadas por dos miembros o las que tienen una mamá o un papá.

El segundo libro de este conjunto de reseñas Ileva por título "Psicología y Salud: Obstáculos y posibilidades para su desarrollo en el siglo XXI", en él su autor examina la manera en que se relaciona la conducta humana con la salud.

En la reseña que hace Sandra Ivonne Muñoz Maldonado del libro motiva a leerlo remarcando una de las muchas bondades que posee relacionadas principalmente con la manera de abordar el papel que tienen los sistemas teóricos en la fundamentación de las explicaciones científicas, así como también en su potencial aplicación práctica en los ámbitos de la prevención y tratamiento de las enfermedades más apremiantes que hoy en día aquejan a amplios sectores. 


\section{Referencias}

Bland, J. M., \& Altman, D. G. (1986). Statistical methods for assessing agreement between two methods of clinical measurement. Lancet, 327(8), 307-310. https://wwwusers.york.ac.uk/ mb55/meas/ba.pdf

Glass, G. V., Wilson, F., \& Gottman, G. (1975). Design and analysis of time-series experiments. Boulder: Colorado Associated Press.
Menard, S. (1991). Longitudinal research. London: SAGE University paper.

Silva-Rodríguez, A. (2004). Diseño de investigación con $\mathrm{N}=1$ o series de tiempo. In A. Silva Rodríguez (Ed.), Métodos cuantitativos en psicología. Un enfoque metodológico (pp. 45-70). México: Trillas.

Yin, R. K. (1984). Case study research: design and methods. Thousand Oaks: Sage Publications, Inc..

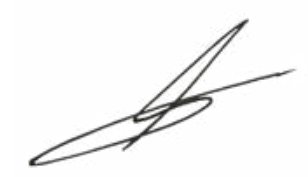

Arturo Silva Rodríguez

Diciembre, 2015 


\section{Editorial}

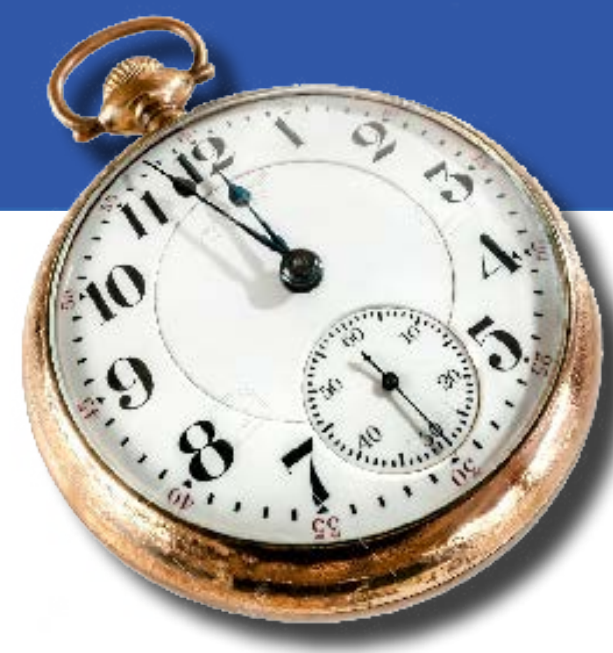




\title{
Racionalidad, Posmodernidad, Complejidad e INVestigación Científica. NUESTRO RUMBO
}

\author{
Arturo Silva-Rodríguez \\ UNAM, FES IZTACALA
}

MÉXICO

\section{RESUMEN}

Este artículo editorial tiene el propósito de guiar y orientar a sus autores y lectores sobre el enfoque y las líneas editoriales que se siguen en la revista, con la finalidad de romper con la inercia de sólo publicar lo que se produce, sino también estimular la producción de conocimiento fijando líneas editoriales que respondan al concepto de racionalidad más actual que sustenta la investigación científica en esta época posmoderna, como es el pensamiento complejo. Para lograr este objetivo en primer término, se aborda el sentido del concepto de racionalidad que es el principio que organiza todas las acciones encaminadas a la generación de conocimiento científico; en seguida se examina el papel que tiene la racionalidad en la investigación científica; a continuación, se analiza la relación entre racionalidad y verdad; posteriormente se aborda la manera en que el pensamiento complejo ha cambiado las formas de hacer investigación científica en nuestro tiempo; el artículo finaliza concluyendo que la adopción del enfoque de la complejidad en la investigación científica conlleva un cambio en la mentalidad de la sociedad y se revolucionen las decisiones de poder entre los diferentes niveles de decisión de la comunidad científica.

\section{Palabras Clave:}

Racionalidad, Posmodernidad, Complejidad, Investigación científica, Verdad científica, Ciencias de la complejidad

\section{Rationality, Postmodernism , Complexity and SCIENTIFic ResearCh. OUR COURSE}

\begin{abstract}
The purpose of this paper is to function as a source of guidance and orientation to the authors and readers about the main focus and editorial paths that this journal follows, in order to break up the inertia of simply publishing what is produced and stimulate the knowledge production anchored in editorial paths that correspond with the cutting edge concept of rationality that supports postmodern science, as critical thinking. To accomplish this objective, first the main sense of rationality concept, as the principle that organizes all the actions toward scientific knowledge generation, is addressed. Second, an examination of the role of rationality in scientific knowledge generation follows. Then, the relationship between rationality and the truth is analyzed. Later, how the way critical thinking has changed the ways of conducting scientific research in our time is addressed. The paper closes pointing out that embracing the complexity approach in scientific research leads to a mentality change in society, followed by revolutionary changes in the scientific decision-taking process across all hierarchical levels in the scientific community.
\end{abstract}

\section{Keywords:}

Rationality, Postmodernism, Complexity, Scientific Research, Scientific Truth, Complexity Sciences

Bitácora del Artículo:

| Recibido: 27 de mayo de 2015 | Aceptado: 3 octubre de 2015 | Publicado en línea: 15 de diciembre de 2015 | 


\title{
Autoría y Derechos de Propiedad Intelectual
}

\section{Racionalidad, Posmodernidad, Complejidad e INVESTigación Científica. NUESTRO RUMBO}

\author{
Arturo Silva-Rodríguez
}

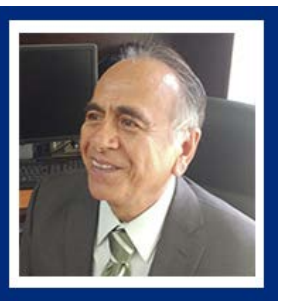

Arturo Silva-Rodríguez

UNAM - FES Iztacala

Correo: arturomeister@gmail.com

Psicólogo por la Facultad de Estudios Superiores Iztacala, estudios de matemáticas aplicadas en la Facultad de Ciencias de la UNAM, maestría en modificación de conducta por la Facultad de Estudios Superiores Iztacala, doctor en sociología por la Facultad de Ciencias Políticas y Sociales de la UNAM.

Ver más...

\section{AgRADECIMIENTOS}

La elaboración de este artículo fue financiado con recursos proporcionados por la Dirección General de Asuntos de Personal Académico de la UNAM a través del proyecto PAPIME PE303215.

\section{DAtOS DE FILIACIÓN DEL AUtOR}

Universidad Nacional Autónoma de México | FES-Iztacala

Copyright: (c) 2015 Silva-Rodríguez, A.

Este es un artículo de acceso abierto distribuido bajo los términos de la licencia Creative Commons Reconocimiento-NoComercial 4.0 Internacional, por lo que su contenido gráfico y escrito se puede compartir, copiar y redistribuir total o parcialmente sin necesidad de permiso expreso de su autor con la única condición de que no se puede usar con fines directamente comerciales y los términos legales de cualquier trabajo derivado deben ser los mismos que se expresan en la presente declaración. La única condición es que se cite la fuente con referencia a la Revista Digital Internacional de Psicología y Ciencia Social y a su autor. 


\section{TABLA DE CONTENIDO}

RACIONALIDAD. EL PRINCIPIO ORGANIZADOR

EL PAPEL DE LA RACIONALIDAD EN LA INVESTIGACIÓN CIENTÍFICA

Tradición galileana, 199

Tradición aristotélica, 199

POSMODERNIDAD E INVESTIGACIÓN CIENTÍFICA

Discusión 


\section{INTRODUCCIÓN}

P or lo común las revistas científicas son consumidoras de lo que producen los académicos y los investigadores, pero muy raramente, más allá de su título —el cual proporciona una idea de la temática que cultiva-, ofrecen una idea a sus autores de las líneas editoriales que siguen para la difusión de los conocimientos que ahí se publican. Son como diría Bartra (2015), revistas conservadoras, puesto que sólo reciben lo que se está produciendo, pero no estimulan la creación original de conocimiento, convirtiéndose en consecuencia en grandes depósitos de información y de artículos, que es, por supuesto al margen de las ideas anteriores, una función valiosa.

En esta nueva época de la Revista Digital Internacional de Psicología y Ciencia Social se tiene el firme propósito de romper con esta inercia, utilizando el espacio editorial para exponer las ideas del pensamiento científico que guían la toma de decisión para enviar los artículos a evaluación para su posible publicación, así como también el marco conceptual que fundamenta la misión y la visión que enmarcan todas las acciones que se toman en su publicación ${ }^{1}$.

Precisamente este artículo editorial tiene el propósito de guiar y orientar a sus autores y lectores acerca del enfoque y las líneas editoriales que se siguen en la revista, con la finalidad de romper con la inercia de sólo publicar lo que se produce, sino también estimular la producción de conocimiento fijando líneas editoriales que respondan al concepto de racionalidad más actual que sustenta la investigación científica en esta época posmoderna, como es el pensamiento complejo.

Para lograr este objetivo, en primer término se aborda el sentido del concepto de racionalidad, que es el principio que organiza todas las acciones encaminadas a la generación de conocimiento científico; en seguida se examina el papel que tiene la racionalidad en la investigación científica; a continuación se analiza la relación entre racionalidad y verdad; posteriormente se aborda la manera en que el pensamiento complejo ha cambiado el

1 En el artículo editorial del número anterior se abordaron los fundamentos que sustentan la decisión de adoptar una política editorial de revisión por pares totalmente abierta. [Descargar el artículo]. modo de hacer investigación científica en nuestro tiempo; el artículo finaliza concluyendo que la adopción del enfoque de la complejidad en la investigación científica conlleva un cambio en la mentalidad de la sociedad y se revolucionen las decisiones de poder entre los diferentes niveles de decisión de la comunidad científica.

\section{Racionalidad. El principio organizador}

Indiscutiblemente la investigación científica como un producto social es un proceso creado por el hombre que permite a los seres humanos asimilar el patrimonio científico cultural universal e irse construyendo de manera personal, conforme a ciertos patrones referenciales de naturaleza principalmente socioculturales.

Más allá de la vertiente etimológica, el sentido de la investigación científica se dirige a lograr dos grandes fines. Uno de estos objetivos la guía hacia la orientación y conducción del ser humano para que adquiera conocimientos, valores, costumbres y formas de actuar propias de su época y contexto social. El otro sentido la lleva a buscar el desarrollo personal de la raza humana para mejorar sus condiciones de vida y su adaptabilidad al mundo externo.

En la actualidad estas dos visiones -la transmisión y el desarrollo- se han fundido para hacer de la investigación científica un proceso legítimo y necesario para la supervivencia humana, ya que por su naturaleza el hombre tiene la necesidad de aprender para hacerse, y de esta manera conducirse en la vida según va siendo él mismo.

Al margen de los fines de transmitir conocimiento, o bien de desarrollar las potencialidades humanas, la investigación científica se enfrenta a un dilema en términos de qué tipo de racionalidad adoptar para conducir el proceso de indagación propiamente.

La racionalidad es el aparato conceptual que da coherencia a todas las acciones que hacen los círculos de científicos para investigar. En este sentido, la racionalidad se constituye en el principio angular a partir del cual todo se organiza.

En el ámbito científico el principio de racionalidad tiene poco que ver, o más bien no tiene nada que ver, con la aseveración psicológica de que el ser humano actúa racionalmente en la mayoría de los casos; es decir, que adopta una actitud racional en su comportamiento.

Respecto al ámbito de la investigación científica, el principio de racionalidad adquiere un sentido meto- 
dológico, a la manera de como lo delinea Karl Raimund Popper en su ensayo sobre el Principio de Racionalidad de 1967, donde indica que éste es un subproducto de un postulado metodológico que puede ser más o menos apropiado a la situación, por lo que puede debatirse y criticarse en el contexto en donde se aplica, y que con frecuencia se pone a prueba tanto empírica como conceptualmente (Popper, 1995).

La racionalidad pensada como principio metodológico para organizar las acciones humanas se ha considerado por lo general como el razonamiento que permite establecer los medios y los fines. Un ejemplo de esto sería cuando una empresa establece que su objetivo primordial es el beneficio, de ahí que todas sus políticas, es decir sus medios, estarán encaminadas a maximizar los beneficios.

En las organizaciones jerárquicas el tipo de racionalidad se encamina a establecer las reglas lógicas para distribuir la autoridad; las instituciones por excelencia en donde se aplica este tipo de racionalidad son las fuerzas armadas, la Iglesia y el Estado.

Para su organización, los círculos científicos por lo general utilizan también una racionalidad fundamentada en la autoridad; sin embargo, en el ámbito de la investigación la racionalidad basada en la autoridad se diluye y su lugar es ocupado por una serie de juicios fundamentados en razones respecto a los métodos de investigación y su relación con la manera de interpretar la realidad, sea ésta aparente o concreta.

De este modo, en contraste con las empresas cuya razón de ser es la búsqueda de beneficio, principalmente de los propietarios o de sus directivos, en la investigación científica la racionalidad para justificar los medios y los fines que utiliza gravita alrededor de las razones para utilizar tal o cual método o técnica en lugar de otro, y en el ámbito cotidiano un determinado enfoque teórico en lugar de otro cualquiera.

\section{EL PAPEL DE LA RACIONALIDAD EN LA INVESTIGA- CIÓN CIENTÍFICA}

A lo largo del tiempo el laboratorio de la investigación científica ha estado regido por una racionalidad que se le identifica como el paradigma estándar, en donde se considera que la misión de la investigación científica es la transmisión del conocimiento de los que saben a aquellos que no saben, para uso y beneficio de todos. Además de que el conocimiento que se transmite es sobre el mundo, y el conocimiento sobre ese mundo es preciso, inequívoco y no misterioso. De ahí que la mejor manera de cultivarlo es distribuirlo entre disciplinas que no se sobrepongan y que juntas abarquen todo el mundo a conocer. La función que se asigna al científico es la responsabilidad de adoptar un papel autoritario para que difunda a la sociedad lo que él descubre.

Por lo contrario, el paradigma emergente, y que es el que de hecho nos ocupa en este artículo, tiene que ver con la reflexión de la práctica crítica, o mejor dicho de la complejidad del proceso investigativo. Parte de que la investigación científica es el objetivo de la participación en una comunidad de indagación guiada por el científico, entre cuyas metas están la explicación y comprensión de los fenómenos.

Contrariamente a la visión estándar, se considera que al interior de las disciplinas se generan procesos que se yuxtaponen entre ellas, y que además las disciplinas no son exhaustivas en cuanto a su respectiva área de conocimiento. Por su parte, se busca que el científico adopte una posición en donde admita que puede equivocarse y se aleje definitivamente del autoritarismo. Por último, se considera que el foco de atención en la investigación científica no es sólo la adquisición de información, sino la indagación de las relaciones que existen entre los eventos en la materia bajo estudio.

Es un hecho que la investigación científica busca formar seres humanos que respeten las ideas de los otros, que piensen y actúen en forma coherente, preparándolos para que elijan entre diferentes criterios el que se ajuste más a su forma de pensar y ofrezcan razones de por qué lo eligieron, procurando siempre que se alejen de actitudes cerradas y fundamentalistas que sólo minimizan o neutralizan la labor de la investigación científica.

Como se puede ver por estas breves ideas al margen del tipo de racionalidad que se cultive, la importancia de ésta radica en que es el fundamento a partir del cual se sustentan los objetivos y los medios de la investigación científica; es la finalidad englobante y fundamental de cualquier otro propósito que se pretenda buscar con el proceso investigativo.

\section{RACIONALIDAD Y VERDAD}

Independientemente del tipo de racionalidad que se utilice en la investigación científica, todos ellos se nutren de las ideas de verdad, sea ésta científica o revelada; por consiguiente, cuando se afirma que la investigación científica debe ser una práctica racional se recurre implícitamente a la necesidad de establecer cuáles serán las mejores prácticas para alcanzar los objetivos de la investigación científica. 
La manera de establecer este valor de verdad descansa primordialmente en ideas filosóficas relacionadas con el pensamiento científico, adquiriendo el concepto de racionalidad desde una forma simplista, cerrada y limitada hasta una concepción abierta sujeta al tiempo y a la historia, en donde lo complejo, lo caótico, lo evolutivo y lo relativo, también tienen cabida. Una verdad que es un sistema que involucra varios procesos de naturaleza plural, histórica, variables y evolutivos (Maldonado \& Gómez_Cruz, 2010).

La verdad deja de ser sólo un resultado estable e inmutable en el tiempo; el concepto actual de racionalidad incorpora una noción de verdad que se identifica con la totalidad de un proceso evolutivo y se aleja de la noción que la considera como constante y perdurable hasta el fin de los tiempos. La verdad no está en esta explicación, o en aquella comprensión, o bien en esta revelación, sino, retomando el pensamiento de Hegel (1993), en el mismo proceso de una idea que da lugar a otra y luego se ve, en medio de la historia, remplazada por otra.

A lo largo de la historia de la ciencia, la búsqueda de la verdad ha girado siempre alrededor de dos tradiciones claramente diferenciadas. Una de ellas es identificada, según Von Wright (1987), como galileana, la cual adopta una perspectiva mecanicista dirigida a construir conocimiento que permita explicar y predecir los acontecimientos. La otra dirige su atención principalmente en comprender las acciones humanas de modo teleológico o finalista; esta tradición se fundamenta principalmente en el pensamiento de Aristóteles.

\section{Tradición galileana}

Igual que la ciencia desde hace más de un siglo y medio, la investigación científica ha estado dominada por el pensamiento de Copérnico, Galileo, Descartes y Newton. A esta etapa se le conoce como la visión clásica de la ciencia, y en el contexto de la investigación científica se le asocia con el concepto de racionalidad estándar, la cual está construida sobre dos hechos:

1. Se sustenta principalmente en el pensamiento de Newton; establece que hay una simetría entre el pasado y el futuro, por lo que no es necesario distinguir entre ellos debido a que todo coexiste en un presente eterno.

2. La noción de Descartes que plantea la existencia de un dualismo que distingue entre la naturaleza y lo humano, entre la materia y la mente, entre el mundo físico y el mundo de las acciones humanas.

A partir de los anteriores hechos, la investigación científica pasó a ser una empresa cuya finalidad principal sería descubrir las leyes naturales universales que se mantienen en todo tiempo y espacio.

De este modo, al igual que la ciencia, la investigación científica heredó lo que Koyré (1996) Ilama los atributos ontológicos de la divinidad; esto es, en la nueva Cosmología el Universo infinito, infinito en duración y extensión, en el que la materia eterna se mueve sin fin, ni objetivos, en el espacio eterno, gobernada sólo por leyes eternas y necesarias, heredó todos los atributos ontológicos de la divinidad. Pero únicamente esos, porque todos los demás atributos, como los valores morales -
representados por el amor, la humildad y la caridad-, se los llevó la divinidad con su marcha.

Al momento en que se dio la distinción entre la divinidad y la ciencia, el trabajo experimental y empírico pasó a ser más importante para esta nueva visión de la investigación científica, y el conocimiento teológico comenzó a aparecer como una serie de afirmaciones o enunciados que tenían muy poca relación con la vida terrenal del hombre, excepto para su salvación en una vida más allá de ésta.

Con la consolidación del trabajo experimental y empírico, las especulaciones deductivas que se remontaban desde los presocráticos fueron cediendo su lugar como elementos predominantes en la enseñanza, y su lugar fue paulatinamente ocupado por la experimentación.

\section{Tradición aristotélica}

El resurgimiento de la tradición aristotélica en la década de los años cincuenta del siglo pasado, que nutre actualmente el concepto de racionalidad en la investigación científica, fue una reacción sobre todo en contra del positivismo que había desterrado de la ciencia la interpretación de los acontecimientos, debido a que se consideraba que el objetivo de la ciencia era la formulación de leyes o sistemas de leyes que explicaran el universo, pero de ninguna manera dar razón de los hechos recurriendo a intenciones, objetivos o propósitos, y en caso de recurrir a ellos deberían depurarse para eliminar los restos de animismo o vitalismo, con el fin de que una vez depurados se transformaran en explicaciones causales.

Contrariamente a esto, la visión de la tradición aristotélica gira alrededor de la idea que no existe cosa o acontecimiento en el universo que no fluya; por consiguiente, ninguna generalización que se pretenda aplicar 
a dos o más hechos es verdadera: a lo más que se puede llegar es a comprender una secuencia de acontecimientos; en este sentido el objetivo de la ciencia no es explicar los acontecimientos, sino comprenderlos estableciendo las interacciones que tienen las partes para conformar el todo.

Como se verá más adelante, esta tradición se nutre de la idea de que la realidad es más compleja de lo que parece, ya que no basta con separar el todo en sus partes y analizarlas una por una hasta que su suma permita conocer cómo funciona el todo.

\section{Posmodernidad e inVestigación Científica}

En la época actual se promueve el pluralismo y la diversidad alejándonos del dualismo cartesiano que excluye y que nos separa posicionándonos en uno de dos extremos. Un elemento más de este momento es la certeza que tenemos como seres humanos de no tener acceso a la realidad, lo que trae como consecuencia que la verdad se convierta en una cuestión de perspectiva, despojándola de su carácter universal como siempre se le había reconocido desde los pensadores más antiguos (Caputo, Epstein, Stoesz, \& Thyer, 2015; Matusov, 2015; Pantaleo, 2014). Estas ideas y algunas otras han dado origen a una nueva racionalidad fundamentada en el pensamiento posmoderno, el cual pretende cambiar radicalmente las formas tradicionales, cultivadas hasta nuestros días, relacionadas con el arte, la cultura, la vida social y el pensamiento filosófico.

En el ámbito de la investigación científica el posmodernismo se inclina por la institucionalización del pluralismo, el fortalecimiento del espíritu autogestivo de los científicos, con la finalidad de evitar el dogmatismo y fortalecer las libertades individuales; y respecto a los métodos de investigación, el rechazo al establecimiento de estándares en la investigación (Forghani, Keshtiaray, \& Yousefy, 2015). Si bien la investigación científica modernista dirigió a los científicos a la búsqueda de leyes inmutables, la investigación científica posmoderna está impregnada de un sentimiento de incertidumbre, por lo que los científicos deben estar preparados para explicar y comprender el caos (Nguyen, 2010).

A pesar del gran interés que ha despertado la visión de la racionalidad surgida en el posmodernismo, en la mayoría de los círculos científicos la toma de decisiones y la manera de gestionar el conocimiento es a través de la aplicación de una racionalidad alimentada por una lógica aristotélica y por las reglas del método propuesto por Descartes, así como del determinismo newtoniano.
En los años recientes se ha estado abriendo paso a una racionalidad que se aleja de lo que Vilar (1999) denominó las visiones aristotélicas-cartesianas-newtonianas, en las que actualmente se encuentra anclada la investigación científica. Esta nueva aproximación se aleja de los criterios de racionalidad de la ciencia positivista, principalmente del reduccionismo y la refutación de hipótesis, y en su lugar incorpora el principio de la no reducción, de la inclusión de la lógica del tercero y del análisis sistémico.

Es conocido de todos los que se acercan al estudio de la ciencia que la investigación científica está organizada con base en el reduccionismo, idea que segmenta el conocimiento creando divisiones parecidas a parcelas que separan los saberes en disciplinas, haciendo de ellas áreas pluridisciplinarias que ofrecen un espacio físico limitado de convivencia territorial a distintas disciplinas (medicina, psicología, matemáticas, sociología, biología, etcétera).

Dicha convivencia es acompañada de una ignorancia recíproca o falta de interés por las otras, aun las más próximas en el mejor de los casos, y en un desprecio hacia los saberes que se cultivan en las otras disciplinas el peor de los casos; los de las ciencias desprecian a los de letras, o viceversa; los matemáticos infravaloran a los sociólogos, y así sucesivamente, convirtiéndose esta circunstancia en una espiral de múltiples reproches.

La nueva racionalidad surgida del posmodernismo y del concepto de realidad líquida obliga a la investigación científica a cambiar radicalmente y contribuir en la creación de saberes unificados, integrales y no reduccionistas que hagan emerger una investigación científica centrada en el humanismo. El reto que tiene en esta época es modificar su visión y dirigir sus esfuerzos a gestionar una investigación que elimine la transmisión de un conocimiento acrítico, objetivo, lineal y estructurado, y que sea sustituido por un conocimiento multidimensional, significativo, que interactúe con la complejidad interna del ser humano y con la externa de la sociedad y de la naturaleza.

La nueva cultura del mundo obliga a la investigación científica a hacer un esfuerzo de integración que parta de una realidad comprensiva para permitir el florecimiento de una gestión del conocimiento centrada en valores epistémicos donde converja el conocer para hacer, el conocer para innovar, el conocer para repensar lo conocido y la movilidad del conocimiento. Con esta nueva tendencia se pretende alejar a la investigación científica de la creencia de estar transmitiendo verdades absolutas y que se reconozca la incertidumbre y el error con el objetivo de encontrar los consensos entre la varie- 
dad de conocimientos que la humanidad ha construido a lo largo de su existencia (Morin, 1999).

En este sentido, en la actualidad existe la necesidad de que la investigación científica se sustente en una realidad comprensiva, muy semejante a la realidad líquida que postula Bauman (2007). Las ideas principales de lo que es la realidad líquida se abordan en el video 1, en donde se plantea que lo importante es la manera en que los fenómenos fluyen en el tiempo más que el espacio eterno y constante que puedan ocupar.

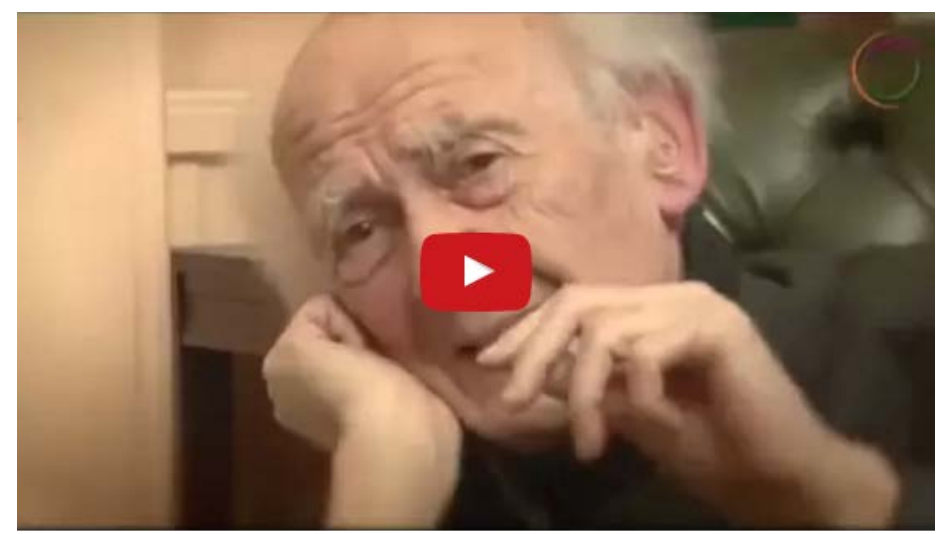

Video. 1

Modernidad líquida

Esta nueva perspectiva estaría dirigiendo los esfuerzos de la investigación científica a la integración de saberes mediante el cultivo de la transdisciplinariedad, alejándose de la creencia de estar transmitiendo verdades absolutas; además permitiría el reconocimiento de la incertidumbre, los cambios constantes en los fenómenos y el error que se presenta en ellos. En todo momento sería la búsqueda de los consensos entre la variedad de conocimientos que la humanidad ha construido a lo largo de su existencia.

\section{INVESTIGACIÓN CIENTÍFICA Y CIENCIAS DE LA \\ COMPLEJIDAD}

En esta época posmoderna se han dado cambios no sólo en la forma de interpretar los acontecimientos, sino también de cómo cambiar nuestro acontecer cotidiano. No obstante, como se ha mencionado, en el ámbito de la investigación científica se sigue mantiéndose una visión aristotélica-cartesiana-newtoniana que permea todos los rincones del conocimiento científico, en contraposición a esta perspectiva analítica, mecanicista y positivista enfocada sólo a observar y explicar de manera unidimen- sional la realidad, actualmente ha surgido una nueva visión unificadora de la naturaleza y de la sociedad.

Esta nueva perspectiva aglutina una serie de teorías que provienen de los más variados campos de conocimiento desarrolladas por diferentes disciplinas científicas que se reúnen bajo el título de ciencias de la complejidad que, en realidad, actualmente son un conjunto de ideas y principios que han sido retomados de otros cuerpos de conocimiento (Burnes, 2005; Hetherington, 2013; Wang, Song \& Barabási, 2013).

El pensamiento complejo emergió en los últimos años del siglo XX, puesto que fue en ese momento cuando comenzaron a interrelacionarse diferentes tendencias científicas de una gran variedad de disciplinas buscando las semejanzas sincrónicas que existen entre ellas, haciendo a un lado las distintas parcelas y los problemas de conocimiento que enfrentan como disciplinas individuales. Es preciso destacar que ninguna perspectiva de cualquiera de las disciplinas que alimentan a las ciencias de la complejidad domina el campo de conocimientos de los estudios que adoptan este enfoque como marco explicativo y comprensivo de la realidad (Burnes, 2005).

El paradigma que aglutina a las ciencias de la complejidad plantea, en el ámbito de la investigación científica, la necesidad de que se construya el conocimiento mediante nuevas formas de observación en donde se incluyan los sentimientos, significados, aptitudes y sentidos del sujeto que conoce y de los objetos que se conocen.

Edgar Morin, el principal ideólogo de las ciencias de la complejidad, dictó en la UNAM una extensa conferencia que aborda algunas de las principales ideas que sustentan al pensamiento complejo (video 2).

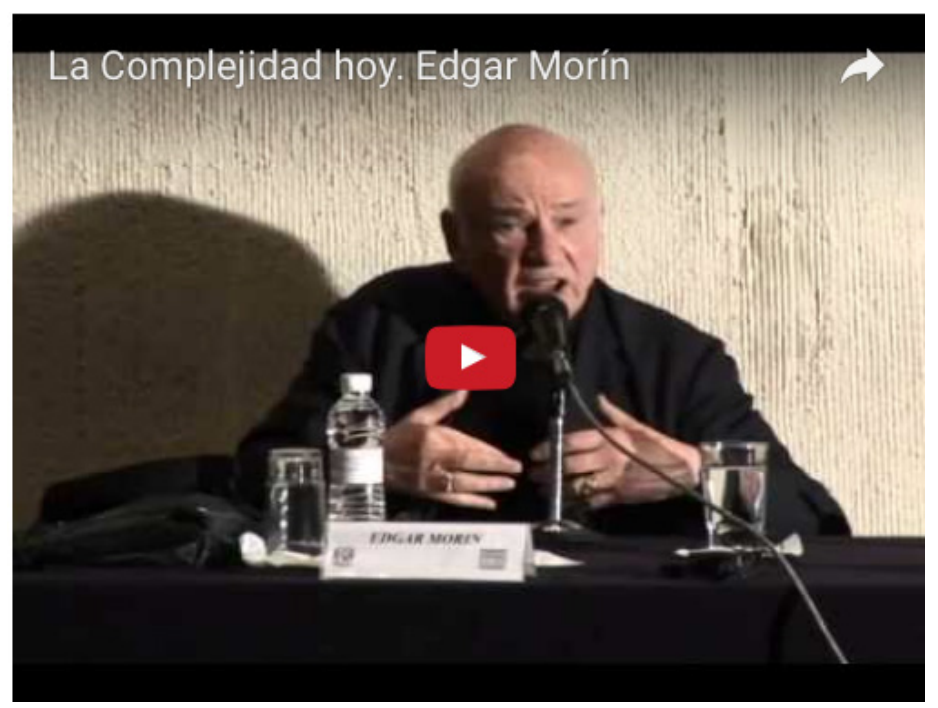

Video 2.

La complejidad hoy 
Evidentemente bajo esta perspectiva la labor investigativa requiere una nueva forma de conocer y enseñar, que parta de la idea de una realidad concebida como inacabada, por hacer y construirse, que incluya al sujeto que interpreta esa realidad de acuerdo con sus experiencias.

Cada vez más académicos, investigadores y profesionales adoptan un enfoque derivado de las ciencias de la complejidad en el entendimiento y comprensión de los fenómenos de su interés y en la promoción de los cambios en la gestión de la investigación científica.

El campo de conocimiento de las ciencias de la complejidad se nutre por perspectivas que provienen tanto de las ciencias naturales como de las ciencias sociales y humanas, estas últimas derivadas sobre todo del pensamiento posmodernista. En el primer caso se utilizan por lo común para fundamentar que el desarrollo de los sistemas dinámicos son el resultado del desequilibrio y el caos; por su parte, en la investigación científica se considera que cualquier fenómeno es un sistema complejo no lineal, y que la manera en que se comporte es impredecible, pero como toda turbulencia, se rige por un conjunto de reglas de generación de cambios.

Como resultado de la perspectiva de las ciencias naturales, y por otro el enfoque de las ciencias sociales, las tendencias metodológicas a lo interno de las ciencias de la complejidad, en el ámbito de la investigación científica, han seguido dos rumbos. El primero de ellos, situado en el enfoque más tradicional de la ciencia, dirige su atención en la modelación de sistemas complejos usando simulaciones de computadora y modelos matemáticos sofisticados. El segundo enfoque está más orientado al estudio de sistemas complejos sociales; se encamina hacia el empleo de la comprensión utilizando enfoques inductivos para encontrar patrones, significados y sentidos de la acción humana en sociedad (Levy, 2000).

Los partidarios del enfoque de la complejidad en el campo de la investigación científica consideran que es necesario que se den cambios académicos, institucionales, políticos y sociales que transformen la mentalidad de la sociedad y, sobre todo, las relaciones de poder entre los diferentes niveles de decisión.

Si bien las ideas que nutren a las ciencias de la complejidad provienen de diferentes disciplinas y campos del conocimiento, sin embargo existe un núcleo central de principios interrelacionados e interdependientes que constituyen una red formal de conceptos transdisciplinarios. Este núcleo, más que ser un modelo clásico constituido por fundamentos y principios que delimitan un marco teórico único, es un conjunto de postulados de naturaleza inductiva y deductiva dirigidos a comprender y explicar los mecanismos mediante los cuales se produce el cambio impredecible y emergente (Mason, 2008). Los principales pilares en que se sustentan las ciencias de la complejidad son la teoría del caos, la teoría de las estructuras disipativas y la teoría de sistemas adaptativos (Stacey, Griffin \& Shaw, 2002).

La primera de ellas hace mención a los sistemas dinámicos que constantemente se están transformado de manera irreversible, y por lo tanto evolutivamente. El ejemplo más evidente es el desarrollo de la vida, que siempre está en evolución, por lo que nunca se vuelve a ser lo que anteriormente se era; como seres vivos crecemos y vamos cambiando, lo que nos modifica como sistema, pero a su vez algo de nosotros permanece.

Una característica más de esta teoría es que rechaza las leyes de causalidad bajo el supuesto de que los sistemas caóticos son no lineales, por lo que no están sujetos a las leyes de causa y efecto (Lefroy \& Yardley, 2015). De acuerdo a este enfoque el caos tiene el poder de amplificar pequeños cambios, y en consecuencia provocar inestabilidad que transforma un patrón existente en uno nuevo. En este proceso existen puntos críticos en donde el sistema se autoorganiza espontáneamente para producir una estructura diferente del patrón de comportamiento característico del sistema.

Estos cambios evolutivos son una mezcla de orden y caos a partir de la cual nacen nuevas estructuras —que reciben el nombre de estructuras disipativas- que analógicamente son, en palabras de Prigogine (2004), islas de orden en un océano de desorden que da origen a una simbiosis creadora. Estas estructuras son el segundo pilar.

El tercer pilar que nutre las ciencias de la complejidad son las teorías de los sistemas adaptativos complejos que parten del supuesto de que dichos sistemas están constituidos por un gran número de agentes, que se comportan de acuerdo con sus propias reglas de interacción, las cuales se ajustan al comportamiento de los otros agentes que constituyen el sistema, por lo que el comportamiento del sistema emerge o evoluciona de la interacción entre los agentes locales que lo constituyen (Burnes, 2005). De esta manera, el estudio del comportamiento de los sistemas emergentes enfocan su atención en las interconexiones de los componentes del sistema y su arquitectura, en lugar de estudiar los componentes como elementos individuales (Matei \& Antonie, 2014).

La ciencia de la complejidad estudia el comportamiento emergente de sistemas complejos concentrándose en las interconexiones de los componentes del sistema y arquitectura de sistemas, en lugar de los componentes individuales. El estudio de los sistemas complejos difiere del pensamiento sistémico; el alcan- 
ce de aquellos es mucho más amplio, ya que analizan los procesos de cambio en lugar de las instancias del sistema en busca de estructuras que se repitan una y otra vez hasta que surja el caos que de origen a un cambio en la estructura y en las interacciones de los agentes que conforman el sistema. Las similitudes y diferencias entre la aproximación de los sistemas complejos y el pensamiento sistémico radica en las reglas que establecen la conceptualización de la manera en que se organizan los sistemas, los elementos que los constituyen, las soluciones y los cambios que ocurren en ellos (Cilliers, 1998; Ramalingam, Jones, Reba \& Young, 2008).

Las ciencias de la complejidad han cambiado el pensamiento actual; este cambio ha ocasionado que se dé un viraje sustancial en la forma en que la investigación científica se ha realizado para que conduzca a una transformación fundamental en los ámbitos teórico, político y práctico.

Las tendencias para dirigir el cambio en el ámbito investigativo han seguido dos caminos; una de ellas se ha dirigido a la utilización de las definiciones teóricas, metodológicas y aplicadas que se encuentran en las ciencias naturales a cualquier tipo de fenómeno, sea éste relacionado con las ciencias naturales o con las ciencias sociales. Como en su momento lo estipuló Ilya Prigogine (1997) al afirmar que la complejidad no es simplemente una teoría del mundo físico, sino que se ocupa de la dinámica de todos los fenómenos que pueden comprenderse mediante métodos matemáticos y estadísticos. Por supuesto que en dichos fenómenos se incluyen los sociales.

Los esfuerzos que se han hecho en la investigación científica desde esta aproximación se han centrado en obtener datos duros que se recolectan a través del tiempo y se analizan buscando identificar la existencia de los principios de las ciencias de la complejidad. Este enfoque parte de la idea de que la complejidad de los fenómenos sociales son idénticos, o al menos comparables, con los que se encuentran en las ciencias naturales.

La otra tendencia está orientada menos por las ciencias naturales debido a que parte de la idea de que no es posible obtener datos duros de los fenómenos sociales, no obstante que son procesos híbridos en donde están presentes el reino físico y el reino social (Wallertein, 1999). Esta tendencia aboga por que la investigación científica construya su propio espacio en las ciencias de la complejidad que se aleje de la visión newtoniana de la ciencia.
A estas dos tendencias se suma otra con menor presencia y más difusa que sostiene la premisa de que las ciencias de la complejidad no muestran nada nuevo en el campo de la investigación científica. En concreto, se considera que dichas ciencias no añaden nada a los enfoques existentes en la comprensión de la investigación científica; sólo ofrecen acercamientos teóricos, metodológicos y aplicados que fueron postulados desde hace mucho tiempo por otros pensadores educativos y su valor radica sólo en la necesidad actual de comprender mejor un mundo cada vez más interconectado e incierto (Ramalingam et al., 2008).

En años reciente cada vez más se afirma que las ciencias de la complejidad permitirían construir un campo unificado entre las ciencias naturales y las sociales a través de la investigación científica, lo que detonaría el surgimiento de una ciencia unificada, pero no en el sentido que le dan los filósofos analíticos de que en el campo social se adopten las premisas de la visión aristotélica-cartesiana-newtoniana, sino que ambos campos del conocimiento formen una vasta familia en la que las premisas y los lazos culturales de todas las actividades conjuntas busquen unificar la investigación científica (Alhadeff-Jones, 2013).

\section{DisCusión}

En esta época posmoderna la investigación científica está ante una encrucijada respecto al tipo de racionalidad que debe asumir para generar conocimiento que fortalezca a las distintas disciplinas científicas, y que a la vez sea útil para resolver los problemas que la sociedad enfrenta, en una la realidad que cada vez se torna más líquida, para volver a la idea de realidad de Bauman (2007).

Esta encrucijada se acentúa debido a la baja en los niveles de credibilidad, sobre todo en las ciencias sociales y humanas, del paradigma hegemónico estándar conocido como la visión aristotélica-cartesiana-newtoniana, ante el surgimiento del pensamiento complejo que ha permitido aglutinar una serie teorías de diferentes disciplinas.

Desde esta última perspectiva, particularmente en el campo de las ciencias sociales y humanas, se plantea la necesidad de que en la investigación científica se incorporen nuevas formas de observación que incluyan los sentimientos, significados, aptitudes y sentidos del sujeto que conoce y de los objetos que se conocen, máxime cuando el objeto que se busca conocer es el ser humano. 
Esta nueva racionalidad rompe con la visión cerrada y limitada del paradigma estándar y aboga para que sea sustituida por una concepción abierta sujeta al tiempo y a la historia que incluya lo caótico, lo evolutivo y lo relativo del conocimiento. En este sentido, la investigación científica debe despojarse de la idea de buscar una verdad absoluta y perene hasta el fin de los tiempos, ya que ésta no es estática sino producto de un proceso evolutivo.

Contrariamente a lo que pudiera pensarse, no es una moneda que una vez acuñada debería guardarse en el bolsillo para siempre, y sólo sacarla cuando fuera necesario develar el grado de certeza de lo que se explica o se argumenta acerca de un determinado fenómeno. Todas las cosas del universo - y el universo mismo- siguen un proceso de desarrollo o devenir, en donde una verdad válida en una determinada época histórica es sólo un estadio imperfecto en un largo proceso de despliegue de la verdad.

En la investigación científica es común pasar por alto que el rechazo de una teoría establecida y consolidada, por una nueva versión que la mejora, es un proceso que construye a partir de un estadio anterior bajo un principio de contradicción que conserva, en su interminable devenir, las ideas centrales de los pasados estadios que se unen con las nuevas ideas, trascendiendo su tiempo al conservar su historia y cambiando hacia su siguiente estadio. Hegel (1993, p. 8) describe más bellamente esta dialéctica del ser en un pasaje de su prolífera obra:

"El capullo desaparece al abrirse la flor, y podría decirse que aquél es refutado por ésta; del mismo modo que el fruto hace aparecer la flor como un falso ser alli de la planta, mostrándose como la verdad de ésta en vez de aquélla. Estas formas no sólo se distinguen entre sí, sino que se eliminan las unas a las otras como incompatibles. Pero en su fluir, constituyen al mismo tiempo otros tantos momentos de una unidad orgánica, en la que lejos de contradecirse, son todos igualmente necesarios, y esta igual necesidad es cabalmente la que constituye la vida del todo".

En la actualidad el pensamiento posmoderno se nutre de estas ideas planteando que el hecho de no tener acceso a la realidad tiene como consecuencia que la verdad se convierta en un problema de perspectiva. La influencia de este enfoque en la investigación científica ha dado origen a que se produzca un cambio radical en la manera de crear conocimientos científicos; uno de estos cambios ha sido la aceptación del pluralismo teórico y la pérdida de certidumbre que ha frenado el dogmatismo y el autoritarismo con que se habían conducido los grupos de investigadores de las más variadas disciplinas (Nguyen, 2010; Wallertein, 1999).
Si bien este freno al dogmatismo por el resurgimiento del pluralismo ha producido cambios en la correlación de fuerzas e intereses de los círculos científicos, la mayoría de las veces han desembocado en parcelas que separan los saberes en disciplinas que carecen del interés de conocerse y unir esfuerzos entre ellas para crear saberes unificados y no reduccionistas que hagan surgir una investigación científica centrada en la transdisciplinariedad.

La alternativa para fortalecer y direccionar estos cambios es adherirse al pensamiento complejo porque representa la mejor opción, hasta el momento, de unir la naturaleza con la sociedad y el ser humano en su propia ontología. En dicho pensamiento se interrelacionan diferentes tendencias científicas de una muy amplia variedad de disciplinas que buscan encontrar las semejanzas sincrónicas que existen entre ellas con la finalidad de lograr una mejor explicación y comprensión de los fenómenos.

Todo esto que plantea el enfoque de la complejidad respecto a la investigación científica implica que se den cambios académicos, sociales, políticos, institucionales, y por supuesto en las políticas editoriales de las revistas científicas que transformen la mentalidad de la sociedad y se revolucionen las decisiones de poder entre los diferentes niveles de decisión de la comunidad científica.

\section{Conclusiones}

En este contexto mundial respecto a la manera de generar conocimiento en el ámbito de la investigación científica, se tomó la decisión que la Revista Digital Internacional de Psicología y Ciencias Social ampliara su enfoque y dejará atrás la especialización en que una gran cantidad de revistas científicas invierten sus esfuerzos. Algunas de las revistas orientadas hacia la especialización no sólo hacia una disciplina, sino más reduccionistamente hacia una temática, han olvidado que la difusión y divulgación del conocimiento científico es una empresa que demanda comprender e interpretar las acciones humanas de los científicos con la finalidad de movilizarlos hacia objetivos comunes y predeterminados, en donde no tienen cabida las verdades reveladas a la que los sacerdotes, magos, políticos e iluminados recurren (Wallertein, 1999).

La especialización en disciplinas y temáticas de las revistas científicas las han conducido al desconocimiento de que sólo son una interpretación plausible de los fenómenos que publican de acuerdo con su referente de realidad, en donde florece una interpretación de la ortodoxia oficial sobre la verdad revelada por la disciplina o la temática que dicen abordar. Es innegable, pues, 
que las disciplinas científicas y su subclasificación en temáticas, son paradigmas que, como atinadamente lo menciona Kuhn (1992), tienen su lado positivo y su contraparte negativa, puesto que si bien ayudan a captar, comprender y guiar en la disciplina o temática declarada en la misión de la revista, también ciegan, engañan y distorsionan la realidad que es investigada en ellas.

Es un hecho que todas las revistas especializadas con un fuerte enfoque disciplinar encontrarán aspectos en su realidad que concordarán y confirmarán su postulados teóricos y empíricos; de igual manera hallarán otros que los distorsionarán o debilitarán, pero, aun así, dentro de la incumbencia de la disciplina existirá la posibilidad de recurrir a aspectos teóricos o aplicados para explicarlos. Sin embargo, viendo más allá de la disciplina a la que se enfoca la revista especializada, y traspasando sus fronteras, habrá otros aspectos que no concordarán con los postulados o con las explicaciones que proporciona la

"La Revista Digital
Internacional de
Psicología y Ciencia
Social se aleja de la
alta especialización y
publica artículos en un
amplio rango de campos
científicos bajo un
enfoque de las ciencias
de complejidad"
disciplina que cultivan, y que son determinados aspectos de la realidad que le serán invisibles, debido a que su mirada no está dirigida hacia esos hechos.

Por la naturaleza paradigmática de las disciplinas científicas, el análisis que se hace en sus ámbitos de influencia parte de postulados teóricos considerados universales y aplicables en todos los señoríos del reino que comprende su realidad, y recurren al relativismo epistemológico sólo para referirse a los postulados teóricos aplicables en los ámbitos de influencia de las otras disciplinas.

Ante este panorama se decidió alejar a la Revista Digital Internacional de Psicología y Ciencia Social de la alta especialización y publicar artículos en un amplio rango de campos científicos, tal y como se declara en su misión, puesto que se pretende difundir los avances en la producción científica y tecnológica en los campos de la psicología, las ciencias sociales, de la salud, las ingenierías y las humanidades para fomentar, generar y desarroIlar el conocimiento transdisciplinario entre las distintas disciplinas que comprenden al campo de estudio de las ciencias sociales y de la salud, y de las ingenierías y de las humanidades. El entorno transdisciplinario abre las puertas a la publicación de contribuciones científicas en cualquier campo de conocimiento, siempre y cuando sean temas relacionados con la forma en que el ser humano aprende, enseña y usa la tecnología para hacer un mundo más comprensible y sustentable.
Debido a esta gran apertura podría pensarse que la revista es un barco que navega sin rumbo; sin embargo, como se abordó en el cuerpo principal de este artículo, el faro que la guía son el pensamiento complejo en donde se aglutina una gran cantidad de teorías que provienen de los más variados campos del conocimiento cultivados por diferentes disciplinas científicas.

Con este rumbo se intenta dirigir y orientar la investigación científica para que cada vez se abra más y disminuya el derecho que se han atribuido los círculos de los científicos atrincherados en su disciplina de proclamar la verdad y se abran el diálogo transdisciplinar para —a través de este cambio- fortalecer el derecho moral que han ganado en la guerra cultural de ser los custodios de la verdad en esta vida terrenal, porque en la vida celestial indiscutiblemente la tienen los sacerdotes de culto, sea la religión que sea.

Al abrirse la revista a un enfoque transdisciplinar arropada en el enfoque de la complejidad, su imagen se decanta perdiendo el conjunto de criterios mínimo mediante los cuales la ciencia moderna juzga como científicas las explicaciones teóricas; criterios que tienen que ver con la linealidad, el equilibrio y la reversibilidad del tiempo. La imagen que adopta la revista está íntimamente relacionada con algunos postulados de la época posmoderna actual, ya que en lugar de ver a la ciencia como fundamentalmente diferente del pensamiento humanista, se concibe como una parte de la cultura.

Considerando los criterios mínimos, la imagen que adopta la revista queda delineada en las disyunciones que enfrenta, según Wallertein (1999), la ciencia actual: en lugar de certidumbre, probabilidades; en vez de determinismo, caos determinista; en vez de linealidad, la tendencia a alejarse del equilibrio y la bifurcación; en lugar de dimensiones enteras, fractales; en lugar de reversibilidad del tiempo, la flecha del tiempo.

Finalmente la revista pretende convertirse en órgano de difusión y divulgación, en donde se entrecrucen diferentes conocimientos y se propicie el intercambio de experiencias en un diálogo horizontal respecto a saberes y prácticas entre diferentes disciplinas científicas, puesto que, como menciona Maldonado (2011), la fortaleza del conocimiento estriba no sólo en su carácter de libertad, sino también en su diversidad, así como a la crítica a la que puede ser sometido y a la posibilidad que brinda de ser aprendido y asimilado culturalmente. 


\section{Referencias}

Alhadeff-Jones, M. (2013). Complexity, Methodology and Method: Crafting a Critical Process of Research. Complicity: An International Journal of Complexity and Education, 10(1/2), 19-44. https://ejournals.library.ualberta.ca/index. php/complicity/article/view/20398/15669

Bartra, R. (2015). Las revistas científicas en la revolución digital: ¿citas o lectores? Revista mexicana de sociología, 77, 3337. http://www.revistas.unam.mx/index.php/rms/article/ view/51755/46186

Bauman, Z. (2007). Los retos de la educación en la modernidad líquida. España: Editorial Gedisa.

Burnes, B. (2005). Complexity theories and organizational change. International Journal of Management Reviews, 7(2), 73-90. doi: 10.1111/j.1468-2370.2005.00107.x. http://onlinelibrary.wiley.com/doi/10.1111/j.14682370.2005.00107.x/abstract

Caputo, R., Epstein, W., Stoesz, D., \& Thyer, B. (2015). Postmodernism: A Dead End in Social Work Epistemology. Journal of Social Work Education, 51(4), 638-647. doi: 10.1080/10437797.2015.1076260. http://www. tandfonline.com/doi/abs/10.1080/10437797.2015.10762 $\underline{60}$

Cilliers, P. (1998). Complexity and Postmodernism. Understanding complex systems. New York: Routledge.

Forghani, N., Keshtiaray, N., \& Yousefy, A. (2015). A Critical Examination of Postmodernism Based on Religious and Moral Values Education: v8 n9 p98-106 2015. http://files. eric.ed.gov/fulltext/EJ1074075.pdf

Hegel, G. W. F. (1993). Fenomenología del espíritu (Vol. Novena reimpresión). México: Fondo de Cultura Económica.

Hetherington, L. (2013). Complexity Thinking and Methodology: The Potential of 'Complex Case Study' for Educational Research. Complicity: An International Journal of Complexity and Education, 10(1/2), 71-85. https:// ejournals.library.ualberta.ca/index.php/complicity/ article/view/20401/15672

Koyré, A. (1996). Del mundo cerrado al universo infinito (Novena ed.). México: Siglo Veintiuno.

Kuhn, T. S. (1992). La estructura de las revoluciones científicas (Tercera ed.). México: Fondo de Cultura Económica.

Lefroy, J., \& Yardley, S. (2015). Embracing complexity theory can clarify best practice frameworks for simulation education. Medical Education, 49(4), 344-346. doi: 10.1111/ medu.12662. http://onlinelibrary.wiley.com/doi/10.1111/ medu.12662/abstract

Levy, D. L. (2000). Applications and Limitations of Complexity Theory in Organization Theory and Strategy. In J. Rabin, G. J. Miller \& W. B. Hildreth (Eds.), Handbook of strategic management (pp. 67-87). New York: Marcel Dekker. (Reprinted from: Second edition).

Maldonado, C. E. (2011). Termodinámica y complejidad. Una introducción para las ciencias sociales y humanas (pp. 208). Retrieved from http://www.carlosmaldonado.org/ articulos/Termodinamica.pdf
Maldonado, C. E., \& Gómez_Cruz, N. A. (2010). El mundo de las ciencias de complejidad. Un estado del arte (pp. 134). Retrieved from http://www.carlosmaldonado.org/ articulos/DI76_Admon_agosto\%2023\%20(2).pdf\%20-\%20 Adobe\%20Acrobat\%20Pro.pdf

Mason, M. (2008). Complexity Theory and the Philosophy of Education. Educational Philosophy and Theory, 40(1), 4-18. doi: 10.1111/j.1469-5812.2007.00412.x. http://onlinelibrary.wiley.com/doi/10.1111/j.14695812.2007.00412.x/abstract

Matei, A., \&Antonie, C. (2014). The New Public Management within the Complexity Model. Procedia - Social and Behavioral Sciences, 109, 1125-1129. doi: http://dx.doi.org/10.1016/j. sbspro.2013.12.599. http://www.sciencedirect.com/ science/article/pii/S1877042813052385

Matusov, E. (2015). Four Ages of Our Relationship with the Reality: An educationalist perspective. Educational Philosophy and Theory, 47(1), 61-83. doi: 10.1080/00131857.2013.860369. http://dx.doi.org/10.1080/00131857.2013.860369

Morin, E. (1999). Los siete saberes necesarios para la educación del futuro. París, Francia: UNESCO-Santillana.

Nguyen, C. H. (2010). The changing postmodern university. International Education Studies, 3(3), 88-99. doi: http:// dx.doi.org/10.5539/ies.v3n3p88

Pantaleo, S. (2014). The Metafictive Nature of Postmodern Picturebooks. The Reading Teacher, 67(5), 324-332. doi: 10.1002/trtr.1233. http://dx.doi.org/10.1002/trtr.1233

Popper, K. R. (1995). El principio de racionalidad. In D. Miller (Ed.), Popper escritos selectos (pp. 384-392). México: Fondo de Cultura Económica.

Prigogine, I. (1997). El fin de las certidumbres. Barcelona: Andrés Bello.

Prigogine, I. (2004). La leyes del caos. Barcelona: Crítica.

Ramalingam, B., Jones, H., Reba, T., \& Young, J. (2008). Exploring the science of complexity: Ideas and implications for development and humanitarian efforts Retrieved from http://www.odi.org/sites/odi.org.uk/files/odi-assets/ publications-opinion-files/833.pdf

Stacey, R. D., Griffin, D., \& Shaw, P. (2002). Complexity and Management: Fad or Radical Challenge to Systems Thinking London: Routledge.

Vilar, S. (1999). Nueva racionalidad. España: Editorial Kairós.

von Wright, G. H. (1987). Explicación y comprensión. Madrid: Alianza Universidad.

Wallertein, I. (1999). El fin de la certidumbre en las ciencias sociales. México: Universidad Nacional Autónoma de México. http://computo.ceiich.unam.mx/webceiich/docs/ libro/El fin de las certidumbres en ciencias sociales. pdf

Wang, D., Song, C., \& Barabási, A. (2013). Quantifying LongTerm Scientific Impact. Science, 342, 127-132. doi: DOI:10.1126/science.1237825.http://science.sciencemag. org/content/342/6154/127 


\section{Sección}

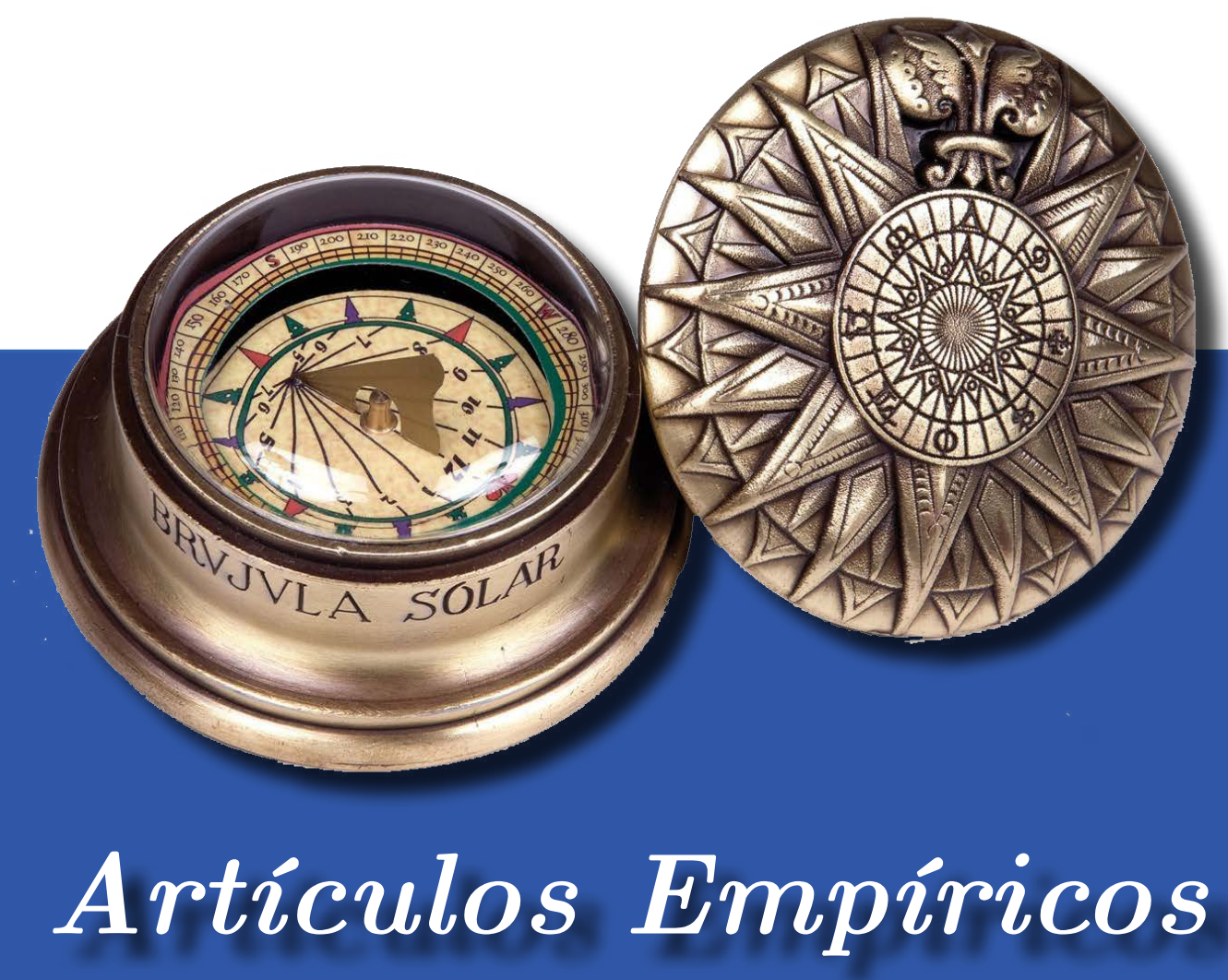




\title{
IMPACTO DEL TRABAJO MULTIDISCIPLINARIO EN NIÑOS CON NeCEsidades Educativas Especiales
}

\author{
Andrea Lorena Ramos-Ramírez \\ UNAM, FES IZTACALA
}

MÉXICO

\section{RESUMEN}

La presente investigación se llevó a cabo en el Centro de Desarrollo Educativo Comunitario (CDEC) Chalma, que tiene como propósito la atención a niños con Necesidades Educativas Especiales (NEE) por parte de estudiantes de Psicología de la Facultad de Estudios Superiores Iztacala, con apoyo ocasional de estudiantes de Odontología y Optometría de la misma Facultad. El objetivo de la presente es dar cuenta reflexivamente del impacto en la atención a niños con NEE al realizar una evaluación y diseño de estrategias de intervención multidisciplinaria (Psicología, Optometría y Odontología), incorporando esta vez una disciplina más, la médica. Se utilizó la metodología cualitativa, particularmente la investigación-acción, idónea para cumplir con nuestro objetivo.

Los resultados muestran, en la mayoría de los casos atendidos por los psicólogos, la posibilidad de integrar a las actividades con los niños la terapia visual sugerida por los optómetras, promoviendo la continuidad del tratamiento. La atención médica en el CDEC propició la detección y atención temprana de diversos padecimientos y el control del niño sano. Se ilustra cómo el trabajo de múltiples disciplinas tiene efectos positivos, ya que las indicaciones de los optómetras y médico permitieron un trabajo integral con los niños en el ámbito psicológico.

Palabras Clave:

Investigación Cualitativa, Metapsicología de Contextos, Necesidades Educativas Especiales, Trabajo Multidisciplinario y Psicología

\section{IMPACT OF MULTIDISCIPLINARY WORK IN CHILDREN With Special Educational Needs}

\begin{abstract}
This research was conducted at the Centro de Desarrollo Educativo Chalma (CDEC), which has the purpose to care children with Special Educational Needs (SEN), by students of the Facultad de Estudios Superiores Iztacala (FESI), with occasional support from students of Dentistry and Optometry at the same university. The purpose of this is to account reflexively of the impacton carefor children with SEN, to make an assessment and design of multidisciplinary intervention strategies (Psychology, Optometry and Dentistry), this time addin gone more discipline, the medical. Qualitative methodology was used, particularly action-research, suitable to meet our goal.

The results show in most cases treated by psychologists the possibility of integrating to the activities with children the vision therapy suggested by optometrists, promoting continuity of treatment; medical care in the CDEC which lead to detection and early treatment of various diseases and control of the healthy child. It illustrates how the work of multiple disciplines, has positive effects, being that the indications by optometrists and doctors, allowed an integral work with children in the psychological realm.
\end{abstract}

Keywords:

Qualitative Research, Metapsychology of Contexts, Special Education Needs, Multidiscipline y Psychology

Bitácora del ARtículo:

| Recibido: 27 de mayo de 2015 | Aceptado: 3 octubre de 2015 | Publicado en línea: 15 de diciembre de 2015 | 


\title{
IMPACTO DEL TRABAJO MULTIDISCIPLINARIO EN NiÑOS CON NeCEsidades Educativas Especiales
}

\author{
Andrea Lorena Ramos-Ramírez
}

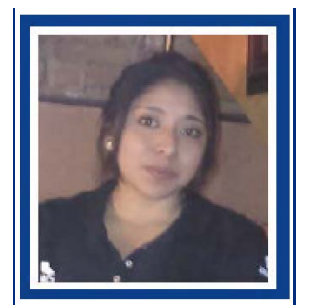

Andrea Lorena Ramos-Ramírez

UNAM - FES Iztacala

Correo:dyan.170893@gmail.com

Egresada de la carrera de Psicología de la Facultad de Estudios Superiores (FES) Iztacala. Actualmente realiza trabajo profesional dando terapia a niños con problemas emocionales y estimulación temprana en la Colonia Guadalupe Chalma, los cursos que ha tomado han sido varios.

Ver más...

\section{AgRADECIMIENTOS}

Agradezco la colaboración de mi asesora Carolina Rosete Sánchez y los conocimientos brindados durante el proceso de realización de este artículo, a mis compañeras Pamela Rosales y Joselin García por el apoyo brindado en el proceso de la investigación; a su vez agradezco la experiencia enriquecedora que he compartido con mis compañeros, profesores y estudiantes del curso PROSAP (Programa de Superación Académica Permanente) «Formación docente: Complejidad y Transdisciplina y Sociocultural y de la Actividad», en el cual yo también he contribuido para lograr una mejor comprensión de la nueva propuesta «Metapsicología de Contextos».

\section{DATOS DE FiLIACIÓN DE LA AUtora}

Psicóloga egresada de la UNAM, FES-Iztacala.

Copyright: (c) 2015 Ramos-Ramírez, A. L.

Este es un artículo de acceso abierto distribuido bajo los términos de la licencia Creative Commons Reconocimiento-NoComercial 4.0 Internacional, por lo que su contenido gráfico y escrito se puede compartir, copiar y redistribuir total o parcialmente sin necesidad de permiso expreso de su autora con la única condición de que no se puede usar con fines directamente comerciales y los términos legales de cualquier trabajo derivado deben ser los mismos que se expresan en la presente declaración. La única condición es que se cite la fuente con referencia a la Revista Digital Internacional de Psicología y Ciencia Social y a su autora. 


\section{TABLA DE CONTENIDO}

\begin{tabular}{lc} 
INTRODUCCIÓN & 211 \\
\hline \hline PLANTEAMIENTO DEL PROBLEMA & 212 \\
\hline \hline JUSTIFICACIÓN & 212 \\
\hline \hline OBJETIVO & 212 \\
\hline \hline HIPÓTESIS & 212 \\
\hline \hline ESTADO DEL ARTE & 212 \\
\hline \hline METODOLOGÍA CUALITATIVA & 213 \\
\hline \hline
\end{tabular}

Participantes, 214

Escenario, 214

Procedimiento, 214

REsultados

214

Evaluaciones, diagnóstico y tratamiento /diseño de

intervención, 215

Sesiones de trabajo multidisciplinario, 217

Entrevistas a las madres, 218

CONCLUSIONES

REFERENCIAS

MetA-AnÁlisis del Artículo

Dimensión Cuantitativa, 223

Dimensión Cualitativa, 225

Historia del Proceso Editorial 


\section{INTRODUCCIÓN}

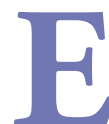
I presente trabajo se realizó en el Centro de Desarrollo Educativo Comunitario Chalma (CDEC), el cual es producto del trabajo de las madres de familia asesoradas por tres profesores de la Facultad de Estudios Superiores Iztacala. Este Centro surgió con el fin de proporcionar la atención necesaria para estimular el desarrollo psicológico en niños con Necesidades Educativas Especiales (NEE), enmarcado por el programa de servicio social "Asesoría Psicológica en el Ámbito Comunitario" que inició en 1983. A partir de este año, con el apoyo de los estudiantes de la carrera de Psicología y las madres que se encontraban sumamente involucradas en atender la situación de sus hijos con NEE, empieza un arduo trabajo para construir el CDEC, el cual actualmente cuenta con distintos servicios como: estimulación temprana, educación inicial, apoyo psicopedagógico, terapia física e hidroterapia.

Dadas las demandas y características de la población atendida, el programa "Asesoría Psicológica en el Ámbito

"Los seres humanos
estamos construidos
simultáneamente
por múltiples
estructuras fisicas y
conceptuales"
Comunitario" tiene los siguientes objetivos generales: a) llevar hasta la propia comunidad la atención a las Necesidades Educativas Especiales que se demanden; b) aprovechar el contacto con el ámbito familiar, escolar y comunitario de los niños, para así poder diseñar estrategias de intervención adecuadas de acuerdo a sus características individuales; c) aprovechar al máximo los recursos materiales y humanos para estimular el desarrollo psicológico de los niños; d) en la medida de lo posible, realizar evaluación y estrategias de intervención multidisciplinarias (Rosete, Salinas \& Orozco, 2002). Este objetivo es el que más atañe a esta investigación. Finalmente, e) promover las actividades de autogestión entre las madres para atender las necesidades de estimulación de sus hijos.

Al realizar las actividades de servicio social en este Centro, detectamos las siguientes problemáticas: a) con respecto a la salud infantil: desnutrición, enfermedades recurrentes y falta de higiene, y b) en el ámbito psicológico: pobreza en la estimulación para el desarrollo infantil, maltrato y limitado nivel de escolaridad en las madres, entre otros. En pocas ocasiones ha sido posible abordar estas situaciones de manera multidisciplinaria, brindando la atención únicamente desde la disciplina psicológica.

Guevara (2012) menciona que a través de los avances que han tenido diversas disciplinas científicas se ha logrado dejar claro que el desarrollo que cada ser humano logre en cada área de su vida es producto de la interacción de un conjunto de factores de índole biológico y médico, con otro conjunto de factores de naturaleza cultural-social y educativa; es así como la evolución del conocimiento científico de diversas disciplinas ha cristalizado en el actual concepto del ser humano como un ser integral. De este modo, un profesional de alguna disciplina en particular, podrá determinar si el estudio y atención a las necesidades de un individuo requieren de la intervención de más profesionales de distintas disciplinas científicas, a fin de aproximarse a las diferentes dimensiones de las que están constituidos los seres humanos.

Rosete, Alcaraz y Nieto (2012) definen la multidimensionalidad como una meta-categoría que reconoce que los seres humanos estamos construidos simultáneamente por múltiples estructuras físicas y conceptuales; esta afirmación plantea la necesidad de realizar un abordaje multidimensional, que se dirija a un trabajo multidisciplinario, dada la relevancia de estudiar al individuo de forma integral, entablando un diálogo con distintos profesionales como neurólogos, odontólogos, médicos, optómetras, terapeutas físicos y de hidroterapia.

La multidimensionalidad del cuerpo nos permite conocer la historia del individuo poseedor de dicho cuerpo "físico". Rosete y Salinas (2008) identificaron que las dimensiones más importantes presentadas en los niños con NEE que asisten al CDEC son las siguientes: orgánica, familiar, económica, cultural, estética, de género, afectivo-emocional y corporal. En esta investigación se buscaron alternativas que favorecieran el desarrollo de los niños, proponiendo no sólo un trabajo psicológico, sino un trabajo multidisciplinario, tendiente a la transdisciplina, que corresponda a la concepción del niño en desarrollo desde la metapsicología de contextos.

Los artículos citados subrayan la importancia de realizar un trabajo multidisciplinario; sin embargo, hasta este momento no se cuenta con datos que fundamenten el impacto de este trabajo dentro del CDEC; documentar esta información es el objetivo que se plantea lograr en esta investigación. 


\section{Planteamiento del problema}

A lo largo del tiempo en el CDEC se han realizado estrategias de evaluación e intervención multidimensionales de manera aislada; en este momento se está sistematizando el trabajo multidisciplinario (servicio psicológico, médico y optométrico), ya que se considera teóricamente que el desarrollo del individuo no se reduce únicamente a la dimensión psicológica, de tal manera que la pregunta de investigación del presente trabajo es: ¿cuál será el impacto que tendrá realizar evaluaciones e intervenciones multidisciplinarias sobre el desarrollo psicológico en los niños con NEE que se atienden en el CDEC?

\section{JUSTIFICACIÓN}

Como se mencionó anteriormente, las referencias que se tienen acerca del trabajo multidisciplinario son sumamente escasas, se remiten a propuestas a futuro; Guevara (2012) menciona que es viable proponer que los profesionales de la salud y la educación encaminen esfuerzos a conocer los aspectos más importantes de las disciplinas que puedan participar en la atención a niños con NEE para tener un panorama amplio de la problemática y remitir cada caso a los profesionales idóneos.

Desde las teorías de la complejidad, la psicología aborda la multidimensionalidad de la realidad, es decir, reconoce el hecho de que nuestra realidad está constituida simultáneamente por múltiples dimensiones tanto físicas como conceptuales, por lo que se deben considerar en su estudio no sólo las dimensiones biológicas y sociales, sino muchas más, entre las que destacan la psico-afectiva, familiar, histórica, política, económica, moral, ética, ecológica, religiosa, entre otras. Con base en esto, es pertinente mencionar que dichas dimensiones se ven relacionadas con las disciplinas que se encuentran involucradas en la atención al desarrollo integral del niño.

De esta manera se realizó una evaluación e intervención multidisciplinaria ya que se considera que la atención a niños con NEE debe involucrar la participación de múltiples especialistas para conocer y diseñar estrategias de intervención que den cuenta de la multidimensionalidad y contextualización del proceso de desarrollo del niño.

\section{Objetivo}

El objetivo de la presente investigación es dar cuenta reflexivamente del impacto en la atención a niños con
NEE al realizar una evaluación y diseño de estrategias de intervención multidisciplinaria (Psicología, Optometría, Odontología y Medicina).

\section{HIPÓTESIS}

La intervención multidisciplinaria contribuirá a la obtención de mayores beneficios para el desarrollo multidimensional de los niños con NEE.

La experiencia del trabajo multidisciplinario brindará una serie de situaciones favorables o desfavorables a reflexionar, impactando positivamente sobre la formación profesional de todos los involucrados.

\section{ESTADO DEL ARTE}

Para llevar a cabo la presente investigación es importante realizar una contextualización de los fundamentos teóricos en los cuales se basó.

Abordar la complejidad del ser humano en ningún sentido es "fácil", desde la Psicología encontramos que existen diversidad de modelos y paradigmas que intentan dar respuesta al comportamiento del ser humano; sin embargo, en dichas teorías damos cuenta de la existencia de una visión mecanicista, en donde en sus concepciones del ser humano resalta únicamente una dimensión y la realidad descrita pareciera ser lineal (paradigma de la simplicidad). Es importante resaltar que la reflexión realizada en la presente investigación se llevó a cabo desde los fundamentos epistemológicos de la MetaPsicología de Contextos (MPC) que tiene como base principal las teorías de la complejidad, las cuales nos dicen que el individuo construye el conocimiento en la diversidad de contextos en los que se desenvuelve. Morín (2004) señala que dichas teorías tienen como principal objeto de estudio los procesos dinámicos, construidos y multidimensionales desde una mirada subjetiva. La constante discrepancia entre los paradigmas de la simplicidad y de la complejidad dio paso a una nueva manera de crear conocimiento.

Un grupo de profesores de la Facultad de Estudios Superiores Iztacala dieron cuenta de dichas limitaciones, involucrándose de esta manera en la búsqueda de respuestas desligadas de procesos lineales, unidimensionales y occidentales. Alcaraz (2008) y Lara (2008) consideran el proceso de desarrollo de los individuos como: único, irrepetible, dinámico, multidimensional y por ende complejo; afirman: "como investigadores reconocemos que nuestro objeto de estudio es al mismo tiempo un 'sujeto' dinámico, recursivo, multidimensional y contextuado". 
A partir de ello se realiza una propuesta que invita a "un nuevo modo de hacer y entender la ciencia", una visión que podrá ser aplicada en contextos que competen al mexicano, dejando de lado estrategias fragmentarias de la realidad del sujeto. La MetaPsicología de Contextos se define como:

"Un marco interpretativo de la realidad, construido en un espacio comunitario de reflexión teórica, filosófica y metodológica, que afirma explícitamente que nuestra interpretación de la realidad psíquica está afectada por nuestro contexto civilizacional". (Alcaraz, 2012, p. 126)

La MPC no pretende ser una teoría con verdades absolutas, de hecho, se nombra a sí misma como una preteoría que cuenta con flexibilidad, apertura y creatividad a la hora de abordar la realidad psicológica, la cual no es unívoca ni estática.

La existencia de múltiples contextos tomará una gran relevancia para el estudio del individuo, "contextos civilizacionales" es una palabra clave dentro de esta MetaPsicología de Contextos, ya que será a partir de la realidad dinámica del sujeto que entenderemos sus diversas formas de comportamiento, conocer cada uno de los contextos en los que el individuo se desenvuelve abrirá puertas a diversos análisis que permitirán dar explicaciones a procesos psicológicos.

Una de las premisas principales de la MetaPsicología de Contextos es reconocernos como sujetos epistémicos de tal manera que el psicólogo se involucra en cada uno de los aspectos que competen al niño con NEE impactando en múltiples dimensiones, lo cual enriquece el trabajo y la manera de mirar y conocer a los otros.

Por lo mencionado anteriormente, el papel del psicólogo toma gran relevancia ya que antes de realizar estrategias de intervención pertinentes para el niño será el encargado de investigar la historia que subyace a la vida del niño con NEE, además de involucrar en ello a los actores presentes en ésta: padres, abuelos, hermanos, entre otros.

Recordemos que para la MPC la realidad es una construcción humana, dinámica, pluricultural, multiforme y multidimensional, la cual se encuentra inserta en un contexto civilizacional, en donde los sujetos que la crean son al mismo tiempo "producto y productores de su realidad" (Alcaraz, 2012, p. 140).

\section{Metodología cualitativa}

Una vez sintetizada la perspectiva desde la cual se llevó a cabo la investigación, es importante aclarar que se uti- lizará una metodología cualitativa, la cual se encuentra sumamente vinculada con el propósito de la MetaPsicología de Contextos. La investigación cualitativa se enfoca en la realización de registros narrativos, ésta trata de identificar la naturaleza profunda de las realidades, su sistema de relaciones y su estructura dinámica (Pita \& Pértegas, 2002, p. 76), es decir, se habla de un estudio contextual del comportamiento de otras personas dentro de sus procesos de vida.

La metodología cualitativa contribuye a la generación de conocimiento de manera multidisciplinaria, ya que al identificar elementos multidimensionales (histórico-sociales, culturales, económicos y subjetivo-emocionales) es posible mirar desde diferentes perspectivas la situación a la que nos enfrentamos, encontrando así diversas explicaciones dadas por profesionales de la salud, lo cual permite llevar a cabo nuestro trabajo como psicólogos de una manera integral.

Los investigadores de las ciencias sociales consideran que la producción de conocimiento desde una perspectiva contextual debe estar situada específicamente en el lugar donde ocurren los fenómenos, subrayando con ello su cualidad histórica y dinámica; al mismo tiempo reconocen la participación del investigador en esta producción de conocimiento. Esta nueva visión ha dado paso a distintas metodologías como las historias de vida, la observación participante, la etnografía y la investigación-acción, esta última se utilizó en la presente investigación.

Elliott (1993, como se citó en Sandín, 2003) menciona que el objetivo de la investigación-acción consiste, prioritariamente, en mejorar la práctica y no así la producción y utilización del conocimiento, de tal manera que se subordina a este objetivo fundamental y está condicionado por él.

Según Bartolomé y Pérez Serrano (como se citó en Sandín, 2003, p. 38) las características de la investigación-acción son:

- Transformación y mejora de una realidad educativa y/o social.

- Parte de la práctica, de problemas prácticos.

- Es una investigación que implica la colaboración de las personas.

- Implica una reflexión sistemática en la acción.

- Se realiza por las personas implicadas en la práctica que se investiga. 
- El elemento de "formación" es esencial y fundamental en el proceso de investigación-acción.

- El proceso de investigación-acción se define o se caracteriza como una espiral de cambio.

En este estudio empleamos la investigación-acción con el propósito de mejorar la atención multidisciplinaria de los niños del CDEC, rescatamos el proceso a través de entrevistas, observaciones directas y reuniones multidisciplinarias en el espacio de trabajo con los protagonistas del proceso: optómetras, médico, odontólogos, psicólogos, padres de familia e investigadora.

\section{Método}

\section{Participantes}

Participaron 35 niños (en promedio) que asistieron al CDEC; se dividen en 5 grupos: Lactantes (6), Estimulación temprana (7), Preescolar (8), Escolar (7), Jóvenes y adultos (7); las madres de familia de los niños asistentes, odontólogo (1), optómetras (15), médico (1) y psicólogos (25).

\section{Escenario}

La investigación se realizó en el CDEC, el cual cuenta con distintas aulas para la intervención psicológica de los 35 niños inscritos, salones destinados para estimulación temprana, terapia física, masoterapia, hidroterapia y salones adecuados para la educación escolarizada, además de un consultorio médico. La atención optométrica y odontológica se proporcionó en la Facultad de Estudios Superiores Iztacala.

\section{Procedimiento}

Se utilizó una metodología cuantitativa y cualitativa, refiriéndonos a la primera con obtención de datos cuantitativos mediante el diseño y la aplicación de registros sobre la asistencia, diagnóstico y tratamiento de la disciplina médica y optométrica. La metodología cualitativa sustentada por la investigación-acción incluyó:

a) Evaluaciones, diagnóstico, tratamiento o diseño de intervención de los 35 niños con NEE que son atendidos en el CDEC en el turno matutino, desde cada una de las distintas disciplinas científicas (Psicología, Optometría, Odontología y Medicina).

b) Sesiones de trabajo multidisciplinario (psicólogos y médico, psicólogos y optómetras) en las que se presentaron los avances de los casos, se analizaron y reflexionaron el impacto del diagnóstico, tratamiento y también los benefi- cios recibidos durante el proceso que se llevó a cabo en estas evaluaciones e intervenciones multidisciplinarias en el desarrollo de los niños en general y en casos específicos.

c) Entrevistas a las madres, en las que se refirió la calidad del servicio: diagnóstico, tratamiento, número de sesiones y beneficios recibidos.

d) Elaboración de un informe que dio cuenta del proceso de trabajo multidisciplinario y su impacto en el desarrollo de los niños.

Realizamos una programación para que cada niño tuviera su evaluación, diagnóstico, tratamiento o diseño de intervención por parte de cada una de las disciplinas (Psicología, Medicina, Optometría y Odontología). El psicólogo del niño estuvo presente durante cada una de las evaluaciones y tratamientos. La atención psicológica y médica se proporcionó en el CDEC Chalma; la optométrica y odontológica en las clínicas correspondientes de la FES Iztacala UNAM.

Tuvimos sesiones de trabajo multidisciplinario una vez a la semana, con una duración de una hora, entre los 25 psicólogos y la médico del CDEC. Durante estas sesiones se presentaron los avances de los casos, se analizó y reflexionó acerca del impacto -tipo de diagnósti$\mathrm{CO}$, tratamiento y beneficios recibidos durante el proceso que tienen éstas evaluaciones e intervenciones multidisciplinarias en el desarrollo de los niños en general y en casos específicos. Asimismo, se comentaron las dificultades presentadas a lo largo del proceso y las formas en las que cada psicólogo colaboró con el tratamiento sugerido por las otras disciplinas y cómo las incorporó a su estrategia de intervención.

Una vez terminado el proceso, se realizó una entrevista a cada una de las madres participantes, en la que se les pidió que evaluaran la calidad del servicio, diagnóstico, tratamiento, número de sesiones y beneficios recibidos. Se elaboraron tablas en las que se concentran los datos de los diagnósticos y tratamientos de cada disciplina participante, a partir de las cuales se hizo la reflexión del impacto de la intervención multidisciplinaria.

Con toda la información anterior, su análisis y reflexión, se llevó a cabo el informe que da cuenta del proceso de trabajo multidisciplinario y su impacto sobre el desarrollo de los niños.

\section{Resultados}

Es importante mencionar que los datos mostrados en las tablas corresponden a una población fluctuante debido a que hubo niños que se dieron de baja a lo largo de la investigación, por lo que se incorporaron algunos más 
a mediados del proyecto. En las tablas no se encuentra una coincidencia en el número de niños atendidos en todos los servicios, debido a que recibir la atención de cada servicio fue determinada por las características particulares de cada niño.

\section{Evaluaciones, diagnóstico y tratamiento / diseño de intervención}

\section{Medicina}

De acuerdo al reporte de la médico, atendió a 45 niños, 4 se dieron de baja, 4 fueron de nuevo ingreso, quienes Ilegaron a un mes de concluir el semestre y sólo recibieron atención médica y psicológica. De los 45 niños, 9 acudieron sólo a control de niño sano. El padecimiento más frecuente reportado por la médico fue amigdalitis bacteriana o viral (11 casos), también amibiasis y gastroenteritis en 2 casos respectivamente, obesidad en 3 casos, desnutrición severa en 2 y anemia en uno de ellos. La médico reporta que 12 niños asistieron sólo a una consulta, 11 a dos consultas y 24 niños entre tres y cinco consultas. El reporte médico arrojó datos sobre la etiología de los casos, las más frecuentes fueron: embarazo de alto riesgo con amenaza de aborto, anoxia perinatal con meconio fetal, preclamsia en la madre y sufrimiento fetal.

De acuerdo a la médico la atención de 24 casos fue satisfactoria, proporcionándoles en total 101 consultas; 12 no acudieron a consulta en su cita programada y 5 no siguieron el tratamiento. Es importante mencionar que la médico no sólo atendió a los niños, también a las mamás de los niños a las que les dio en total 77 consultas.

\section{Optometría}

El número de niños que recibieron evaluación y tratamiento optométrico fueron 24,4 de los niños no presentaron ninguna patología, sólo se les dio la recomendación de revisión periódica en seis meses. El diagnóstico optométrico se dividió en tres categorías: refractivo, binocular y patológico.

Tabla 1

Etiología, Condición actual y Condición emocional de los participantes

\begin{tabular}{|c|c|c|c|c|c|}
\hline Etiología & Núm. & CONDICIÓN ACTUAL & Núm. & CONDICIONES EMOCIONALES & Núm. \\
\hline \multicolumn{6}{|l|}{ Prenatal } \\
\hline Embarazo de alto riesgo & 11 & Hipotonía muscular & 2 & Nacimiento de su hermano & 3 \\
\hline Amenaza de aborto & 4 & Cuadriplejia espástica & 2 & Hijo único Sobreprotección & 2 \\
\hline Caída & 1 & Epilepsia & 4 & Crianza multifamiliar & 3 \\
\hline $\begin{array}{l}\text { Infección en las vías } \\
\text { urinarias }\end{array}$ & 2 & Retraso psicomotor & 2 & Crianza autoritaria & 2 \\
\hline Diabetes & 1 & Síndrome de Down & 3 & Embarazo muy deseado & 1 \\
\hline Abortos previos & 1 & $\begin{array}{l}\text { Inmadurez } \\
\text { neuromotora }\end{array}$ & 2 & Miedo a que le pase algo & 1 \\
\hline Madre añosa & 2 & $\begin{array}{l}\text { Displasia asetibular } \\
\text { bilateral }\end{array}$ & 1 & Poco apoyo familiar & 2 \\
\hline Cirugía de apéndice & 1 & Hipertiroidismo & 1 & $\begin{array}{l}\text { Embarazo con alta tensión } \\
\text { emocional }\end{array}$ & 1 \\
\hline $\begin{array}{l}\text { Intentos prolongados } \\
\text { por embarazarse }\end{array}$ & 1 & Anemia & 2 & $\begin{array}{l}\text { No aceptación por parte de la } \\
\text { madre }\end{array}$ & 1 \\
\hline $\begin{array}{l}\text { Sarampión congénito y } \\
\text { rubéola }\end{array}$ & 1 & Cardiopatía & 1 & Violencia intrafamiliar & 1 \\
\hline Perinatales & & $\begin{array}{l}\text { Secuelas de } \\
\text { extirpación de tumor }\end{array}$ & 1 & Soledad & 1 \\
\hline Preclamcia & 6 & Problemas renales & 1 & Mala alimentación & 4 \\
\hline Anoxia & 3 & Obesidad & 1 & & \\
\hline Síndrome de meconio & 1 & & & & \\
\hline Paro cardiaco & 1 & & & & \\
\hline
\end{tabular}


En el refractivo las condiciones encontradas más frecuentemente fueron astigmatismo1, hipermetropía2 y miopía 3 en 8 casos.

El diagnóstico binocular se encontró en 4 casos, la alteración consistió en movimientos lentos y limitados, hiperemia4 generalizada, disfunción oculomotora y ortoposición, 5 y en los casos faltantes se encontraron movimientos suaves, coordinados y completos.

En la categoría de patología se encontró conjuntivitis bacteriana en tres casos, meibomitis inflamatoria6 y mala calidad lagrimal.

Las recomendaciones con respecto al diagnóstico refractivo fueron las siguientes: uso de lentes en 4 casos, terapia visual en 7 , de estos solamente a 4 casos se les indicó cita abierta.

En la categoría de patología la recomendación fue limpieza ocular en 6 casos; si la infección bacteriana era severa recetaron tratamiento en gotas o en crema.

\section{Psicología}

Las tablas generales del trabajo psicológico integraron las recomendaciones de la médico y de los optómetras. Los datos respecto de la etiología (ver tabla 1) corroboran los datos de la historia clínica de todos los casos, elaborada por la médico, los cuales fueron ampliados con la realización de la historia de vida de la madre, por parte de los psicólogos, que reconstruyeron la historia de vida del desarrollo del niño, entre otros aspectos.

La tabla 1 (columna 1) muestra que la etiología con más frecuencia fue la de embarazo de alto riesgo (11 casos), la que estuvo vinculada con amenazas de aborto, infecciones en las vías urinarias, diabetes de la madre, abortos previos y madres añosas; asimismo, algunas madres presentaron tratamiento prolongado para embarazarse, sarampión, rubéola congénita y cirugía de apéndice durante el embarazo. Las etiologías perinatales presentadas fueron preclamsia, anoxia, síndrome de meconio y paro cardiaco. En la columna dos de la tabla (condición actual) encontramos: inmadurez neuromotora, retraso psicomotor, espasticidad, epilepsia, entre otras; encontramos también que entre las condiciones actuales están algunos trastornos alimentarios como obesidad, anemia y casos con Síndrome de Down, hipertiroidismos y problemas renales. En la última columna se presentan las condiciones emocionales detectadas como lo son las diversas situaciones que dan cuenta de factores que afectan al óptimo desarrollo de los niños, tales como: sobreprotección, nacimiento de un hermano, crianza autoritaria y multifamiliar, entre otras.

Tabla 2

Aspectos multidisciplinarios a atender

\begin{tabular}{lcllc}
\multicolumn{1}{c}{ Aspectos A Atender } & Núm. & \multicolumn{1}{c}{ AsPeCtos A Atender } & NúM. \\
Demora en el desarrollo psicomotor & 16 & Autosuficiencia & 8 \\
Espasticidad & 3 & Movimientos rápidos & 1 \\
Motricidad fina & 15 & Apego a la madre & 8 \\
Equilibrio & 4 & Socialización & 13 \\
Bajo tono muscular & 4 & Berrinches & 2 \\
Demora en el desarrollo del lenguaje & 12 & No comparte & 4 \\
Articulación & 1 & Dificultad en la interacción con sus pares & 3 \\
Atención dispersa & 3 & Agresión & 3 \\
Noción corporal & 3 & Aislamiento & 2 \\
Noción derecha izquierda & 4 & Tono de voz bajo & 2 \\
Noción espacial & 5 & Poca afectividad & 1 \\
Memoria visual y auditiva & 5 & No respeta normas sociales & 4 \\
Noción temporal & 1 & Expresión de emociones & 3 \\
Dificultades en el desarrollo de la lecto- & 12 & Manejo de emociones & 7 \\
escritura & 2 & Nutrición & 3 \\
Matemáticas & &
\end{tabular}


En la tabla 2 presentamos los aspectos que, en conjunto con las otras disciplinas, se acordó trabajarían los psicólogos.

Encontramos que, en lo correspondiente a las áreas de desarrollo, los aspectos más frecuentes fueron: la demora en el desarrollo motor (16 casos), la motricidad fina en 15 niños, el lenguaje (12 casos) y demora en el desarrollo del lenguaje en 12 casos, y en las condiciones emocionales destacan como aspectos a atender: la socialización (13 casos), el apego a la madre (8 casos) y dificultades en el desarrollo de la lecto-escritura en 12 casos.

En la tabla 3 se presentan las estrategias de intervención empleadas por los psicólogos, a las que se incorporaron los aspectos aportados por la médico como la nutrición y de los optómetras como el uso de los len-

\section{Sesiones de trabajo multidisciplinario}

Se llevó a cabo una sesión por semana, en la cual se trabajó con la médico y los psicólogos, en donde se describían los casos y las aportaciones que había tenido la inclusión de estas distintas disciplinas en el plano psicológico, había comentarios que permitían clarificar la manera de trabajar respecto a lo aportado por las distintas disciplinas, inclusive había psicólogos que dentro de su plan de trabajo semanal contemplaban sesiones de terapia visual, tomando en cuenta las indicaciones dadas por el optómetra; los resultados en todos los casos mencionados fueron favorables, ya que había una mejoría en cuando a la agudeza visual de los niños.

El servicio médico se encargaba de dar recomendaciones y tratamiento en relación a la salud y alimen-

Tabla 3

Estrategias de Intervención Psicológica

\begin{tabular}{lclc} 
Aspectos Y Estrategias de Atención & Num. & AspeCtos Y Estrategias de AtenCión & Num. \\
\hline Terapia física & 29 & Manejo del dinero & 2 \\
Hidroterapia & 15 & Pre-académicas & 4 \\
Estimulación multisensorial & 11 & Noción corporal & 4 \\
Masoterapia & 13 & Actividades grupales & 5 \\
Lenguaje & 14 & Expresión y manejo de emociones & 4 \\
Motricidad fina & 8 & Seguridad personal & 1 \\
Autoayuda & 5 & Nutrición & 4 \\
Socialización & 15 & Cambio de roles & 2 \\
Lecto- escritura & 6 & Terapia visual & 3 \\
Matemáticas & 5 & Valores & 1 \\
Cognición & 7 & Seguimiento de instrucciones & 2 \\
Pre-escritura & 2 & Control de esfínteres & 1 \\
Atención & 1 & Relaciones familiares & 6 \\
\hline
\end{tabular}

tes y la terapia visual. Entre las estrategias más empleadas destacan la terapia física, la hidroterapia, el trabajo en socialización y lenguaje, masoterapia y estimulación multisensorial.

Finalmente, en la tabla 4 se presentan los avances presentados por los niños, los que son considerablemente positivos, de los que destacan: el inicio y amplitud del lenguaje, el avance en la lecto-escritura, la autosuficiencia, la desaparición del Ilanto al apartarse de su madre, la mayor disposición para el trabajo, la distinción, el manejo y expresión de sus emociones. tación de los niños. Los psicólogos, al narrar su caso, hacían referencia a una cuarta disciplina (la cual no se tenía contemplada) que apoyó en el avance de los niños, esta era la de Nutrición; la médico del CDEC se encargó de proporcionar esta información con ayuda de otro profesionista (nutriólogo). Se reportaron avances sumamente favorables al reunir el trabajo de estas disciplinas, la médica y la nutrición, pues se tenía una alternativa distinta para mejorar la salud integral del niño, a través de una alimentación balanceada. Participantes con problemas de obesidad o desnutrición pudieron Ilevar a cabo un tratamiento favorable, además de obtener 
Tabla 4

Avances en los diferentes aspectos atendidos

\begin{tabular}{|c|c|c|c|c|c|}
\hline Avances & Num. & Avances & Núm. & Avances & Núm. \\
\hline $\begin{array}{l}\text { Reducción de la } \\
\text { espasticidad }\end{array}$ & 2 & Autosuficiencia & 6 & $\begin{array}{l}\text { No llora cuando su } \\
\text { madre se ausenta }\end{array}$ & 7 \\
\hline Se sienta solo & 2 & $\begin{array}{l}\text { Identificación de las } \\
\text { partes del cuerpo }\end{array}$ & 3 & Es más independiente & 3 \\
\hline Se rueda & 4 & Mejoró su atención & 2 & $\begin{array}{l}\text { Muestra más disposición } \\
\text { para el trabajo }\end{array}$ & 6 \\
\hline Gatea & 3 & Hace trazos finos & 2 & $\begin{array}{l}\text { Comparte alimentos y } \\
\text { material }\end{array}$ & 8 \\
\hline Se para solo & 2 & $\begin{array}{l}\text { Mejoró en su } \\
\text { coordinación motriz fina }\end{array}$ & 4 & Sigue normas & 2 \\
\hline $\begin{array}{l}\text { Consolidó la marcha y } \\
\text { mejoró equilibrio }\end{array}$ & 3 & Nombra números & 3 & $\begin{array}{l}\text { Distinción, manejo y } \\
\text { expresión de emociones }\end{array}$ & 7 \\
\hline $\begin{array}{l}\text { Mejoró en la } \\
\text { coordinación motriz } \\
\text { gruesa }\end{array}$ & 5 & Nombra letras & 3 & Tono de voz más alto & 2 \\
\hline Mejoró su tono muscular & 2 & Usa tijeras & 3 & No agrede & 2 \\
\hline $\begin{array}{l}\text { Dijo sus primeras } \\
\text { palabras }\end{array}$ & 3 & Nombra animales & 2 & Asertividad & 1 \\
\hline Dice de 15 a 29 palabras & 7 & $\begin{array}{l}\text { Integración auditivo, } \\
\text { visual, táctil }\end{array}$ & 1 & $\begin{array}{l}\text { Más tolerancia a la } \\
\text { frustración }\end{array}$ & 1 \\
\hline $\begin{array}{l}\text { Imitación de sonidos y } \\
\text { palabras }\end{array}$ & 5 & $\begin{array}{l}\text { Mejoró su coordinación } \\
\text { ocular }\end{array}$ & 1 & Mejoró su socialización & 4 \\
\hline Toma su mamila sola & 4 & en la lecto- escritura & 10 & $\begin{array}{l}\text { Acepta contacto físico de } \\
\text { sus compañeros }\end{array}$ & 1 \\
\hline $\begin{array}{l}\text { Empezó a comer con } \\
\text { cuchara }\end{array}$ & 2 & Maneja dinero & 1 & Trabaja en equipo & 5 \\
\hline $\begin{array}{l}\text { Control de esfínteres y } \\
\text { come solo }\end{array}$ & 1 & Elabora alimentos & 2 & $\begin{array}{l}\text { Acepta } \\
\text { responsabilidades }\end{array}$ & 1 \\
\hline
\end{tabular}

más energías para continuar con el trabajo en psicología. Hubo casos donde claramente se mostró el impacto positivo.

\section{Entrevistas a las madres}

Se realizaron 28 entrevistas a las madres de los niños asistentes al CDEC acerca del servicio médico y de optometría.

Los resultados arrojaron los siguientes datos: de las 28 personas entrevistadas, 28 asistieron al servicio médico, en algunos casos sólo fue por control del niño sano, es decir, su asistencia era recurrente para chequeos generales como lo era conocer su peso y talla. Para optometría se reportaron un total de 22 asistencias, además se contó con la asistencia de una persona al servicio de odontología. Como se puede observar, el servicio médi- co tuvo una mayor asistencia que el optométrico, esto se puede atribuir a que, en primera instancia, el servicio médico estaba ubicado dentro del CDEC, para ir a la clínica optométrica tenían que trasladarse a otro lugar, y en algunos casos esta opción no era tan factible, ya sea por tiempo, por falta de recursos económicos o debido a la condición orgánica de sus hijos; otra causa puede ser que debido a la asistencia previa a optometría ya se tenía el diagnóstico y tratamiento de algunos niños, como el uso de lentes, por lo que quizás no consideraron necesario volver asistir, aunque muchos tenían programadas citas. Sin duda el traslado y la desidia fueron situaciones que contribuyeron para no asistir a la revisión optométrica, por lo que se infiere que asistir al servicio médico es más cómodo, rápido y afecta en menor grado la economía. 
En cuando a la posibilidad de continuar con el servicio médico, se obtiene un total de 26 respuestas afirmativas y 2 respuestas negativas, lo que nos indica que los resultados al tener este servicio médico fueron favorables, encontramos que la valoración positiva se presentó en las siguientes categorías.

a) Expediente médico: Al respecto afirmaron: "La doctora puede llevar un expediente médico".

b) Mejoría: "La atención de un solo doctor, se enferma menos y no toma tanto medicamento, además de una nutrición adecuada". "Ya le tiene más confianza a la médico pues se deja revisar mejor". "Ayudó mucho". "Siguió su desarrollo hasta que se mejoró". "Ha salido muy rápido de este malestar".

c) Nutrición adecuada: "Tiene sobrepeso y con la dieta que ella le está dando está bajando de peso y talla". "Diagnosticaron desnutrición a través de la revisión médica, y pues la doctora nos mandó una dieta especial, con los nutrientes necesarios".

d) Prevención: "Se enfermó menos veces, por el tratamiento adecuado y continuo". "Pudimos checar cómo estaban nuestros hijos".

e) Economía: "Ante la economía actual del país, el beneficio de tener servicio médico gratuito "La dimensión familiar
tiene un impacto
fundamental en el
desarrollo psicológico
del niño" y además dentro de la escuela". "Bueno, nos ha servido de mucho, ya que muchas mamás faltaban por tener a sus hijos enfermos y sin posibilidad de llevar a sus hijos al médico por falta de dinero".

f) Comodidad: "Que se enferma menos y la ventaja es que esta súper cerca". "Muchos beneficios, pues es más fácil asistir aquí al Centro para cualquier revisión sin necesidad de andar buscando a otro doctor, aparte de que no me es tan fácil transportar".

En la valoración del servicio médico encontramos que 9 personas valoraron el servicio como "Muy bueno", 13 como "bueno" y 6 como "regular". En la valoración del servicio optométrico encontramos que de 22 que asistieron a optometría, 13 calificaron a este servicio como "bueno" y 6 como "muy bueno"; algunos niños del CDEC ya cuentan con lentes, los cuales se hicieron fundamentales para continuar en su avance en el ámbito psicológico, pues relatan un avance considerable en lectura o escritura.

\section{ConcLusiones}

Una vez recabada la información, se obtuvieron datos que fueron de gran ayuda para poder llegar a las siguientes conclusiones.

Las asistencias al servicio médico son mayores que al servicio de optometría, pues el consultorio se encuentra ubicado en el mismo inmueble en que se da atención psicológica, es decir, encontramos mayor facilidad y comodidad para la asistencia a este servicio; asimismo, la no asistencia de algunas de las madres a optometría imposibilitaron la atención a la salud integral que el niño debería tener para un buen desarrollo, ya que detectamos niños que requieren de asistencia optométrica y, sin embargo, no fueron llevados.

Por ello es importante resaltar que, aunque se brinde un servicio multidisciplinario, las mamás algunas veces suelen no aceptarlo; es por esta razón que se considera que la dimensión familiar tiene un impacto fundamental en el desarrollo psicológico del niño, pues contribuye a determinar la manera en la que se puede intervenir. Esto ocurre también en cada una de las dimensiones involucradas en el desarrollo psicológico, de tal manera que se puede alterar el desarrollo de sus hijos favorable o desfavorablemente.

Hablando específicamente del impacto que tuvo el trabajo multidisciplinario, los resultados finales permitieron conocer más detalladamente de qué manera impactó dicho trabajo, una vez obtenidas las tres tablas que sintetizan los aspectos de diagnóstico y tratamiento. Al reflexionar acerca de esos hallazgos nos pudimos percatar de que hubo avances en todos los ámbitos de intervención, los niños mostraron una mejoría notable en habilidades sociales, motrices y de autocuidado, gracias al múltiple trabajo de las disciplinas implicadas, cada una de ellas contribuyendo en su ámbito de la salud. A pesar de las facilidades otorgadas, en algunos casos el tratamiento requerido no fue llevado a cabo por las madres.

Fue fundamental el trabajo realizado por cada uno de los profesionales involucrados, la contribución que cada de uno aportaba a los psicólogos fortaleció las propuestas de intervención y permitió posibilitar el trabajar multidimensionalmente con cada uno de los niños y adultos. En las reuniones del trabajo multidisciplinario, pudimos constatar que es factible la integración del trabajo médico, psicológico, de los optómetra y odontólogos para enriquecer las estrategias de intervención de los niños con NEE. Sin duda el impacto fue favorable, 
ya que los resultados de las entrevistas a las madres nos permitieron conocer los comentarios positivos que hicieron de cada uno de los servicios.

Los psicólogos en cada una de las sesiones demostraron haber tenido una experiencia grata al hacer este trabajo en conjunto con otras disciplinas, ya que existían comentarios afirmando que "el niño se encontraba más activo durante las actividades", esto debido al cambio de alimentación "podía permanecer más tiempo realizando la actividad" ya que no había algún malestar físico que impidiera esto "observaba minuciosamente los detalles pequeños o a distancia", lo cual implicaba mayor atención; había psicólogos que se mostraban satisfechos de compartir estrategias de intervención multidisciplinarias señalando lo enriquecedor que era el conocer el hacer de otras disciplinas y que a su vez esto permitiera la incorporación de estrategias y recomendaciones de los demás profesionales.

En conjunto, los resultados del trabajo psicológico, médico y de los optómetras fue sumamente favorable, dando como resultado avances en los aspectos a atender, tales como comprensión de nociones corporales, espaciales y temporales, mayor control de su cuerpo (equilibrio y psicomotricidad), mejoría en la memoria visual y auditiva, atención y lenguaje, así mismo se encontraron progresos en aspectos educativos, desarrollo de lecto-escritura y comprensión matemática, fueron pocas personas las que no asistieron a algunos de los tres servicios.

El trabajo multidisciplinario dio cuenta de cómo las indicaciones de los optómetras y la médico permitían un buen desempeño en el ámbito psicológico; es necesario resaltar que durante la investigación encontramos que participaron también otras disciplinas involucradas, no previstas en la investigación, como fue la nutrición y la neurología, a las que se recurrió dadas las características particulares de algunos niños. Este trabajo integrado por múltiples disciplinas es de suma relevancia para continuar con progresos en la educación y la salud de los niños, brindando así la oportunidad de abarcar más dimensiones involucradas en su proceso psicológico.

En relación a la experiencia de los psicólogos con las otras disciplinas encontramos al inicio una dificultad, en términos de la comunicación, sobre todo con los optómetras, ya que existía una serie de términos desconocidos, lo que se comentó en las reuniones multidisciplinarias. Sin embargo, poco a poco, con la ayuda de los docentes y compañeros de las distintas disciplinas, se fueron aclarando y de esa manera enriquecieron la formación de los psicólogos y recíprocamente de los participantes de optometría y medicina.

La investigación realizada nos permite reflexionar acerca del impacto multidisciplinario, el cual es el objetivo de la investigación. Encontramos que los avances con cada una de las personas asistente al CDEC fueron positivos, además de dar cuenta que los contextos y los ambientes en que se desenvuelve el niño no son excluyentes de dicho desarrollo que el individuo

pudiera tener.

La nueva propuesta, MetaPsicología de Contextos, abre una gama de posibilidades y herramientas para poder comprender la realidad de cada uno de los individuos involucrados en esta práctica, para de esta manera realizar un trabajo que nos permita analizar más allá de la simplicidad.

\section{Referencias}

Alcaraz, G. J. R. (2008). La percepción consciente en el marco de la metapsicología de contextos. En López, R. S. (coordinador.). Reflexiones para la formación del psicólogo, (pp. 19-56). México: UNAM, FES Iztacala, DGAPA.

Alcaraz, G. J. R. (2012). Metapsicología para principiantes. En López, R. S. (coordinador.). Una formación metodológica en psicología, (pp. 125-151). México: UNAM, FES Iztacala, DGAPA.

Guevara, B. Y. (2012) Trabajo multidisciplinario para la atención de personas con necesidades educativas especiales. Revista Electrónica de Psicología Clínica Iztacala, 15(3). Universidad Nacional Autónoma de México, Facultad de Estudios Superiores Iztacala. Recuperado de http://www. iztacala.unam.mx/carreras/psicologia/psiclin/vol15num3/ Vol15No3Art9.pdf

Lara, V. J. (2008). Metapsicología de contextos: algunas reflexiones filosóficas para la innovación de conceptos en psicología. En López, R. S. (coordinador.). Reflexiones para la formación del psicólogo, (pp.79-112). México: UNAM, FES Iztacala, DGAPA.

Morín, E. (2004). La epistemología de la complejidad. [Internet]. En Gaceta de antropología, 2. España. Ruiz, S. L. J. Recuperado de http://digibug.ugr.es/html/10481/7253/ G20_02Edgar_Morin.html

Pita, F. S. \& Pértegas, D. S. (2002). Investigación cuantitativa y cualitativa. Unidad de Epidemiologia clínica y bioestadística. Complejo Hospitalario Universitario Juan Canalejo. España. pp. 76-78.

Rosete, S. C., Salinas, A. F \& Orozco, A. G. A. (2002). El servicio social como espacio de compromiso y formación ética del psicólogo. En Revista Electrónica SEF, FENAPSIME, UNAM, 9(3). 
Rosete, S. C. \& Salinas, A. F. (2008) Contextualización multidimensional de dificultades en el desarrollo psicocorporal. En López, R. S. (coordinador.). Reflexiones para la formación del psicólogo, (pp. 251-266). México: UNAM, FES Iztacala, DGAPA.

Rosete, S. C., Alcaraz, G. J. R. \& Nieto, O. M. B. (2012). La construcción multidimensional del cuerpo. Estudio de caso. En López, R. S. Una formación metodológica en psicología, (pp. 153-170). México: UNAM, FES Iztacala, DGAPA.
Sandín, M. (2003). Tradiciones en la investigación-cualitativa. En María Paz Sandín. Investigación cualitativa en la educación: fundamentos y tradiciones. Mac Graw Hill. Interamericana de España. p. 70. 


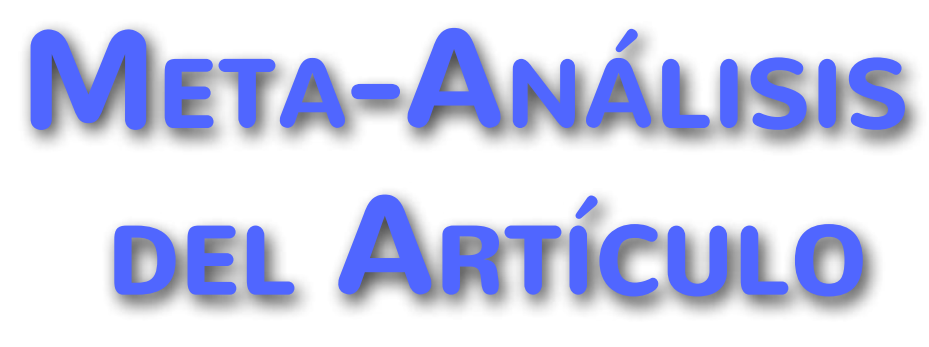




\section{Dimensión Cuantitativa}

\section{Perfil de Evaluación entre pares}


MWAMD 


\section{Índice de Concordancia}

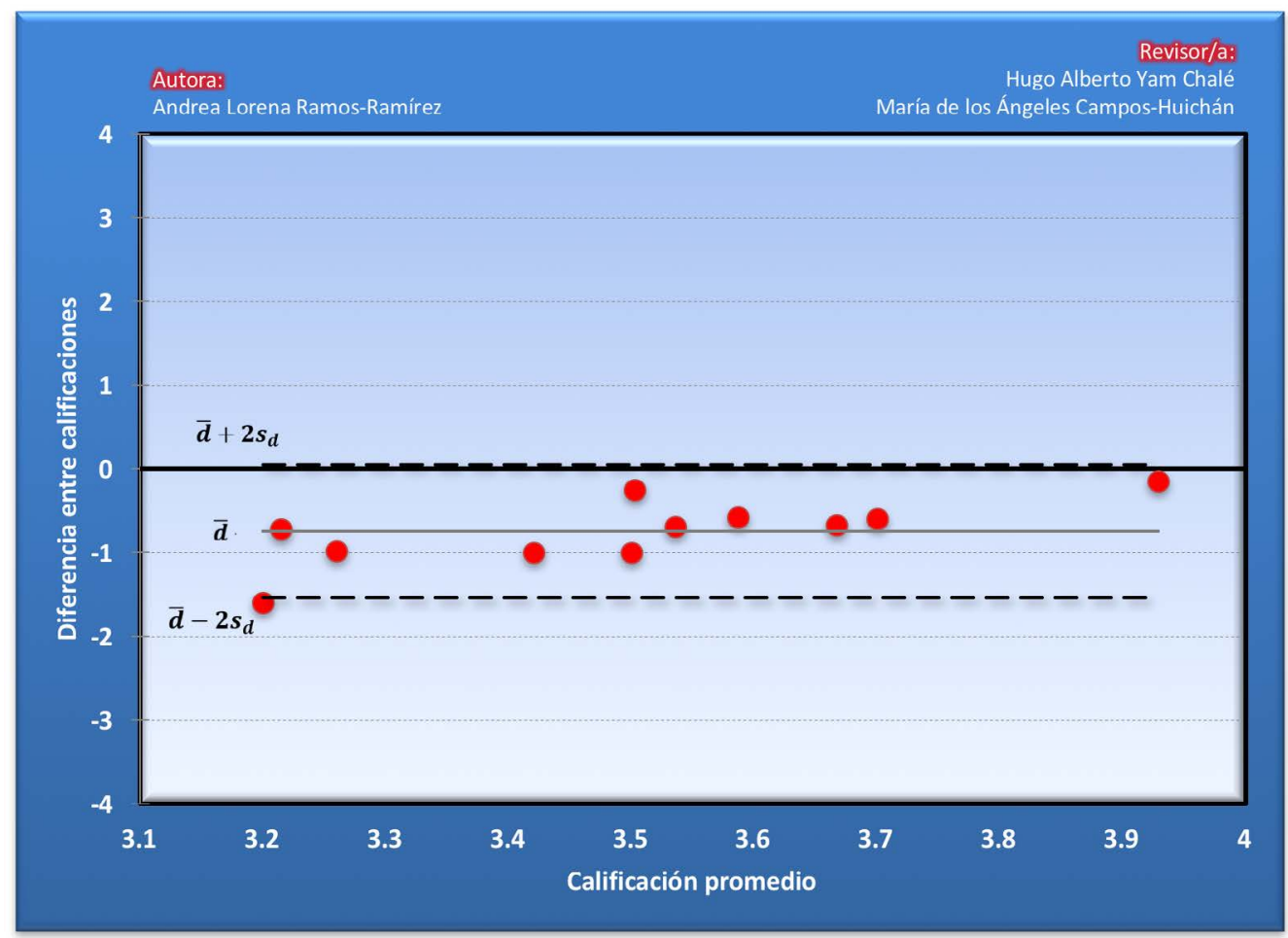

\section{Índice de Acuerdo}

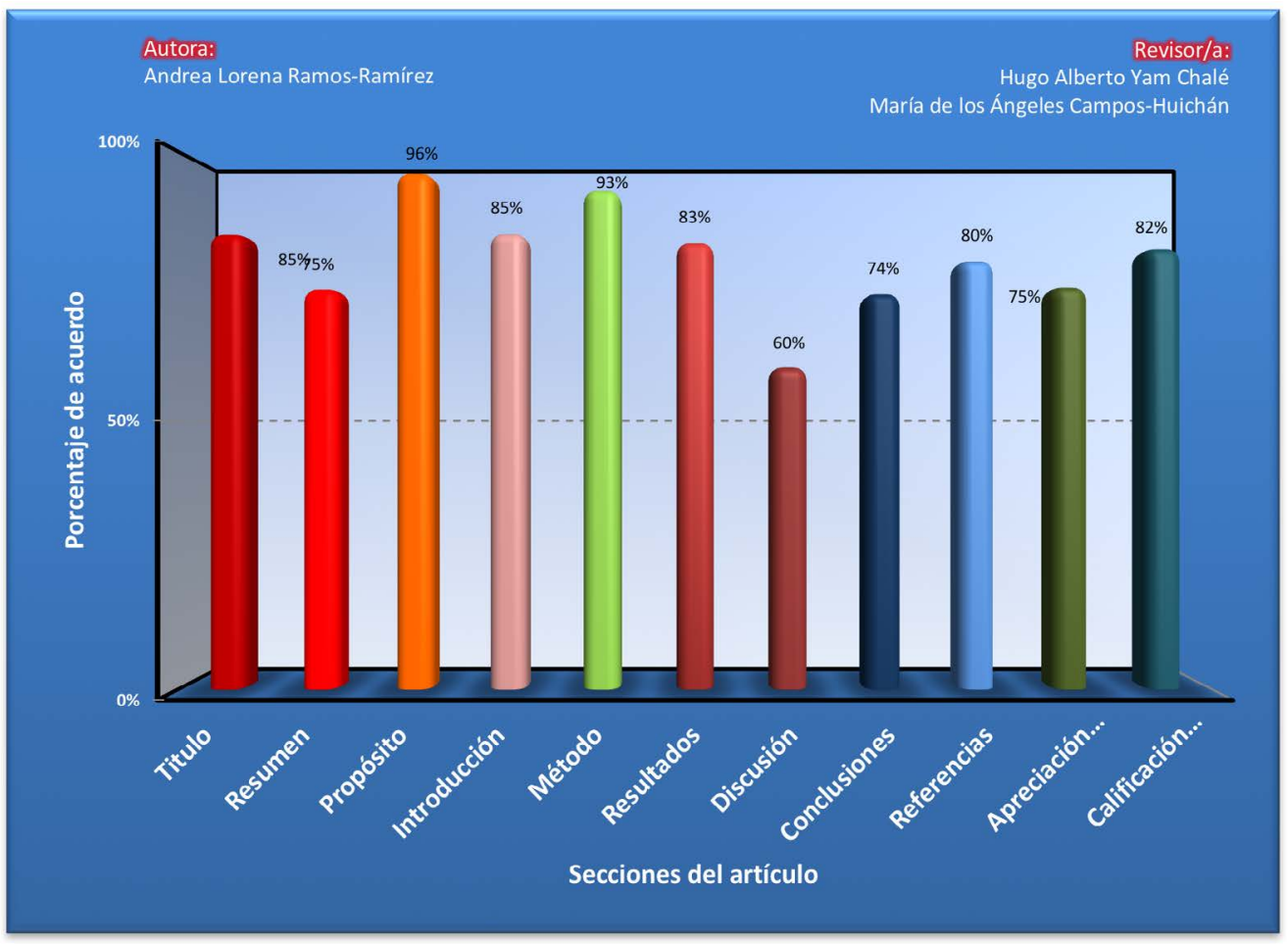




\begin{tabular}{|c|c|}
\hline REVISOR 1 & REVISOR 2 \\
\hline Hugo Alberto Yam-Chalé & María de los Ángeles Campos-Huichán \\
\hline \multicolumn{2}{|c|}{ TÍtulo/Autoría } \\
\hline Sin cometario & $\begin{array}{l}\text { Me parece que el título es adecuado y no es necesa- } \\
\text { rio realizar ningún cambio }\end{array}$ \\
\hline \multicolumn{2}{|c|}{ Resumen } \\
\hline $\begin{array}{l}\text { Conviene hacer divisiones de cada sección en pár- } \\
\text { rafos (hipótesis primer parrafo, metodología en el se- } \\
\text { guno párrafo...) }\end{array}$ & $\begin{array}{l}\text { Es importante que logren abreviar el resumen para } \\
\text { que sea de } 150 \text { palabras, pero me parece que a pesar } \\
\text { de ello es conveniente. }\end{array}$ \\
\hline
\end{tabular}

\section{Próposito del Estudio}

Tener en cuenta que cuando se habla de la teoría de la complejidad se habla de trabajo transdisciplinario. Conviene señalar ese aspecto cuando se menciona, haciendo la diferencia con la propuesta del escrito

Me parece muy completo y congruente. ngruente.

\section{INTRODUCCIÓN}

Las observaciones de deficientes son relacionadas con los objetivos específicos que menciona la autora; se sugiere trabajar en ellos ya que lo que plantea son tareas o actividades más que objetivos. De igua forma se sufiere trabajar en la redacción de las hipótesis con la intención de que se comprenda la relación entre variables, y teniendo en cuenta que son hipótesis descriptivas más que correlacionales. O en dado caso no colocar hipótesis, sino resultados esperados.

Los objetivos específicos podrían mejorarse si se redactaran en infinitivo, por ejemplo: Realizar evaluaciones, diagnósticos...., en el objetivo específico número uno. Sería necesario redactar así los demás

Sin comentario

\section{MÉTodo}

Dado que se utiliza una metodología cualitativa, lo único que faltaría sería describir los cuestionarios y las entrevistas.

\section{Resultados}

Sin comentario

Me parece que son congruentes 


\section{Discusión}

Se sugiere trabajar más en la discusión. Tratando de de hacer especulaciones con base en los resultados obtenidos y relacionar con otros estudios realziados. Proponer investigaciones futuras, mencionar las deficiencias de la investaigación

La discusión es apropiada

\section{Conclusiones}

El anterior comentario abarca también las conclusiones.

Faltó proponer estudios futuros

\section{Referencias}

Algunas referencias no se ecuentran citadas en el texto.

Hizo falta incluir referencias de los últimos cinco años, sin embargo la mayoría de las referencias sólo son de hace 8 años. 


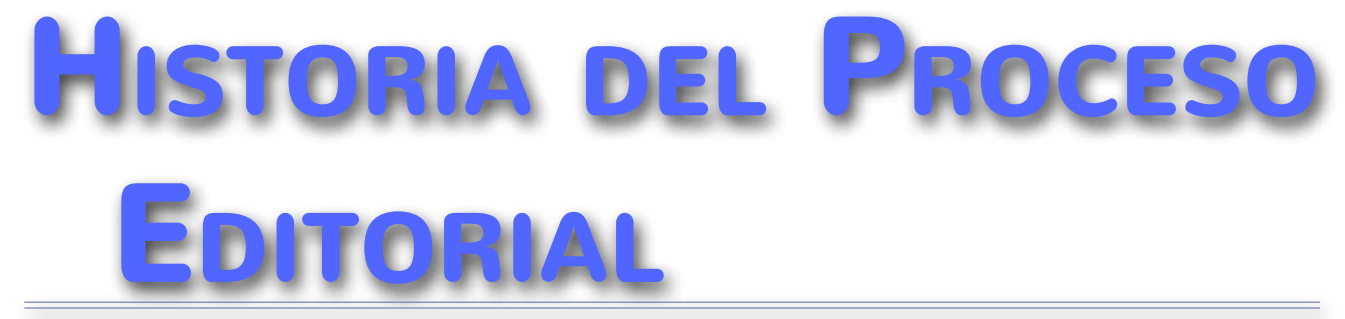




\title{
Propiedades Psicométricas del Cuestionario de Autoeficacia PROFESIONAL (AU-10) EN JÓVENES MEXICANOS QUE ESTUDIAN Y TRABAJAN

\author{
Andrés Valdez-Estrella, Edgar Jiménez-Hernández, Fabiola Itzel Villa-George
} UNAM, FES ZARAGOZA
}

MÉXICO

\begin{abstract}
RESUMEN
El objetivo del presente estudio fue evaluar las propiedades psicométricas del cuestionario de Autoeficacia Profesional (AU-10) en una población de 210 mexicanos ( $49 \%$ mujeres y $51 \%$ hombres) que estudian y trabajan. Se desarrolló un análisis factorial exploratorio, así como un análisis de confiabilidad y de validez concurrente. Los resultados mostraron que el cuestionario es confiable $(\alpha=.95)$. A partir de AFE se comprobó el carácter unidimensional de la escala reportando una varianza explicada de $73.65 \%$. Los resultados de validez concurrente con el cuestionario de Autoeficacia General muestran una correlación positiva significativa $(r=$ .839), así como una relación significativa positiva con las subescalas del Inventario de Desempeño Laboral: Desempeño de Tarea ( $r$ $=.44)$, Desempeño Contextual $(r=.50)$ y Desempeño Organizacional $(r=.53)$, y las subescalas del cuestionario de Engagement UWES: Vigor $(r=.19)$, Absorción $(r=.24)$ y Dedicación $(r=.18)$.
\end{abstract}

Palabras Clave:

Autoeficacia Profesional, Validez, Confiabilidad, Validez concurrente, Propiedades psicométricas.

\section{Psychometric Properties of the Professional Self-Efficacy QUESTIONNAIRE ( AU -10 ) IN YOUNG MEXICANS WHO STUDY AND WORK}

\begin{abstract}
The objective of this study was assess the psychometric properties of Professional Self-efficacy questionnaire (AU-10) in a population of 210 Mexican students (49\% women and 51\% men) who also work with an average age of 22 years old. It was developed a cross-sectional study with a factorial analysis exploratory, besides a reliability analysis and concurrent validity. The results show that the scale is reliable $(\alpha=.95)$ beginning with exploratory factorial analysis the one-dimensional character of the scale was verified with an explained variance of $73.65 \%$. The results of concurrent validity with General Self-Efficacy questionnaire shows a positive and significant correlation $(r=.839)$, as well as a positive and significant correlation with Job Performance Inventory subscales: Task Performance $(r=.44)$, Contextual Performance $(r=.50)$ and Organizational Performance $(r=.53)$, and subscales of Engagement UWES: Vigor $(r=.19)$, Absorption $(r=.24)$ and Dedication $(r=.18)$.
\end{abstract}

Keywords:

Professional Self-efficacy, Validity, Reliability, Concurrent validity, Psychometric properties.

Bitácora del Artículo:

| Recibido: 10 de diciembre de 2015 | Aceptado: 06 mayo de 2016 | Publicado en línea: 15 de diciembre de 2015 | 


\title{
Propiedades Psicométricas del Cuestionario de Autoeficacia PROFESIONAL (AU-10) EN JÓVENES MEXICANOS QUE ESTUDIAN Y TRABAJAN
}

\author{
Andrés Valdez-Estrella, Edgar Jiménez-Hernández y Fabiola Itzel Villa-George
}

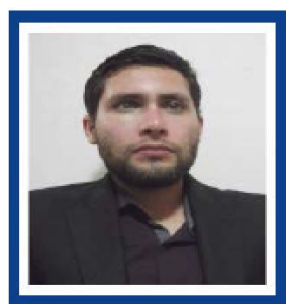

Andrés Valdez-Estrella UNAM - FES Zaragoza

Correo: dasein511@gmail.com

Psicólogo en la Facultad de Estudios Superiores Zaragoza, ha participado como organizador del 1er Foro de Psicología del
Trabajo y las Organizaciones, y en el Primer Foro de Multidisciplina en Ciencias de la Salud.

Ver más...

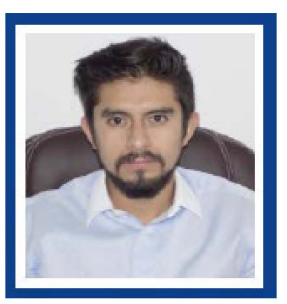

Edgar Jiménez-Hernández UNAM - FES Zaragoza

Correo: yo_gared15@comunidad.unam.mx

Psicólogo de la Facultad de Estudios Superiores Zaragoza, ha sido parte de diversos comités organizadores en congresos y foros de psicología, algunos de estos son: 3er, 4to y 5 to Congreso Estudiantil de Investigación en Psicología de la FES Zaragoza.

Ver más...

\section{CONTRIBUCIÓN DE lOS Autores(AS)}

El primer autor redactó el marco teórico y realizó análisis estadístico; el segundo autor realizó el análisis estadístico y redactó los resultados; la tercer autora revisó la redacción, los procedimientos estadísticos y las correcciones.

\section{AgRADECIMIENTOS}

Se agradece el apoyo brindado por la Dra. Fabiola Itzel Villa George para la elaboración y culminación de la presente investigación.

\section{Datos de Filiación de los Autores(AS)}

Primer y segundo autor: Psicòlogos de la, FES Zaragoza, UNAM. Tercer autor; Profesora de la Carrera de Psicología, FES Zaragoza, UNAM.

Copyright: (c) 2015 Valdez-Estrella, A.; Jimenez-Hernandez, E., \& Villa-George, F. I.

Este es un artículo de acceso abierto distribuido bajo los términos de la licencia Creative Commons Reconocimiento-NoComercial 4.0 Internacional, por lo que su contenido gráfico y escrito se puede compartir, copiar y redistribuir total o parcialmente sin necesidad de permiso expreso de sus autores(as) con la única condición de que no se puede usar con fines directamente comerciales y los términos legales de cualquier trabajo derivado deben ser los mismos que se expresan en la presente declaración. La única condición es que se cite la fuente con referencia a la Revista Digital Internacional de Psicología y Ciencia Social y a sus autores(as). 


\section{TABLA DE Contenido}

MÉTOdo

Participantes, 232

Materiales, 232

Procedimiento, 233

Resultados

Análisis Factorial Exploratorio, 233

Consistencia interna, 233

Validez Concurrente, 234

Discusión

CONCLUSIONES

Limitaciones, 235

REFERENCIAS

MetA-Analisis del Artículo

Dimensión Cuantitativa, 238

Dimensión Cualitativa, 240

Historia del Proceso Editorial 


\section{INTRODUCCIÓN}

L

a autoeficacia ha sido uno de los conceptos más importantes en la investigación psicológica contemporánea (Judge, Jackson, Shaw, Scott \& Rich, 2007). Atendiendo a lo estipulado por la Teoría Social Cognitiva, la autoeficacia se define como los juicios de cada individuo sobre sus capacidades, con base en los cuales organiza y ejecuta sus actos, y estos le permiten alcanzar el rendimiento deseado (Quijano \& Navarro, 2012).

Desde la Teoría Social Cognitiva se proponen cuatro fuentes principales para fortalecer las creencias de autoeficacia: (a) las experiencias de éxito o dominio, el éxito aumenta las evaluaciones positivas de autoeficacia influyendo en el éxito futuro, (b) la experiencia obtenida mediante el aprendizaje vicario, observando los aciertos y fracasos de terceros a través del modelamiento, (c) la persuasión social, conformada por las críticas y evaluaciones de terceros, así como la asignación de tareas que garanticen altas probabilidades para conseguir el éxito, y (d) los estados fisiológicos o activación emocional, entendida como las consecuencias estresoras percibidas causadas por el esfuerzo invertido al realizar cierta tarea, mientras se presente mayor estrés es más probable que los juicios de autoeficacia disminuyan (Bandura, 1982; Salanova, Bresó \& Schaufeli, 2005).

Siguiendo los planteamientos de la Teoría Social Cognitiva referidos por Olaz (2001), las evaluaciones de autoeficacia tienen consecuencias en el comportamiento humano de cuatro formas distintas: (a) influye en la elección de actividades y conductas, (b) establece la cantidad de esfuerzo que se invierte en una actividad determinada, (c) afecta el comportamiento modificando los pensamientos y las reacciones emocionales, e (d) interviene en los planteamientos de proyecciones futuras del sujeto, dándonos la oportunidad de decidir y enfocar el comportamiento en cierta tarea, es decir, estableciendo las metas y retos guía de nuestro proceder, alentándonos a participar en nuevas experiencias y percibiendo menos estrés si los índices de autoeficacia son altos.

Específicamente, desde la Psicología Organizacional se ha utilizado el término de Autoeficacia profesio- nal que puede definirse como el conjunto de creencias que poseen los trabajadores de sus propias capacidades para llevar a cabo, de manera exitosa, actividades asociadas a su profesión (Maffei, Spontón, Spontón, CasteIlano \& Medrano, 2012).

La investigación empírica ha demostrado que la autoeficacia se relaciona significativamente con diversas variables en el contexto laboral, por ejemplo: la adaptabilidad a la tecnología avanzada, generación de ideas de gestión, desempeño de gestión, el engagement, el bienestar afectivo relacionado al trabajo, el desempeño, la adquisición de habilidades y el ajuste del recién Ilegado al entorno organizacional (Lubbers, Loughlin \& Zweig, 2005; Salanova, Bresó et al., 2005; Stajkovic \& Luthans, 1998;). Estas relaciones señalan a la autoeficacia como un antecedente de la motivación y el comportamiento (Bandura, 1982; Ramis, Manassero, Ferrer \& García-Buades, 2007). Con lo anterior, podemos considerar a la autoeficacia como un constructo relevante para el desempeño (Blanco, 2010; Lindley, 2006).

En diversas investigaciones se diseñan instrumentos que tienen la finalidad de medir la autoeficacia que experimentan las personas al Ilevar a cabo tareas específicas, algunos investigadores que diseñan estas escalas persiguen el objetivo de encontrar correlaciones entre las creencias de autoeficacia y el desempeño, la satisfacción y otros fenómenos psicológicos de índole social, educativa o laboral (Earley, 1994; Gist, Schwoerer \& Rosen, 1989; Locke, Frederick, Lee \& Bobko, 1984). En este caso nos centramos en evaluar la autoeficacia en el ámbito laboral midiendo este constructo desde una perspectiva contextual.

La Autoeficacia Profesional forma parte del núcleo de la Psicología Organizacional Positiva y es uno de los recursos que permiten generar bienestar ocupacional e índices de desempeño óptimos (Moreno-Jiménez, Garrosa, Corso, Boada \& Rodríguez-Carvajal, 2012). Por otra parte, se considera de suma importancia contar con instrumentos con propiedades psicométricas adecuadas que nos permitan determinar el papel que juega la Autoeficacia Profesional en trabajadores mexicanos y la relación de esta variable con otros constructos sustanciales abordados por la Psicología Organizacional.

El cuestionario de Autoeficacia Profesional (AU-10) desarrollado por Salanova (2004), basado en los ítems del cuestionario de Autoeficacia General de Schwarzer y Jerusalem (1995), se asocia de manera directa con los 
planteamientos expresados por Bandura (Stajkovic \& Luthans, 1998), quien remarca la importancia de mantener una relación cercana de evaluación entre la eficacia y el contexto en que se desempeña la tarea, así como el nivel de demanda que implica la conducta; sin embargo, el cuestionario de Autoeficacia Profesional (AU-10) es una escala de dominio específico contextual centrada en el trabajo desempeñado por una persona, sin especificar cuáles son las tareas específicas incluidas en el puesto de trabajo. La bondad de este instrumento es que se adecua a medir las evaluaciones de autoeficacia laboral que se encuentran presentes dentro de una muestra de trabajadores heterogénea.

Se sigue esta línea de estudio ya que el poder modulador de la autoeficacia tiene que ver con el nivel de especificidad con el cual se mide el constructo, debido a la tendencia de las personas a cambiar sus puntuaciones de autoeficacia dependiendo del dominio concreto que evalúen. Por estas razones se considera la necesidad de crear y emplear medidas específicas de autoeficacia relacionadas con dominios concretos (Salanova, Grau \& Martínez, 2005).

El cuestionario de Autoeficacia Profesional se clasifica como una escala de dominio específico y está compuesto por 10 ítems. Las pruebas utilizadas se consideran de dominio específico por cumplir con las siguientes características: (a) cuenta con pocos ítems (menos de 30), (b) puede ser contestado con rapidez, menos de 15 minutos necesarios para completarlo, y (c) su campo de aplicación se delimita exclusivamente a entornos laborales (Barraza, 2010).

De acuerdo a la revisión bibliográfica realizada, se encontró un estudio donde se evalúan las propiedades psicométricas del cuestionario de Autoeficacia Profesional (AU-10) en una población de trabajadores argentinos, encontrando indicadores adecuados de validez y confiabilidad. Mediante un análisis factorial exploratorio corroboraron su estructura unidimensional que explica el $53 \%$ de la varianza de la prueba, su confiabilidad en este estudio fue: $\alpha=.88$, y a través del análisis factorial confirmatorio que realizaron con una modificación en su modelo inicial encontraron los siguientes índices de ajuste: $\chi^{2}=135.92 ; p<0.00 ; \mathrm{GFI}=.92 ; \mathrm{CFI}=.92 ; \mathrm{RM}$ SEA $=.09$ (Maffei et al., 2012).

En el presente estudio se analizan las propiedades psicométricas del cuestionario de Autoeficacia Profesional (AU-10) en mexicanos que estudian y trabajan. Esta disertación empírica tiene el objetivo de aclarar el papel que juega la autoeficacia profesional en distintos trabajos y poblaciones (Lindley, 2006), tomando en cuenta las diferencias interculturales que pueden Ilegar a presentarse en cuanto a la evaluación de la autoeficacia laboral con una población del área metropolitana de México. Para ello, estudiamos su estructura factorial, analizamos su consistencia interna y evaluamos su validez concurrente a través del estudio de su asociación con otras variables con las que esperamos que estuviera relacionada con base en la evidencia empírica previa

\section{MÉTodo}

\section{Participantes}

La muestra empleada en este estudio estuvo compuesta por 210 participantes, los cuales fueron seleccionados de manera no probabilística por conveniencia, el criterio de inclusión de los participantes fue que estudiaran y trabajaran. La media de edad fue de 22.1 (DE 2.79; rango $=15-30)$, 103 son mujeres (49\%) y 107 son hombres (51\%).

\section{Materiales}

\section{Cuestionario de Autoeficacia Profesional (AU- 10) (Salanova, 2004).}

Examina las creencias que poseen los trabajadores de sus propias capacidades para llevar a cabo, de manera exitosa, actividades asociadas a su profesión. Consta de 10 ítems y es unidimensional $(\alpha=$.95) ("Seré capaz de encontrar lo que quiero en mi trabajo aunque alguien se me oponga"), diseñado en una escala tipo Likert donde 1 es "nunca o ninguna vez" y 7 "siempre o todos los días", un puntaje alto en el cuestionario indica una mejor autoeficacia profesional percibida.

\section{Cuestionario de Autoeficacia General (Schwarzer \& Jerusalem, 1995).}

Dirigida a evaluar el sentimiento estable de competencia personal para manejar de forma eficaz una gran variedad de situaciones estresantes. Consta de 10 ítems y es unidimensional $(\alpha=.94)$ ("Puedo encontrar la manera de obtener lo que quiero aunque alguien se me oponga"), diseñado en una escala tipo Likert donde 1 es "nunca o ninguna vez" y 7 "siempre o todos los días", un puntaje alto en la prueba indica una mejor autoeficacia general percibida.

\section{Inventario de Desempeño Laboral (Salgado \& Cabal, 2011).}

Compuesto por tres subescalas: (a) Desempeño de Tarea $(\alpha=.80)$ ("Me tomo un tiempo para organizar mis actividades en el trabajo"); (b) Desempeño Contextual ( $\alpha$ $=.83$ ) ("Me siento comprometido con la organización 
para la cual trabajo") y (c) Desempeño Organizacional $(\alpha=.81)$ ("Utilizo de manera adecuada los materiales que me proporcionan para realizar mi trabajo"). Consta de 15 ítems con una gradación tipo Likert donde 1 es "nunca" y 6 "siempre".

\section{Cuestionario de Engagement UWES (Demerouti, Bakker, de Jonge, Janssen \& Schaufeli, 2001).}

Se compone por tres subescalas de 5 ítems cada una: (a) Vigor $(\alpha=.86)$ ("Mi trabajo es retador"); (b) Absorción ( $\alpha$ $=.80$ ) ("Puedo continuar trabajando durante largos periodos de tiempo"); (c) Dedicación $(\alpha=.90)$ ("Soy muy persistente en mi trabajo"). Consta de 15 ítems con un anclaje tipo Likert donde 1 es "nunca" y 6 "cada día".

\section{Hoja de variables sociodemográficas.}

Está compuesta por preguntas cerradas sobre edad, sexo, nivel y sistema de estudios; por otra parte contenía algunas preguntas relacionadas con las condiciones laborales como puesto y antigüedad, este cuestionario se realizó exprofeso para esta investigación.

\section{Procedimiento}

Se realizó una batería de pruebas digital (Formularios de google) que contenía los cuestionarios de Autoeficacia Profesional (AU-10), Autoeficacia General, el Inventario de Desempeño Laboral, el Cuestionario de Engagement UWES y la hoja de variables sociodemográficas para su posterior aplicación vía Internet. Esta batería de pruebas se realizó con el único fin de servir a la investigación por lo cual se eliminó al finalizar la etapa de recolección de datos.

Se hizo una convocatoria por redes sociales con el fin de que la gente se interesará en participar, la batería de pruebas se puso al alcance de la población que cumpliera con los criterios de inclusión mencionados anteriormente; al participante que aceptaba responder se le asignó una clave conformada por sus iniciales y año de nacimiento, además, se le explicó que los datos serían confidenciales y servirían para fines estadísticos. La aplicación de las pruebas empezó el 8 de marzo del 2015 y finalizó el 17 de abril del 2015. El tiempo aproximado para responder la batería de pruebas era de 25 minutos.

Al término de la recolección de datos, se consiguieron 218 respuestas; sin embargo, se eliminaron 8 de la base de datos por no cumplir con los criterios de inclusión establecidos. Posteriormente se utilizó el paquete de datos SPSS V.22 con el fin de hacer los análisis estadísticos correspondientes a la investigación.

\section{Resultados}

El grado educativo actual de nuestra muestra fue de 1.4\% en secundaria, $8.1 \%$ preparatoria, $89 \%$ licenciatura y $1.4 \%$ maestría. El sistema de estudios que cursaban era de $89.5 \%$ en modalidad escolarizada, $9 \%$ en sistema abierto y $1.4 \%$ a distancia. Los puestos de trabajo en los que laboran se conforman por un $64.8 \%$ de operativos, $26.2 \%$ en el cargo administrativo, $6.7 \%$ ejecutivo y directivo $2.4 \%$. La antigüedad en el puesto se constituía de $54.8 \%$ con menos de un año de contratación, 33.8\% tenían una antigüedad de 1 a 5 años de mantenerse laborando y el $11.4 \%$ restante tenía más de 5 años laborando.

\section{Análisis Factorial Exploratorio}

Antes de realizar el análisis factorial exploratorio utilizamos la prueba Kaiser-Meyer-Olkin (Kaiser, 1970) y la prueba de esfericidad de Bartlett (1950) para comprobar la adecuación psicométrica de los ítems. La prueba Kaiser-Meyer-Olkin fue de .947 indicando un valor superior al mínimo de .5. La prueba de Esfericidad de Bartlett (1950) fue significativa (chi cuadrado aproximado = 2060.808, $\mathrm{gl}=45, \mathrm{p}<.000$ ). Las variables presentan una distribución normal por tal motivo una estructura factorial estable puede encontrarse en los datos analizados.

Mediante el método de análisis factorial con rotación ortogonal varimax (técnica: componentes principales) se corroboró la estructura unifactorial del cuestionario de Autoeficacia Profesional (AU-10). Las cargas factoriales de los ítems oscilan entre .758 hasta .908 (tabla 1). El total de la varianza explicada es de $73.65 \%$.

\begin{tabular}{|c|c|}
\hline \multicolumn{2}{|c|}{$\begin{array}{l}\text { Tabla } 1 \\
\text { Carga factorial de los ítems del cuestionari } \\
\text { de Autoeficacia Profesional (AU-10). }\end{array}$} \\
\hline Ítems & COMPONENTE 1 \\
\hline AU10-1 & .758 \\
\hline AU10-2 & .832 \\
\hline AU10-3 & .856 \\
\hline AU10-4 & .908 \\
\hline AU10-5 & .891 \\
\hline AU10-6 & .882 \\
\hline AU10-7 & .855 \\
\hline AU10-8 & .864 \\
\hline AU10-9 & .866 \\
\hline AU10-10 & .861 \\
\hline
\end{tabular}




\section{Consistencia interna}

El coeficiente de alfa de Cronbach obtenido del cuestionario de Autoeficacia Profesional (AU-10) es .958, se considera como una prueba de confiabilidad muy buena según la clasificación de Cohen y Swerdlik (2006). Las correlaciones inter-ítem abarcan valores comprendidos entre $r=.55$ hasta $r=.82$

\section{Validez Concurrente}

La validez del constructo fue evaluada analizando las correlaciones entre la Autoeficacia Profesional y las puntuaciones obtenidas en otras variables relacionadas teóricamente con el constructo de Autoeficacia Profesional como el engagement y el desempeño (Salanova, Llorens \& Schaufeli, 2011; Stajkovic \& Luthans, 1998). Mientras que la validez concurrente se analizó a partir de la correlación entre la Autoeficacia Profesional y el Cuestionario de Autoeficacia General. Los resultados se presentan en la tabla 2.

Existe una correlación positiva y significativa entre el cuestionario de Autoeficacia Profesional y el cuestionario de Autoeficacia General $(r=.839 p<.01)$. En el ámbito de desempeño también se encuentra una correlación significativa y positiva entre el cuestionario de Autoeficacia Profesional y las tres subescalas del Inventario de Desempeño, en el apartado de Desempeño de Tarea $(r=.441)$, Desempeño Contextual $(r=.507)$ y Desempeño Organizacional $(r=.537)$, con una significancia de 0.01 . Las correlaciones obtenidas entre el cuestionario de Engagement y el cuestionario de Autoeficacia Profesional son positivas y significativas con un nivel de 0.01, para las subescalas de Vigor $(r=.199)$, Absorción $(r=$ .24) y Dedicación $(r=.189)$.

\section{Discusıón}

A través de estos resultados podemos corroborar que el cuestionario de Autoeficacia Profesional (AU-10) tiene un índice apropiado de confiabilidad $(\alpha=.958)$ y presenta una estructura unifactorial, con una varianza explicada del $73.65 \%$. Esto corrobora lo encontrado por Maffei et al. (2012), donde la escala permanece con un índice de confiabilidad adecuado $(\alpha=.88)$ y mantiene la estructura de un solo factor, aunque el porcentaje de varianza explicada que obtuvieron fue menor (53\%).

La validez concurrente se probó por medio de la correlación positiva y significativa entre el cuestionario de Autoeficacia Profesional y el cuestionario de Autoeficacia General ( $r=.839$ ) lo cual nos indica una estrecha relación entre los constructos abordados. La diferencia entre estas dos escalas consiste en que el cuestionario de

Tabla 2

Matriz de Correlaciones

\begin{tabular}{|c|c|c|c|c|c|c|c|c|c|c|c|}
\hline & 1 & II & III & IV & $\mathbf{V}$ & VI & VII & VIII & 口 & ST & $\alpha$ \\
\hline 1 & & & & & & & & & 5.56 & 1.00 & .94 \\
\hline II & $.839 * *$ & & & & & & & & 5.59 & .997 & .95 \\
\hline III & $.423^{* *}$ & $.441^{* *}$ & & & & & & & 4.70 & .844 & .80 \\
\hline IV & $.476^{* *}$ & $.507^{* *}$ & $.657^{* *}$ & & & & & & 4.80 & .840 & .83 \\
\hline V & $.443^{* *}$ & $.537^{* *}$ & $.595^{* *}$ & $.799 * *$ & & & & & 5.05 & .788 & .81 \\
\hline VI & $.149 *$ & $.199 * *$ & .003 & .065 & $.141^{*}$ & & & & 4.18 & 1.12 & .85 \\
\hline VII & $.189 * *$ & $.24^{* *}$ & .041 & .095 & .135 & $.878^{* *}$ & & & 4.34 & 1.08 & .84 \\
\hline VIII & $.142 *$ & $.189^{* *}$ & -.039 & .032 & .069 & $.856^{* *}$ & $.852^{* *}$ & & 4.21 & 1.08 & .80 \\
\hline
\end{tabular}

**. La correlación es significativa al nivel 0,01 (bilateral).

* La correlación es significativa al nivel 0,05 (bilateral).

I: Cuestionario de Autoeficacia General; II: Cuestionario de Autoeficacia Profesional; III: Desempeño de Tarea; IV:

Desempeño Contextual; V: Desempeño Organizacional; VI: Vigor; VII: Absorción; VIII: Dedicación. 


\begin{tabular}{|c|c|c|c|}
\hline \multicolumn{4}{|c|}{$\begin{array}{l}\text { Tabla } 1 \\
\text { Lista de Cotejo basada en los criterios sugeridos por la APA }\end{array}$} \\
\hline Secciones (APA) & ESTRUCTURA DEL TEXTO & ESTRUCTURA PUNTUACIÓN & LIMPIEZA DEL TEXTO \\
\hline Título & Párrafo & Punto y aparte & Normatividad \\
\hline Resumen & Frase & Punto y seguido & Precisión \\
\hline Introducción & Palabra & Coma & Unión (conectores) \\
\hline Método & & Punto y coma & \\
\hline \multicolumn{4}{|l|}{ Resultados } \\
\hline Discusión & & & \\
\hline
\end{tabular}

Autoeficacia Profesional atiende los postulados de Bandura (2001), quien recomienda elaborar medidas de autoeficacia para ámbitos de funcionamiento específico. Stajkovic y Luthans (1998) refieren que existen estudios que han encontrado una correlación negativa y significativa entre las variables de autoeficacia específica y general definiéndolas como constructos separados de manera conceptual y psicométrica, esto puede deberse a que en algunas investigaciones (Lubbers et al., 2005; Rapp, Baker, Bachrach, Ogilvie \& Skinner Beitelspacher, in press; Salanova et al., 2011) se han desarrollado cuestionarios de autoeficacia para profesiones específicas; sin embargo, en este estudio no se presentó una correlación negativa con la Autoeficacia General, la correlación positiva entre la Autoeficacia Profesional y la Autoeficacia General obedece al parecido en la redacción entre las dos pruebas, la correlación positiva sustenta su validez concurrente, esto puede indicar que en esta población los cuestionarios de Autoeficacia Profesional y General podrían ser utilizados de manera indistinta.

Por otra parte, Blanco (2010) encontró correlaciones positivas y significativas entre la Autoeficacia Académica y la Autoeficacia Estadística $(r=.314)$, y entre la Autoeficacia Estadística y la Autoeficacia General $(r=.244)$, argumentando que estos constructos mantienen un vínculo fuerte, pero pueden ser diferenciados. Estos hallazgos no pudieron replicarse de manera similar en este estudio como lo demuestra la alta correlación encontrada entre la Autoeficacia General y la Autoeficacia Profesional ( $r=$ .839); sin embargo, esto puede atribuirse al desarrollo de ítems Ilevado a cabo por (Salanova, 2004) que manifiesta una estructura sintáctica similar a la Escala de Autoeficacia General de Schwarzer y Jerusalem (1995).

Sumado al análisis de validez concurrente del cuestionario, se encontraron correlaciones positivas y significativas con las subescalas del Inventario de Desempeño; en las subescalas de Desempeño de Tarea $(r=.441)$,
Desempeño Contextual $(r=.507)$ y Desempeño Organizacional $(r=.537)$, con una significancia de 0.01. Esto corrobora lo encontrado en gran cantidad de estudios que relacionan la autoeficacia y el desempeño (Bandura, 1982; Lubbers et al., 2005; Rapp et al., in press; Stajkovic \& Luthans, 1998).

De manera consecuente, el análisis de validez convergente entre el cuestionario de Engagement y el cuestionario de Autoeficacia Profesional muestra correlaciones positivas y significativas en las subescalas de Vigor $(r=.199)$, Absorción $(r=.24)$ y Dedicación $(r=.189)$, con una significancia de 0.01 . Estos resultados corroboran la relación positiva y significativa entre las creencias de eficacia y las subescalas de Engagement: (a) Vigor $(r=.32)$ y (b) Dedicación $(r=.42)$, con un nivel de significancia de .001 encontradas por Salanova, Bresó et al. (2005).

\section{ConcLusiones}

El cuestionario de Autoeficacia Profesional (AU-10) cuenta con adecuadas propiedades psicométricas de confiabilidad y validez, de manera consecuente puede utilizarse en investigaciones relacionadas con el ámbito laboral en población mexicana.

\section{Limitaciones}

Recomendamos replicar el estudio de propiedades psicométricas del cuestionario de Autoeficacia Profesional (AU-10) con una muestra de características laborales homogéneas con la finalidad de corroborar la sensibilidad del instrumento ante distintas ocupaciones, así como considerar ocupar una muestra de diferentes estados, para verificar y confirmar las propiedades psicométricas del cuestionario.

Por otra parte, los resultados aquí presentados no pueden generalizarse en otras poblaciones, lo cual va 
relacionado con el punto mencionado anteriormente; se debe tener cautela pues no todas las variables psicológicas se comportan igual en distintas muestras.

Como sugerencia para nuevas líneas de investigación se propone realizar estudios de diseño longitudinal que permitan aclarar los efectos de la Autoeficacia Profesional en trabajadores mexicanos en diferentes contextos laborales y la relación de este constructo con otras variables psicológicas relevantes en la psicología organizacional.

\section{Referencias}

Bandura, A. (1982). Self-Efficacy Mechanism in Human Agency. American Psychologist, 37 (2), 122-147.

Bandura, A. (2001). Guía para la construcción de escalas de autoeficacia. Psychological Bulletin, 124, 240-261.

Barraza, A. (2010). Validación del inventario de expectativas de autoeficacia académica en tres muestras secuenciales e independientes. CPU-e, Revista de Investigación Educativa, (10), 1-30.

Bartlett, M. S. (1950). Periodogram analysis and continuous spectra. Biometrika, 37 (1-2), 1-16.

Blanco, A. (2010). Creencias de autoeficacia de estudiantes universitarios: un estudio empírico sobre la especificidad del constructo. Relieve, 16 (1), 1-28.

Cohen, R. J. \& Swerdlik, M. E. (2006). Pruebas y evaluación psicológicas. Introducción a las pruebas y a la medición (6 ed.). México, D.F.: McGraw Hill.

Demerouti, E., Bakker, A. B., de Jonge, J., Janssen, P. P. \& Schaufeli, W. B. (2001). Burnout and engagement at work as a function of demands and control. Scandinavian Journal of Work, Environment \& Health, 27 (4), 279-286.

Earley, P. C. (1994). Self or group? Cultural effects of training on self-efficacy and performance. Administrative Science Quarterly, 39 (1), 89-117.

Gist, M. E., Schwoerer, C. \& Rosen, B. (1989). Effects of alternative training methods on self-efficacy and performance in computer software training. Journal of applied psychology, 74 (6), 884-891.

Judge, T. A., Jackson, C. L., Shaw, J. C., Scott. B. A. \& Rich, B. L. (2007). Self-Efficacy and Work-Related Performance: The Integral Role of Individual Differences. Journal of Applied Psychology, 92 (1), 107-127.

Kaiser, H. F. (1970). A second generation little jiffy. Psychometrika, 35 (4), 401-416.

Lindley, L. D. (2006). The Paradox of Self-Efficacy: Research With Diverse Populations. Journal of Career Assessment, 14 (1), 143-160.

Locke, E. A., Frederick, E., Lee, C. \& Bobko, P. (1984). Effect of selfefficacy, goals, and task strategies on task performance. Journal of applied psychology, 69 (2), 241-251.

Lubbers, R., Loughlin, C. \& Zweig, D. (2005). Young workers' job self-efficacy and affect: Pathways to health and performance. Journal of Vocational Behavior, 67, 199-214.

Maffei, L., Spontón, C., Spontón, M., Castellano, E. \& Medrano,
L. A. (2012). Adaptación del Cuestionario de Autoeficacia Profesional (AU-10) a la población de trabajadores cordobeses. Pensamiento Psicológico, 10 (1), 51-62.

Moreno-Jiménez, B., Garrosa, E., Corso, S., Boada, M. \& Rodríguez-Carvajal, R. (2012). Personalidad resistente y capital psicológico: las variables personales positivas y los procesos de agotamiento y vigor. Psicothema, 24 (1), 7986.

Olaz, F. (2001). La Teoría Social Cognitiva de la Autoeficacia. Contribuciones a la Explicación del Comportamiento Vocacional (Tesis de licenciatura). Facultad de Psicología, Universidad Nacional de Córdoba.

Quijano, S. \& Navarro, J. (2012). La autoeficacia y la motivación en el trabajo. Apuntes de Psicología, 30 (1-3), 337-349.

Ramis, M. C., Manassero, M. A., Ferrer, V. A. \& García-Buades, E. (2007). ¡No es fácil ser un buen jefe/a! Influencia de las habilidades comunicativas de la dirección sobre la motivación, la autoeficacia y la satisfacción de sus equipos de trabajo. Revista de Psicología del Trabajo y de las Organizaciones, 23 (2), 161-181.

Rapp, A., Baker, T. L., Bachrach, D. G., Ogilvie, J. \& Skinner Beitelspacher, L. (in press). Perceived customer showrooming behavior and the effect on retail salesperson self-efficacy and performance. Journal of Retailing, $x x x$ $(x x x, 2015), x x x-x x x$.

Salanova, M. (2004). Una escala de medida de la autoeficacia en el trabajo. En A. Osca (Ed.), Prácticas de Psicología del Trabajo y de las Organizaciones. Madrid: Sanz y Torres.

Salanova, M., Bresó, E. \& Schaufeli, W. B. (2005). Hacia un modelo espiral de las creencias de eficacia en el estudio del burnout y del engagement. Ansiedad y Estrés, 11 (2-3), 215-231.

Salanova, M., Grau, R. M. \& Martínez, I. M. (2005). Demandas laborales y conductas de afrontamiento: el rol modulador de la autoeficacia profesional. Psicothema, 17 (3), 390395.

Salanova, M., Llorens, S. \& Schaufeli, W. B. (2011). "Yes, I Can, I Feel Good, and I Just Do It!" On Gain Cycles and Spirals of Efficacy Beliefs, Affect, and Engagement. Applied Psychology: an International Review, 60 (2), 255-285.

Salgado, J. F. \& Cabal, A. L. (2011). Evaluación del Desempeño en la Administración Pública del Principado de Asturias: Análisis de las Propiedades Psicométricas. Revista de Psicología del Trabajo y de las Organizaciones, 27 (1), 7591.

Stajkovic, A. D. \& Luthans, F. (1998). Self-Efficacy and WorkRelated Performance: A Meta-Analysis. Psychological Bulletin, 124 (2), 240-261.

Schwarzer, R. \& Jerusalem, M. (1995). General self-efficacy scale. En J. Weinman, S. Wright, \& M. Johnston (Eds.), Measures in health psychology: A user's portfolio. Causal and control belief (pp. 35-37). Windsor, Reino Unido: NFER-NELSON. 


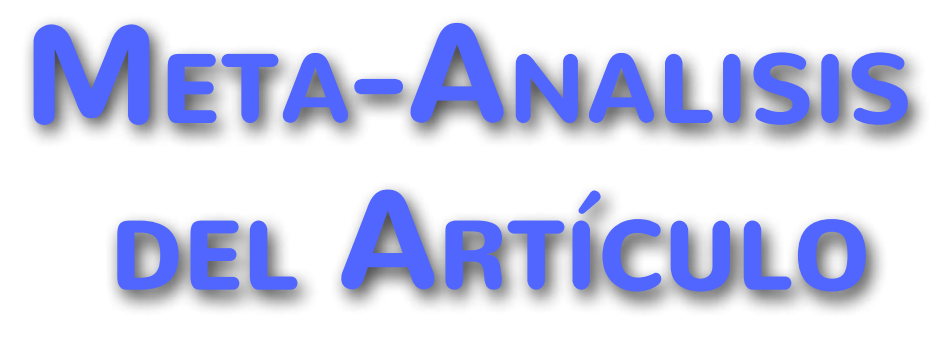
MNANan 


\section{Dimensión Cuantitativa}

\section{Perfil de Evaluación entre pares}
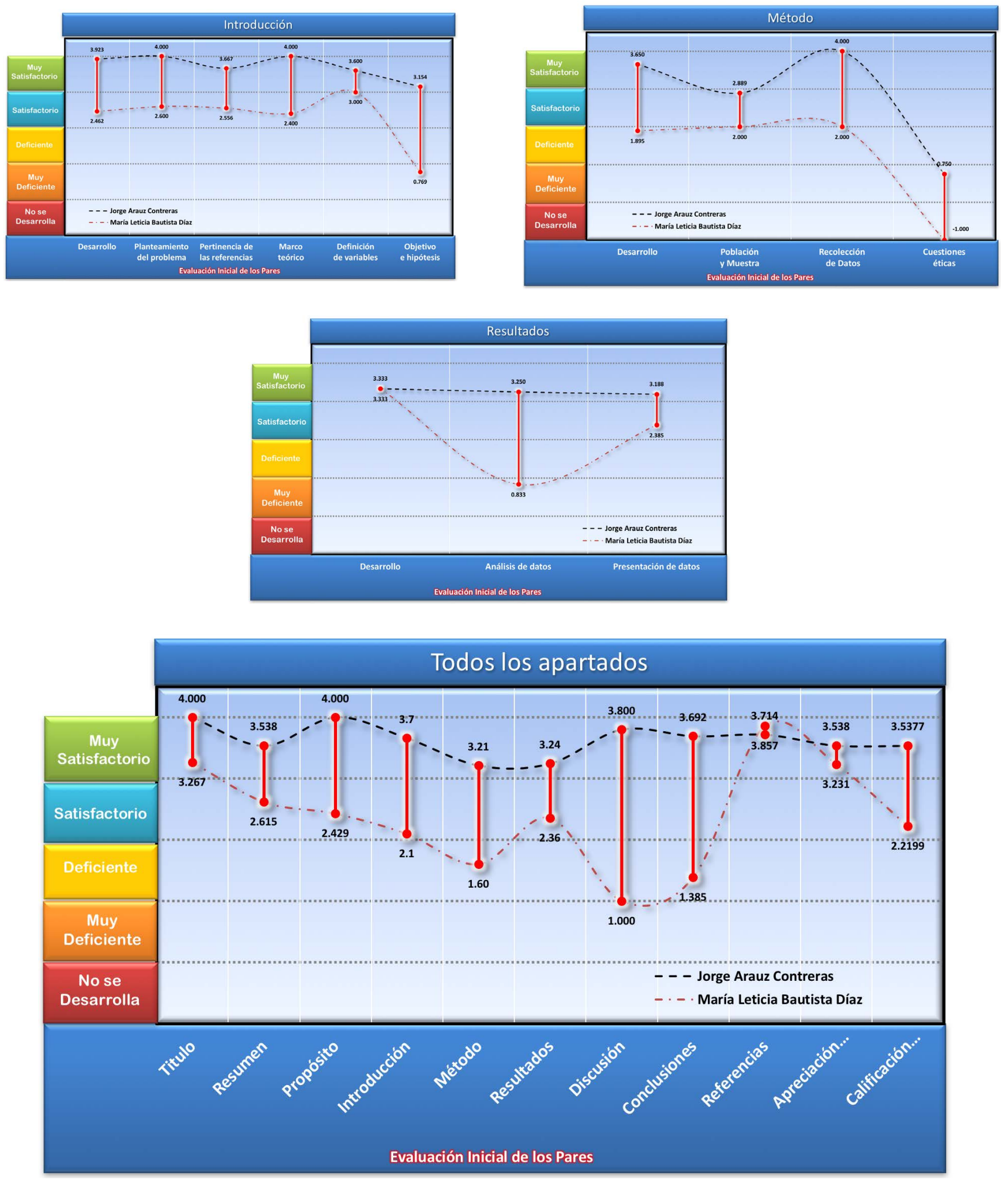

$\min \rightarrow \infty$ 


\section{Índice de Concordancia}

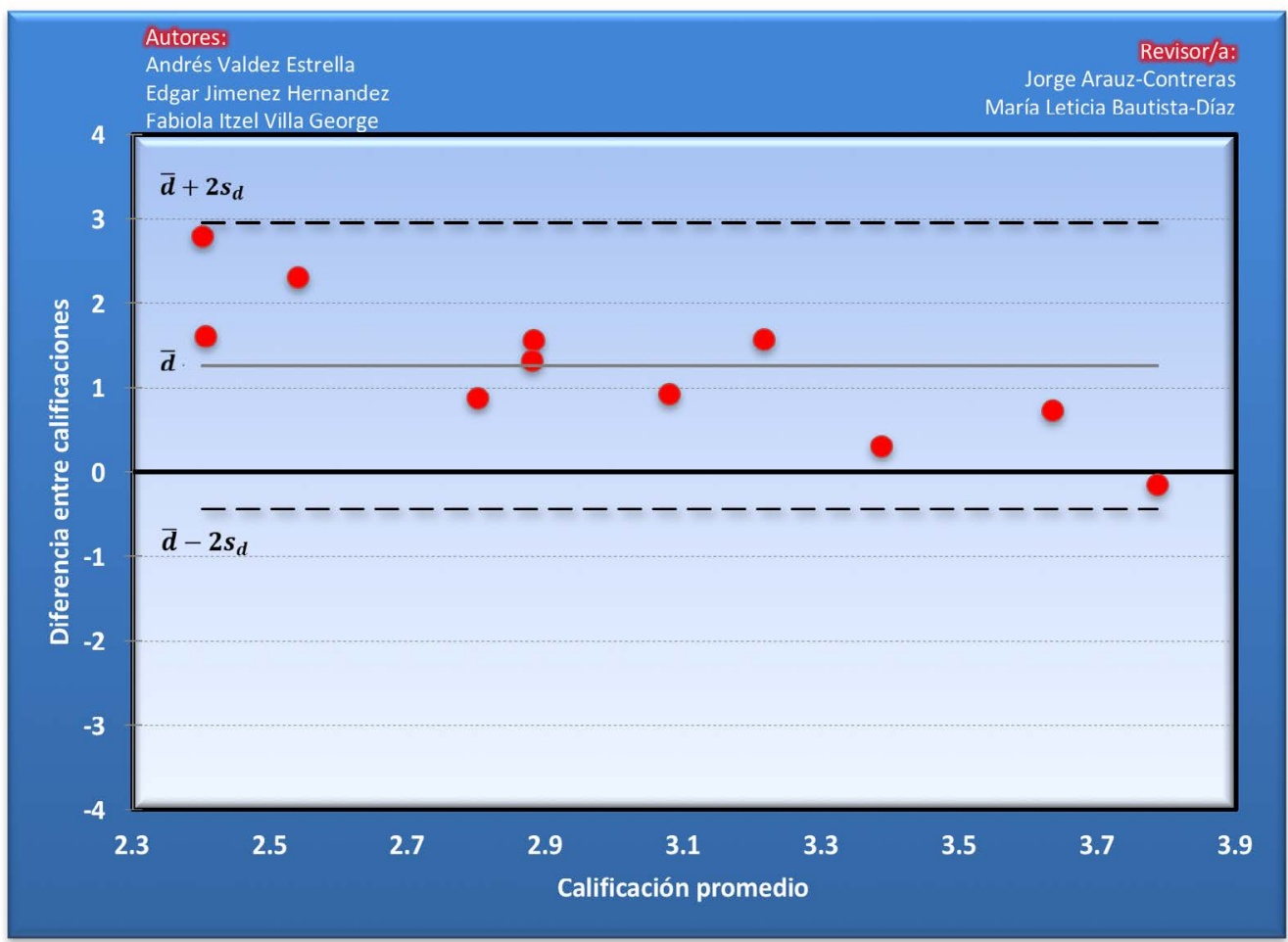

\section{Índice de Acuerdo}

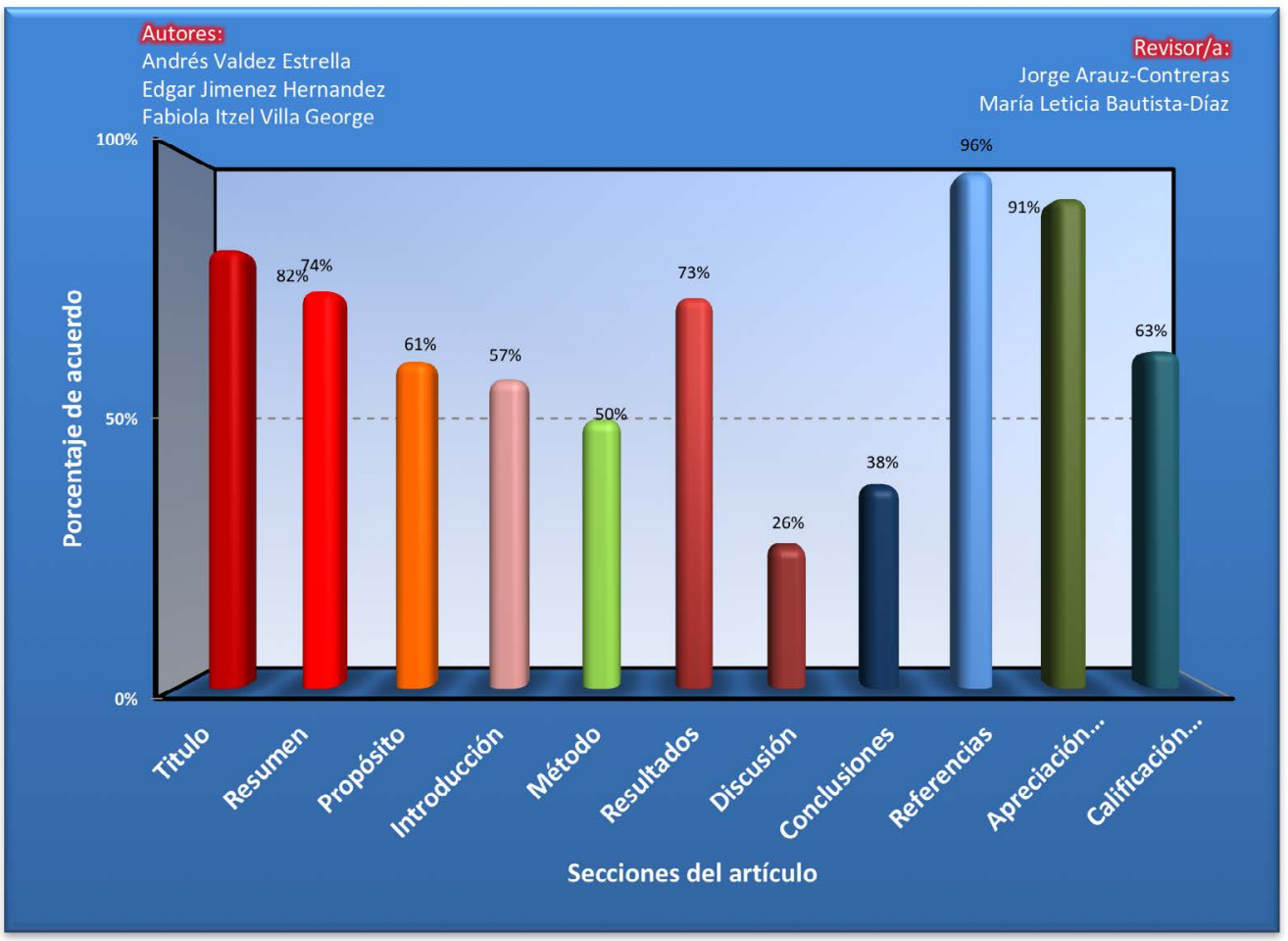

\section{$\cos \rightarrow \infty x$}




\begin{tabular}{|c|c|}
\hline ReVISOR 1 & ReVISOR 2 \\
\hline Jorge Arauz Contreras & María Leticia Bautista-Díaz \\
\hline \multicolumn{2}{|c|}{ Título/Autoría } \\
\hline Título adecuado. No hay sugerencias & No hay observaciones al título \\
\hline \multicolumn{2}{|c|}{ Resumen } \\
\hline $\begin{array}{l}\text { Resumen aceptable. Sugerencias: Reducir una pa- } \\
\text { labra en e resumen para atender el criterio de } 150 \\
\text { palabras. Agregar una palabra clave para cumplir el } \\
\text { criterio de cinco }\end{array}$ & $\begin{array}{l}\text { El resumen incluye } 151 \text { palabras, pero no contiene con- } \\
\text { clusión. Usa la palabra key words en el resumen en es- } \\
\text { pañol }\end{array}$ \\
\hline
\end{tabular}

\section{Próposito del Estudio}

El planteamiento es claro. Sugrencia: Revisar la es- $\mid$ El propósito del estudio se puede mejorar con las observatructura de las citas ciones hechas para el apartado del marco teórico

\section{INTRODUCCIÓN}

La introducción es clara. Sugerencias: Precisar de forma clara y adecuada la pregunta de investigación y la hipótesis. Definir operacionalmente las variables estudiadas.
En este rubro no es necesario el título "Relevancia histórica de la autoeficacia". Este apartado lo conforman 12 párrafos que a partir del quinto son telegráficos (con menos de 5 líneas cada uno), sería mejor integrar, parafrasear y resumir información. Se sugiere el siguiente orden de los primeros párrafos $(1,3,4,5,2)$. Por otro lado, una vez que se ha definido y determinado la relevancia de la Autoeficacia, -primero de manera general y después específicamente en la psicología organizacional-, es importante, mencionar los instrumentos que existen para evaluarla y sus limitaciones, para finalmente, mostrar las bondades del Cuestionario de Autoeficacia Profesional AU-10, ya que la justificación del estudio se limita al párrafo 6 y todavía se vislumbra muy general. Se sugiere dar mayor peso (o ampliar información) al cuestionario de Autoeficacia Profesional AU-10, por ejemplo, quiénes son los autores y el año de publicación de la versión original, sus propiedades psicométricas, así como los países donde se ha utilizado y validado, lo anterior permitirá una justificación más sólida. Ya que, en la investigación que se presenta para publicación, no es claro si se utilizó la versión original o la de Argentina y si fue así, es necesario saber si se realizó alguna adaptación de lenguaje coloquial debido a cuestiones transculturales. 
Describir con precisión los procedimientos de análisis estadístico. Precisar el tipo de muestra estudiada. Especificar el software empleado como auxiliar en el análisis estadístico.

\section{MÉTOdo}

Participantes: en este apartado es necesario mencionar el muestreo así como las estrategias usadas y no en el rubro del procedimiento. Mediciones: Es necesario referir los autores originales del cuestionario de Autoeficacia Profesional AU-10, del Cuestionario de Engagement UWES y mencionar si la hoja de variables sociodemográficas se realizó exprofeso. Procedimiento: Es importante mencionar si los formularios de google están disponibles al público en general o se diseñaron exprofeso (para la susceptibilidad de réplica), referir cómo fue la convocatoria. Se debe mencionar el periodo de evaluación o recabación de los datos (días, meses o años, etc.), así como referir cuántos se registraron y cuántos se descartaron si fuera el caso. Sería interesante contar con un apartado de análisis estadísticos y referir el plan analítico de los mismos, sobre todo cuando la muestra es muy heterogénea, así un análisis descriptivo daría al lector una visión general de cómo se comporta la autoeficacia en esta población. Será necesario referir cuál paquete estadístico se utilizó, así como su versión, etc. Un plan analítico previo permitirá visualizar cada paso de dicho análisis y de esta manera en el apartado de resultados no se presentarán abruptamente las propiedades psicométricas del cuestionario.

\section{Resultados}

Precisar los valores obtenidos de la prueba de esfericicidad de Bartlett y del índice Kaiser-Meyer-Olkin como supuestos básicos para el análisis factorial exploratorio. Vincular la Tabla 1 al texto de la sección de resultados.
Se sugiere hacer un análisis descriptivo (comparativo) de los datos. Se sugiere referir los indicadores de la adecuación muestral y de la validación de la estructura factorial (modelo): Kaiser-Mayer-Olkin (KMO, por sus siglas en inglés) y la prueba de esfericidad de Bartlett, respectivamente. En el rubro de Consistencia Interna, en primer lugar se puede hablar del coeficiente alfa y posteriormente la homogeneidad vía las intercorrelaciones. 


\section{Discusión}

Revisar la estructura de las citas

Participantes: en este apartado es necesario mencionar el muestreo así como las estrategias usadas y no en el rubro del procedimiento. Mediciones: Es necesario referir los autores originales del cuestionario de Autoeficacia Profesional AU-10, del Cuestionario de Engagement UWES y mencionar si la hoja de variables sociodemográficas se realizó exprofeso. Procedimiento: Es importante mencionar si los formularios de google están disponibles al público en general o se diseñaron exprofeso (para la susceptibilidad de réplica), referir cómo fue la convocatoria. Se debe mencionar el periodo de evaluación o recabación de los datos (días, meses o años, etc.), así como referir cuántos se registraron y cuántos se descartaron si fuera el caso. Sería interesante contar con un apartado de análisis estadísticos y referir el plan analítico de los mismos, sobre todo cuando la muestra es muy heterogénea, así un análisis descriptivo daría al lector una visión general de cómo se comporta la autoeficacia en esta población. Será necesario referir cuál paquete estadístico se utilizó, así como su versión, etc. Un plan analítico previo permitirá visualizar cada paso de dicho análisis y de esta manera en el apartado de resultados no se presentarán abruptamente las propiedades psicométricas del cuestionario.

\section{Conclusiones}

Revisar la estructura de las citas

Las conclusiones del estudio se resumen en el párrafo 1, en los cuatro párrafos posteriores, se indican limitaciones, por tanto, se debería precisar si son conclusiones o limitaciones. En el párrafo 4, se indica como limitación, utilizar medidas de auto-reporte, en todo caso también se debería precisar el hecho de que la recabación de los datos fue vía la red y que un criterio de inclusión fue que los participantes estudiaran y trabajaran. El párrafo 5 es de una línea y media, misma que se pude integrar en los párrafos anteriores. Los autores sugieren realizar investigaciones de corte longitudinal, la pregunta que surge es iestudio longitudinal para evaluar las propiedades psicométricas? Los autores sugieren ampliar el tamaño de muestra, no obstante, no es claro cuál es el criterio para dicha sugerencia.

\section{RefERENCIAS}

Incluir, cuando el documento haya sido recuperado de internet, la dirección electrónica del sitio de recuperación del documento.
Son adecuadas las referencias, no obstante, algunas tienen la conjunción " $y$ " y otras " $\&$ ", se sugiere homologar. 


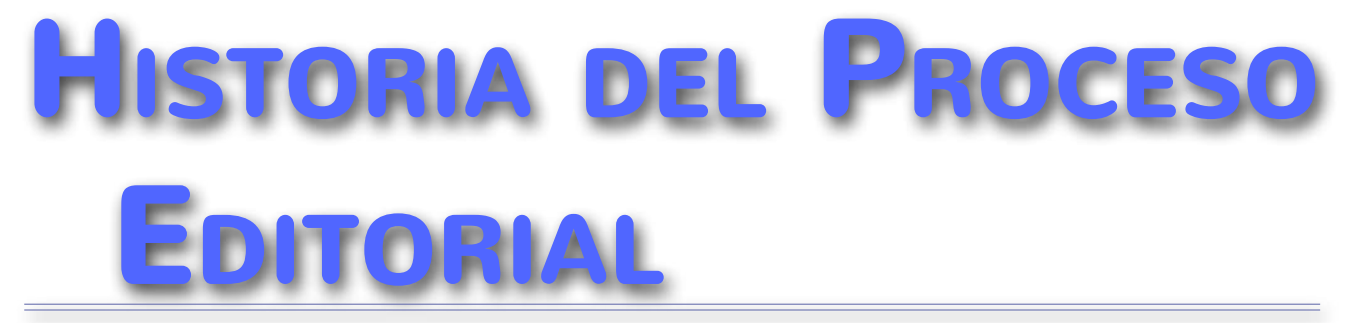




\author{
LA TESIS DE LICENCIATURA: IMPOSIBILIDAD \\ POR FALTA DE HABILIDADES REDACTORAS \\ Jorge Daniel Fabila-Cervantes y Alberto Hurtado-Páramo \\ UNIVERSIDAD AUTÓNOMA DEL ESTADO DE MÉXICO, UNIDAD ZUMPANGO \\ MÉXICO
}

\begin{abstract}
RESUMEN
El presente artículo plantea que la falta de habilidades redactoras se generan desde la educación básica y tales deficiencias trascienden hasta la educación superior, traduciéndose al momento del egreso de la licenciatura en una incapacidad para elaborar una tesis, lo cual lleva al egresado a buscar otras opciones de titulación que impliquen un esfuerzo menor y, en consecuencia, obtener un título sin gran dificultad; por lo cual se procedió a realizar una investigación de tipo mixta, con predominio en el aspecto cualitativo, en donde se analizaron 15 ensayos y se realizaron 34 entrevistas semi-estructuradas; los resultados muestran que el $93 \%$ de los escritos tienen problemas de ortografía, puntuación, sintaxis y en general mala redacción. Respecto a los entrevistados, el $62 \%$ argumentó que no le gusta hacer investigación, debido a la complejidad de buscar, interpretar y citar la información consultada.
\end{abstract}

Palabras Clave:

Redacción, tesis, competencias, investigación.

\title{
BACHELOR's DegREe THESIS: IMPOSIBILITY FOR LACK OF REDACTIVE SKILLS
}

\begin{abstract}
This article raises that the lack of writing skills, it generate since basic education and these deficiencies transcend to the higher education; translating at the moment of bachelor's egress of degree, in an incapacity to elaborate thesis, this leads to the graduate to find other titration's ways, involving less effort and in consequence get a degree without any difficulties; we proceeded to make a mixed type research, with predominance in the qualitative aspect, where we analyzed 15 essays (These ones do not have no access to thesis that were in evaluation), we found that $93 \%$ (14 essays) have problems with orthography, punctuation, syntax and bad writing in general; concerning to the interviewed, the $62 \%$ said that they don't like to do investigation, because of the complex to find out, understanding and citing information consulted.
\end{abstract}

Keywords:

Drafting, Thesis, Competence, Researching.

Bitácora del Artículo:

| Recibido: 02 de diciembre de 2015 | Aceptado: 06 mayo de 2016 | Publicado en línea: 15 de diciembre de 2015 | 


\title{
Autoría y Derechos de Propiedad Intelectual
}

\section{LA TESIS DE LICENCIATURA: IMPOSIBILIDAD POR FALTA DE HABILIDADES REDACTORAS}

\author{
Jorge Daniel Fabila-Cervantes y Alberto Hurtado-Páramo
}

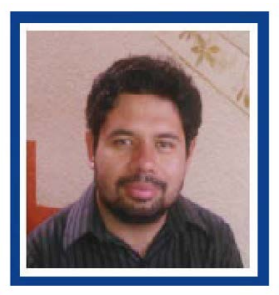

Jorge Daniel Fabila-Cervantes UAEM - Unidad Zumpango

Correo: daniel.fabila.c@gmail.com

Egresado de la Licenciatura en Psicología, Universidad Autónoma del Estado de México (UAEM), Unidad Zumpango. En proceso de titulación. Línea de investigación acerca de la formación y competencias de los profesionales en psicología. Atención de psicoterapia individualizada a adolescentes de secundaria. Ver más...

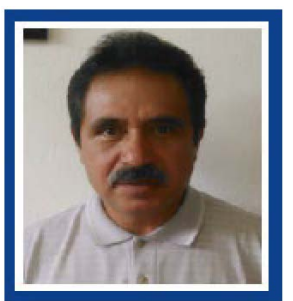

Alberto Hurtado-Páramo UAEM - Unidad Zumpango

Psicólogo social por la Universidad Autónoma Metropolitana, Unidad Iztapalapa (UAM-I). Pasante de la Maestría en Orientación Educativa y Asesoría Profesional, por la Normal Superior del Estado de México, Unidad Cuautitlán Izcalli. Docente de la UAEM Unidad Zumpango.

Ver más..

\section{CONTRIBución DE lOS Autores}

El primer autor Jorge Daniel Fabila Cervantes concibió el estudio y lo desarrolló en su totalidad. El segundo autor Alberto Hurtado Páramo revisó y asesoró en la elaboración del trabajo

\section{Datos de Filiación de los Autores}

Psicólogo y Docente de la Universidad Autónoma del Estado de México.

Copyright: (c) 2015 Fabila-Cervantes, J. D. \& Hurtado-Páramo, A.

Este es un artículo de acceso abierto distribuido bajo los términos de la licencia Creative Commons Reconocimiento-NoComercial 4.0 Internacional, por lo que su contenido gráfico y escrito se puede compartir, copiar y redistribuir total o parcialmente sin necesidad de permiso expreso de sus autores con la única condición de que no se puede usar con fines directamente comerciales y los términos legales de cualquier trabajo derivado deben ser los mismos que se expresan en la presente declaración. La única condición es que se cite la fuente con referencia a la Revista Digital Internacional de Psicología y Ciencia Social y a sus autores. 


\section{TABLA DE CONTENIDO}

INTRODUCCIÓN

247

Educación Básica y Media Superior: Deficientes en Lectura y

Redacción, 248

Las implicaciones de una mala redacción en la Educación

Superior, 249

MÉTOdO

Participantes, 250

Materiales, 250

Procedimiento, 250

Mediciones, 251

Procesamiento de la Información, 251

Análisis, 252

RESULTADOS

Análisis cualitativo, 252

Discusión

CONCLUSIONES

REFERENCIAS

Meta-Analisis del Artículo

Dimensión Cuantitativa, 257

Dimensión Cualitativa, 259

Historia del Proceso Editorial 


\section{INTRODUCCIÓN}

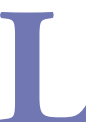

as habilidades lectoras, así como la redacción son complementarias una con la otra, ya que una es inherente a la otra. La importancia de la adquisición de estas habilidades abre la posibilidad al individuo de comunicarse, realizar una crítica y a formar su identidad como individuo e incluso más ampliamente como sociedad, como lo señala Hernández (2004) "Si la cultura escrita de un pueblo o grupo social es el fundamento de su identidad y, por tanto, de su proyecto de futuro, ésta no puede ser importada; necesita ser producida por él mismo" (párr. 7). De lo anterior se deriva la importancia de leer y escribir correctamente; desafortunadamente los indicadores internacionales y nacionales ubican a los estudiantes mexicanos en un nivel insuficiente en los diferentes grados educativos, es decir, los estudiantes son incapaces de entender $y$ redactar un texto aun teniendo un buen nivel de fluidez verbal (Flores, R., Jiménez, J. E. \& García, E., 2015).

En el caso de los estudiantes universitarios la situación se torna compleja, de hecho, imposibilita el desarrollo de las competencias señaladas por la Asociación Nacional de Universidades e Institutos de Educación Superior (ANUIES, 2006), pues la educación superior debe enfrentar dos responsabilidades: a) mejorar continuamente la calidad de la formación en los aspectos cognitivos e instrumentales (conocimientos, destrezas y habilidades), y b) ofrecer espacios que favorezcan el desarrollo de su autonomía.

A decir de Benítez, Barajas y Hernández (2014), para el logro de estos propósitos, las Instituciones de Educación Superior (IES) han implementado modelos curriculares que redimensionan el proceso de enseñanza-aprendizaje e incluyen estrategias basadas en: 1) uso de las Tecnologías de Información y Comunicación (TIC); 2) implementar ambientes de aprendizaje más estimulantes entre estudiantes y profesores; 3 ) promover el desarrollo de competencias y habilidades intelectuales, y mejorar los procesos de comprensión lectora que son fundamentales para el desarrollo cognitivo; por ende, el estudiante se convierte en autónomo, reflexivo, crítico y propositivo.

Es importante destacar que la problemática de la falta de habilidades lectoras ha sido abordada en Méxi- co desde los noventas por Guevara (1991), quien expone que pese a tener un nivel de eficiencia terminal superior al $75 \%$ y un aprovechamiento de 8.0 , los conocimientos se encuentran en promedio de 5.6 y sólo el $15 \%$ tenía los elementos inherentes a su ciclo escolar. Lo anterior fue una de las bases para iniciar con las continuas reformas educativas, específicamente diseñadas para superar ese rezago educativo, por ejemplo:

La enseñanza de la lectura se ha cimentado en los fundamentos del constructivismo y asociacionismo; Waldegg y Block (1997) refieren que el constructivismo nunca parte de cero, ya que se cuenta con conocimientos previamente construidos, mientras el asociacionismo se reduce a la adquisición del código de correspondencia grafofonética (correspondencia de sonidos, con las letras o palabras de la escritura). Se cree que ambas teorías pueden ser aplicadas en la enseñanza de la escritura, siempre que se tenga un conocimiento sólido de ellas y una justificación válida de cuándo utilizar una u otra.

Derivado de lo anterior se crea el método onomatopéyico, en el que no sólo se relaciona la letra con su nombre, sino que además relaciona el sonido de la letra con algún sonido "fonético" de algún animal o persona (Hernández, 2004). Este método está actualmente en desuso, por considerarse de corte conductista.

Otro de los métodos de enseñanza de la lectura es el global de análisis estructural; el cual se describe de la siguiente forma: "Se fundamenta en procesos perceptuales del aprendiz, caracterizados por la tendencia a globalizar los contenidos y a descubrir su organización interna y las relaciones que la explican" (Saavedra, 2001, p. 85). Esto es, que el maestro le muestre ideas completas al niño para que las visualice y las repita con ayuda del docente, después se hace énfasis en una letra que se esté enseñando, para que empiece a comprender la estructura.

Estos métodos de enseñanza de lectura están encaminados a que el alumno no sólo extraiga información e identifique todas y cada una de las letras y sílabas, sino que posteriormente al avanzar grados e integrar estos conocimientos aprenda a plasmar sus pensamientos $\mathrm{y} / \mathrm{u}$ opiniones; es decir, que aprenda a redactar. Idealmente, la redacción es una de las habilidades que se enseñan desde de la educación básica y conforme se avanza en los ciclos educativos, ésta va perfeccionándose al grado que el discente puede comunicarse de manera escrita, 
adecuada y entendible, conforme a los lineamientos gramaticales, ortográficos, entre otros.

Sin embargo, en la actualidad el sistema educativo de nuestro país no logra desarrollar estas habilidades y en consecuencia, esto impide que se realicen y adquieran las actividades y competencias proyectadas en el plan de estudios; aclarando que a pesar de las carencias institucionales, algunos de los docentes se adaptan y ajustan a este conjunto de deficiencias y van dejando que dicha problemática se agudice, ya que las exigencias nacionales obligan al profesor a acreditar al menos al 95\% de su población estudiantil.

Así, con el doble compromiso de acreditar en cantidad y enseñar con calidad, la redacción es uno de los grandes temas a tratar y es que a lo largo de muchos años ha fallado en el sistema de enseñanza, ya que se ha reemplazado por un sistema fragmentado, en el cual la escritura es reducida por abreviaturas informales, sin un uso de puntuación adecuado, que dé orden a las ideas expresadas por escrito; esto fomentado por las telecomunicaciones y específicamente por las redes sociales; por ejemplo, Márquez (1997; como se citó en Bilbao, 2004, p.178) refiere:

Nunca hubo en el mundo tantas palabras con tanto alcance, autoridad y albedrío como en la inmensa Babel de la vida actual. Palabras inventadas, maltratadas o sacralizadas por la prensa, los libros desechables, por los carteles de publicidad; habladas y cantadas por la radio, la televisión, el cine, el teléfono, los altavoces públicos; gritadas a brocha gorda en las paredes de la calle.

Continuando con Márquez, estamos en un mundo de palabras inventadas, maltratadas; las cuales están influidas por los medios de comunicación y la tecnología que pareciera ser que es un idioma totalmente diferente al que tenemos, sin ningún sentido de la redacción, ni el uso de la ortografía, por el cual se dan muchas dificultades en la enseñanza del lenguaje en las escuelas.

Al respecto el Ministerio de Educación y Cultura de España, por sus siglas MEC, en 1996 (como se citó en Rodríguez, Márquez \& Estrada, 2005, p.18) refiere: “Muchas de las dificultades de aprendizaje son el resultado de una respuesta educativa que no cumple con las demandas de los alumnos." A lo que Rodríguez et al. (2005) explica que una de esas dificultades es la redacción.

El problema es que realmente ya no se ve como una demanda o requisito indispensable; ni siquiera por parte de algunos docentes, a quienes también es un problema la comunicación por escrito. Lo más preocupante es que esta dificultad se sigue arrastrando hasta el nivel superior, en donde se supondría que este tema ya no representa un problema para el alumno de universidad, pero la realidad es otra.

En este tenor se puede apreciar que ni siquiera las escuelas especializadas en la enseñanza-aprendizaje (Normales, Universidad Pedagógica Nacional, por sus siglas UPN) están lo suficientemente preparadas para enfrentar los problemas de aprendizaje que se desarrollan dentro de las aulas, hablando específicamente sobre la deficiencia de la redacción, ya que ellos padecen de las mismas carencias; al respecto comenta Rodríguez (2002) que los estudiantes de la licenciatura de la UPN padecen de deficiencias en la redacción y ortografía, en consecuencia, es la incapacidad para elaborar diversos escritos de forma adecuada. Por lo tanto, si estos futuros docentes, que se están formando en dichas instituciones, tienen una deficiencia en el área mencionada, será imposible que se dé la transmisión de un verdadero conocimiento hacia los alumnos y por consecuencia se estará dibujando un ciclo vicioso en donde algunos de estos alumnos llegarán con las mismas carencias al nivel superior.

\section{Educación Básica y Media Superior: Deficientes en Lectura y Redacción}

Lo señalado en el párrafo anterior se puede corroborar al observar los resultados de las diferentes pruebas que se aplican a nivel nacional, como lo es la prueba Evaluación Nacional de Logro Académico en Centros Escolares, por sus siglas ENLACE, en el 2013 (SEP, 2013), la cual evalúa las siguientes áreas: español, matemáticas, cívica y ética a partir del desempeño, en donde éste puede ser medido como:

- Insuficiente: Necesita adquirir los conocimientos y desarrollar las habilidades de la asignatura evaluada.

- Elemental: Requiere fortalecer la mayoría de los conocimientos y desarrollar las habilidades de la asignatura evaluada.

- Bueno: Muestra un nivel de dominio adecuado de los conocimientos y posee las habilidades de la asignatura evaluada.

- Excelente: Posee un alto nivel de dominio de los conocimientos y las habilidades de la asignatura evaluada.

Los resultados de esta prueba en el área de Español en los grupos de 3er grado a 6to grado se tiene que el $57.2 \%$ de los alumnos evaluados tiene un nivel de insuficiente y elemental, el $42.8 \%$ de bueno a excelente; mientras que en secundaria se tiene que el $80.3 \%$ está entre insuficiente a elemental y el $19.7 \%$ de bueno a excelente. Estos resultados nos hablan de una deficiencia en ambos niveles acentuándose en la secundaria, lo 
cual hace dudar que si esos alumnos que calificaron con habilidades aceptables en la primaria ¿Deberás aprendieron bien? En cuanto al nivel medio superior los resultados de la prueba "Plan Nacional para la Evaluación de los Aprendizajes", por sus siglas PLANEA, realizada por la Secretaría de Educación Pública en el 2015 (SEP, 2015), en el área de lenguaje de comunicación y lenguaje, se encontró que el $43.3 \%$ tiene un nivel insuficiente, $20.7 \%$ tiene un nivel elemental, $23.8 \%$ tiene un nivel bueno y $12.2 \%$ tiene un nivel excelente. PISA, por sus siglas en inglés (Programa para Estudiantes Internacionales) en 2012, nos dice que el promedio de lectura en México fue de 411 puntos, mientras que el promedio de los países de la Organización para la Cooperación y Desarrollo Económico, por sus siglas OCDE, en 2012, fue de 478 puntos lo que nos lleva a corroborar el bajo nivel que los estudiantes en México tienen en esta área desde el nivel básico (OCDE, 2012).

Actualmente ENLACE fue reemplazada por PLANEA. Los resultados de la educación básica de esta última prueba no se citan en el presente documento, ya que aún no se han publicado. Todas estas pruebas refieren el "Existe un bajo indice
de rendimiento a nivel
básico y medio superior
que trasciende hasta
el nivel superior" bajo índice de rendimiento en cuanto a habilidades lectoras y de escritura que hay en el nivel básico y medio superior; por lo tanto, no es una sorpresa que trascienda hasta el nivel superior.

\section{Las implicaciones de una mala redacción en la Educación Superior}

Como ya se hablaba de la trascendencia del problema, en cuanto a los problemas de redacción en la elaboración de una tesis, se procedió a revisar datos sobre los índices de titulación y diversos aspectos de los trabajos de investigación de la Licenciatura en Psicología, mismos que fueron encontrados en el plan curricular de la Licenciatura en Psicología de la Facultad de Ciencias de la Conducta de la Universidad Autónoma del Estado de México 2014, página 15, y son los siguientes indicadores:

- A pesar de existir diversos programas encaminados a promover la investigación, la inscripción por parte de los alumnos de la Facultad es casi nula.

- Las dificultades referidas por los egresados para incorporarse al empleo son las siguientes: competencia profesional, deficiencias en formación, crisis económica, requisito del título (éstas enunciadas de mayor a menor frecuencia).

- Existe un bajo índice de titulación (sólo el 24\% de todos los encuestados están titulados).
Particularmente hablando de la UAEM-Zumpango (2016), según los datos brindados por la biblioteca del plantel, se tiene que sólo se han elaborado 29 tesis en el periodo 2009 al 2011 de la licenciatura en Psicología. Tomando estos datos, se puede deducir que aunque hay una fuerte orientación en el plan de estudios de psicología hacia la investigación, ésta no es utilizada, ni siquiera en los trabajos finales para la titulación; esto podría deberse a la falta de preparación o interés en la elaboración de tesis; sabiendo que la elaboración de una tesis o trabajo de investigación implica dedicar considerablemente tiempo a leer, analizar textos para comprenderlos y posteriormente redactar la situación desde el enfoque particular del tesista.

Éste es uno de los principales problemas que se tiene al hacer una tesis, ya que al no saber redactar, no hay forma de reflejar el pensamiento, y al tener dificultades para plasmar el pensamiento, se podría tener problemas de análisis y reflexión; así como de las habilidades fundamentales para desarrollar cualquier tema académico; esto sin demeritar aspectos metodológicos y económicos, que pueden intervenir de forma importante en la elaboración de un trabajo de investigación. Ramírez (2002) señaló que la lectura y la redacción traen la posibilidad de adquirir una capacidad reflexiva, hábitos de estudio, un pensamiento analítico, una reflexión oral y escrita. Estas habilidades que engloban el quehacer del estudiante de nivel básico hasta nivel superior son fundamentales en su formación, y a partir de esta reflexión se plantea el siguiente cuestionamiento: ¿Qué tipo de estudiantes están formando las instituciones educativas? O si no están formando estudiantes ¿Qué están formando?

En este sentido, es necesario mencionar que en las instituciones educativas el principal propósito de formación de los estudiantes es la adquisición de competencias, las cuales se irán desarrollando desde nivel básico hasta el nivel superior; según La Dirección General de Educación y Cultura de la Comisión Europea (como se citó en García Retana, 2011) "Es una combinación de destrezas, conocimientos, aptitudes y actitudes, y a la inclusión de la disposición para aprender, además del saber cómo, posibilitándole que el educando pueda generar capital cultural o desarrollo personal". (p. 4).

Una competencia comprende varios aspectos, como el saber, el saber hacer y el saber ser. El carácter de este artículo se enfoca a la parte del saber y saber hacer, específicamente a la parte de la habilidad de redactar y a las habilidades que subyacen de ésta, y que a 
la vez son complementarias de la misma. Por lo cual se procederá a analizar las competencias de la licenciatura en Psicología que tengan que ver con este rubro; según el plan de estudios de Psicología de la UAEM (2016, p.13) son las siguientes: habilidad para la expresión escrita, misma que debe ser auspiciada por la habilidad de análisis y síntesis, para una correcta expresión escrita, lo cual Ilevará al sujeto a tener la capacidad de planeación e investigación.

Todas estas habilidades son necesarias para elaborar una correcta redacción, puesto que, en un dado caso, sin el desarrollo de la expresión escrita (redacción) será imposible el desarrollo de las demás habilidades; con lo cual aquel psicólogo y en general aquel profesionista que carezca de estas habilidades estará prácticamente limitado en el ejercicio de su profesión, así como en sus expectativas de superación.

Se puede visualizar que los problemas de la educación básica trascienden hasta los niveles posteriores, llegando hasta el nivel superior, y que están afectando a la calidad de formación de los profesionistas en México, mermando las posibilidades de investigación de cualquier índole, lo que implica dependencia de lo que otros países produzcan en sus investigaciones; además de contribuir a la proliferación de "instituciones patito", en donde está ausente la calidad educativa y lejos de ayudar al desarrollo del país, lo afectan en la integración de las sociedades del conocimiento y como bien señala Altbach (2003) "Si permitimos que proliferen las pseudouniversidades por doquier, la educación superior se verá devaluada y estará cada vez más sujeta a presiones de competitividad que inevitablemente destruirán una de las instituciones más valiosas de la sociedad" (p. 4).

Con base en lo anterior la pregunta de investigación es: ¿Cuál es el nivel de habilidades en la redacción de ensayos en estudiantes apunto de egresar de la licenciatura en psicología?, por ende, el objetivo general es: Identificar el nivel de habilidades de redacción. De forma particular se busca señalar el tipo de errores más frecuentes en los escritos de los estudiantes. Finalmente, señalar a través de entrevistas cuál es el tipo de opción de evaluación profesional preferida por los estudiantes y las razones de ésta.

\section{MÉTodo}

Por lo poco desarrollado del tema en la Universidad Autónoma de Estado de México, se plantea un estudio de tipo descriptivo, híbrido con enfoque dominante cualitativo.

Es descriptivo pues los trabajos de este tipo "...buscan especificar las propiedades, las características y los perfiles importantes de personas, grupos, comunidades o cualquier otro fenómeno que se someta a un análisis. Miden, evalúan o recolectan datos sobre diversos aspectos, dimensiones o componentes del fenómeno a investigar" (Hernández, Fernández \& Baptista, 2003, p. 117).

De tipo no experimental, ya que la investigación se realiza sin manipular las variables (Hernández, Fernández \& Baptista, 2010).

Explicativo porque trata de descubrir, establecer y explicar las relaciones causalmente funcionales que existen entre las variables estudiadas, y sirve para explicar cómo, cuándo, dónde y por qué ocurre un fenómeno social. (Hernández et al., 2010).

Respecto al abordaje cualitativo, esta perspectiva se justifica ya que al no haber un conocimiento acabado del fenómeno a investigar, pueden encontrarse mayores elementos de análisis, así como el acercamiento a la realidad desde el entorno concreto y natural donde se desarrollan los procesos educativos.

Finalmente es una investigación transversal, ya que la recolección de datos se realiza una vez durante una cantidad de tiempo limitada. (Hernández et al., 2010).

\section{Participantes}

15 Estudiantes de noveno semestre de la licenciatura en Psicología, a quienes se les pidió que realizarán un ensayo; el propósito de elaborar este documento es transferir el conocimiento generado gracias a un proceso de investigación.

34 Estudiantes de noveno semestre de la licenciatura en Psicología, a quienes se les entrevistó.

\section{Materiales}

\section{Instrumentos:}

Lista de Cotejo basada en los criterios sugeridos por la APA para evaluar los 15 ensayos (Tabla 1), los cuales fueron solicitados de acuerdo a los constructos de cómo elaborar artículos científicos basados en el estudio de León (2005).

\section{Procedimiento}

La presente investigación es de tipo mixta con predominio en el aspecto cualitativo, en este sentido se hizo un análisis de 15 ensayos elaborados por alumnos del $9^{\circ}$ semestre de la licenciatura en Psicología, los cuales fueron hechos de acuerdo a los constructos de cómo elaborar artículos científicos de la APA, dado que su formación debe ser congruente a lo señalado por dicha asociación. Se consideraron 4 criterios de evaluación como la habilidad de redactar (Secciones APA), uso de la gramática 


\begin{tabular}{|c|c|c|c|}
\hline \multicolumn{4}{|c|}{$\begin{array}{l}\text { Tabla } 1 \\
\text { Lista de Cotejo basada en los criterios sugeridos por la APA }\end{array}$} \\
\hline Secciones (APA) & ESTRUCTURA DEL TEXTO & ESTRUCTURA PUNTUACIÓN & LIMPIEZA DEL TEXTO \\
\hline Título & Párrafo & Punto y aparte & Normatividad \\
\hline Resumen & Frase & Punto y seguido & Precisión \\
\hline Introducción & Palabra & Coma & Unión (conectores) \\
\hline Método & & Punto y coma & \\
\hline \multicolumn{4}{|l|}{ Resultados } \\
\hline Discusión & & & \\
\hline
\end{tabular}

(Estructura puntuación), Ortografía (Párrafo, Frase, Palabra, Acentuación) y citado al estilo APA (Normatividad, Precisión y Unión y/o conectores).

- Redacción, es definida como la capacidad de "Compilar, poner en orden, y significa escribir lo pensado, acordado, sucedido o investigado. Pero simplemente escribir no basta; es necesario que el redactor lo haga con exactitud, originalidad, concisión y claridad". Saad (1982, p. 2).

- Gramática (habilidad sintáctica) o sintaxis, tiene que ver con "...el orden de las palabras en la oración y cómo se combinan para expresar ideas". Cohen (2004, p. 11).

- Ortografía correcta, se puntualiza como la "designación así mismo de la disciplina lingüística de carácter aplicado que se ocupa de describir y explicar cuáles son los elementos constitutivos de la escritura de una lengua y las convenciones normativas en cada caso". (RAE, 2010, p. 9).

Además se llevaron a cabo 34 entrevistas semi-estructuradas (véase anexo 1), para saber cuál era la opción de titulación de mayor preferencia y cuál era la razón por la que se tenía esa preferencia, para posteriormente compararlo con el número de tesis que se han hecho durante los años 2009 a 2011, así mismo relacionar los datos con los resultados de los ensayos, y finalmente, poder llegar a una conclusión que dé respuesta a la problemática planteada, con la finalidad de hacer más comprensible el fenómeno del porqué de las dificultades redactoras y su relación en la elaboración de tesis.

\section{Mediciones}

Se analizaron un total de 15 ensayos. Los sujetos sustentantes se clasificaron de la siguiente forma:

- Género: Hombre "H", Mujer: "M"
- Edad.

- Tipo de alumno (de acuerdo a la Clasificación del Sistema Inteligente para Tutoría Académica (SITA) de la Universidad Autónoma del Estado de México) cuyas clasificaciones son las siguientes: S: Sobresaliente, R: Regular, I: Irregular, N.E: Necesidades Específicas y R.I: Riesgo.

S: Cuando el alumno tiene un promedio igual o mayor a 9 .

R: Cuando el alumno no tiene unidades de aprendizaje reprobatorias.

I: Cuando el alumno tiene una o más unidades de aprendizaje reprobatorias.

N.E: Cuando el alumno ha reprobado hasta 7 o más unidades de aprendizaje. Se considera que el alumno deberá fortalecer ciertas áreas relacionadas con su carrera.

R.I: Se considera que un alumno que se encuentra en riesgo de irse de la Institución cuando éste ha reprobado hasta 14 o más unidades de aprendizaje.

- Vía de titulación, con las siguientes claves: T: Tesis y Tesina, E: Examen de Egreso de Licenciatura (EGEL), A: Artículo y P: Promedio, E.L: Memoria de Experiencia Laboral.

\section{Ejemplo:}

H22IE: Hombre de 22 años, Irregular, Examen de egreso de licenciatura.

Así mismo, se enlistan los tipos de errores sintácticos, de redacción, de ortografía y de puntuación, con las siguientes claves:

E.S: Error de sintaxis. E.R: Error de redacción. E.O: Error de ortografía. E.P: Error de puntuación.

Procesamiento de la Información 
Para el trabajo de los datos cualitativos, Geertz (1987) propone el análisis del discurso social, encontrando los significados y sentidos de los elementos indagados; bajo esta idea se realizó lectura y relectura de las transcripciones con la finalidad de ubicar nuevos datos que permitieran reconstruir o ubicar nuevas categorías en cuanto a los problemas de redacción.

Desde las ciencias sociales se habla de validez en una investigación en la medida que sus resultados reflejen una imagen lo más completa posible, clara y representativa de la realidad o situación estudiada (Hernández et al., 2010). La validez de un estudio es la cualidad que lo hace creíble y da testimonio del rigor con el que se realizó. La validez implica relevancia del estudio con respecto a sus objetivos, así como coherencia lógica entre sus componentes; bajo esta idea se usó la triangulación de métodos y técnicas (LeCompte \& Goetz, 1986), que consiste en el uso de múltiples métodos o técnicas para acercarse al objeto de estudio como lo fue la entrevista y el análisis de textos, cuando se alcanzara la saturación por medio de:

a. Triangulación de datos: en la cual se utilizó como referencia los hallazgos citados en el estado del conocimiento.

b. Triangulación de investigadores: en la cual participaron el director de tesis y revisores con la misma formación y con estudios previos sobre el tema.

c. Triangulación de teorías: que consistió en emplear varias perspectivas para interpretar y darle estructura a un mismo conjunto de datos, en este caso se recurre a los referentes empíricos sustentados en la teoría del intercambio social.

\section{Análisis}

Éste se da en dos momentos o etapas, el primero es un análisis descriptivo, y el segundo, un análisis cualitativo de los datos. Para el análisis cuantitativo se contabilizaron las respuestas obtenidas en las entrevistas semi-estructuradas y se clasificaron por preferencia de titulación; así mismo se contabilizaron las respuestas de cada clasificación; las cuales se representaron en porcentajes y una gráfica que se muestra para su mejor entendimiento.

\section{Resultados}

En la figura 1 se muestra que la mayor preferencia es para la modalidad de Examen General de Egreso de la Licenciatura (EGEL) con un 38\%, las razones principales por la que eligieron esta vía de titulación fueron porque "no se alcanzaba el promedio suficiente para titularse, tiempo, dinero y desinterés por elaborar un tema de te- sis, tesina y/o artículo; ya que refieren de que es difícil elaborar un tema de investigación"; las principales razones por las que encontraron difícil la elaboración de un documento de investigación fueron complicaciones con métodos de investigación, formato APA, lectura y redacción; así mismo la vía de titulación de EGEL se percibe con menor dificultad, que el elaborar una tesis, tesina y/o artículo.

En cuanto a quienes optaron por la vía de titulación aprovechamiento, 35\%, argumentaron que la eligieron

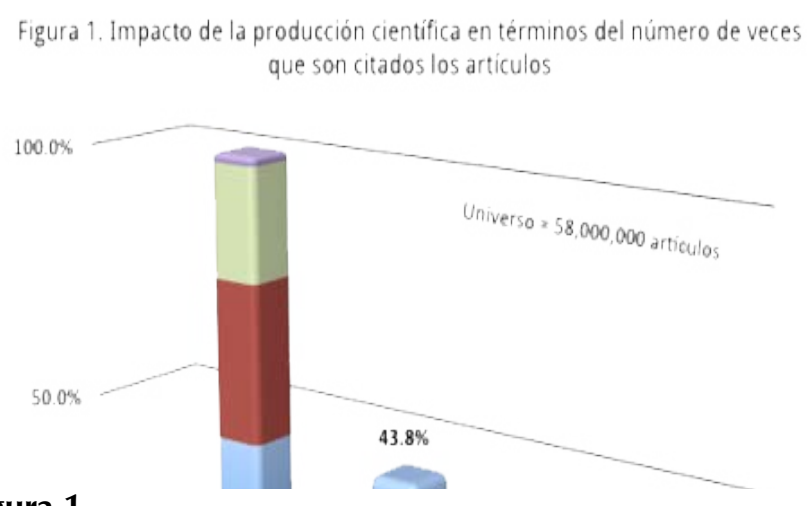

Figura 1.

Preferencia de titulación expresadas en las entrevistas semi-estructuradas

ya que la perciben como un medio más fácil de graduarse, lleva menos tiempo y dinero; además por no querer desarrollar un tema de tesis o tesina y/o artículo, porque también aceptan tener problemas con métodos de investigación, formato APA, así como dificultades con la lectura y redacción.

El grupo de quienes eligieron titularWse por medio tesis, tesina y/o artículo, 27\%, refirió que las principales razones por las cuales era de su preferencia esta modalidad era porque había facilidad y gusto por la investigación y por el valor curricular que este trabajo daba al perfil profesional.

Sumando las poblaciones que eligieron titularse por EGEL $38 \%$ y aprovechamiento 35\%, se tiene que al $63 \%$ de los entrevistados no les gusta hacer investigación por percibirla con mayor dificultad, y sólo el $27 \%$ considera tener las habilidades para redactar y construir un trabajo con características publicables.

\section{Análisis cualitativo}

Respecto a los ensayos, se detectaron ambigüedades en el discurso, por ejemplo, no se completaba una idea o se saltaba de una idea a otra, cometiendo errores sintácticos, ortográficos y en general de redacción. 
M22RP: "Las personas con un alto estatus incurren a actos que dañen a la comunidad y el ambiente que es lo que hablaremos a continuación ya que cuando la vivienda, el automóvil está en malas condiciones y no los arreglan empiezan a dañar el medio ambiente". (sic)

En el anterior fragmento existe incoherencia debido que no hay una conexión lógica entre ideas, de igual forma se incurre en queísmos, como una forma de tratar de argumentar su opinión.

M22RE: "Por tanto la calidad de vida se define como una propiedad que tiene el individuo para experimentar situaciones y condiciones de su ambiente dependiendo su bienestar. Por tanto, el individuo debe de satisfacer sus necesidades básicas para que posteriormente comience con el interés por su calidad de vida." (sic)

La función de la coma y el punto a menudo se confunde, poniendo comas en donde debería de llevar punto y viceversa, haciendo poco entendible el escrito. El uso de muletillas se realiza de forma excesiva, evidenciando la carencia de un lenguaje común que es parte de la disciplina que se ha estudiado y discrepa de las competencias del proyecto ALFA Tuning (s.f.), donde se señala que el alumno de segundo año de cualquier licenciatura debe ser ca-

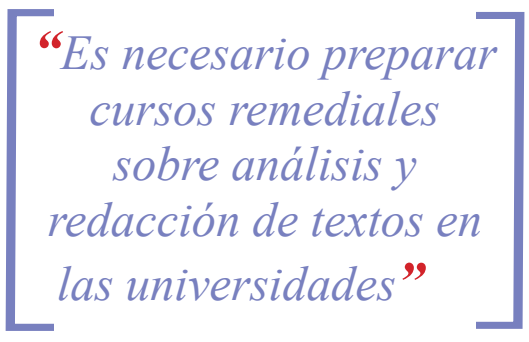

los diferentes espacios laborales, por ejemplo, redactar un informe derivado de una evaluación psicológica, elaborar un proyecto de intervención, realizar una planeación didáctica argumentada, entre otras. Estos hallazgos coinciden con el planteamiento de Carlino (2002), quien señala que la lectura y escritura que se exigen a los alumnos forman parte de las prácticas académicas inherentes al dominio de su disciplina, no poseerlas puede obstaculizar su desempeño futuro.

La temática abordada es un problema generalizado de los diversos niveles de educación en el país, desde el básico al superior, lo que hace necesario que las autoridades de las diferentes universidades se enfoquen en preparar cursos remediales sobre análisis y redacción de textos. Retomando a Arrieta, Batista, Meza y Meza (2006), es importante enfrentar el problema y no atribuirle la responsabilidad a los niveles educativos anteriores (nivel básico y medio superior); es por ello que se está de acuerdo en la encomienda de la elaboración de este tipo de materias a instituciones de educación superior, por tener mayor libertad de cambiar la estructura curricular; así mismo se coincide con Santoyo (2001; como se citó en Cepeda, Santoyo \& López, 2009) en la elaboración de paz de hacer una contribución original, si bien limitada, dentro de los cánones de su disciplina, por ejemplo, una tesis final; así mismo se muestra una carencia para mostrar originalidad y creatividad con respecto al manejo de su disciplina. Otro ejemplo de pobreza lingüística son las expresiones inventadas como "sin en cambio" en lugar de utilizar "sin embargo" o "en contra parte" las cuales representan un pleonasmo, aparte de ser inadecuadas para el nivel educativo.

En el $100 \%$ de los ensayos hay citas que se hacen de manera incorrecta y que no coinciden con las normas de la Asociación Americana de Psicología (APA); en algunos de los casos ni siquiera se intenta citar el autor; además del error que se encuentra en todos los ensayos revisados es que se habla en primera persona y en plural, debiendo referirlas en tercera persona.

\section{Discusión}

Los resultados obtenidos permiten afirmar que las habilidades de Redacción Académica de este grupo de alumnos, con base en el listado de características establecidas, son de tipo bajo a deficientes; por lo tanto, no poseen la habilidad de comunicarse por escrito de una forma adecuada, la cual podría ser una limitante en una estrategia de análisis de textos científicos, la cual se deberá integrar en forma de cursos obligatorios y con un nivel de complejidad creciente.

Es preciso señalar que este fenómeno va más allá del contexto académico, ya que la pérdida de la comunicación escrita representa una carencia cultural muy grande y cada vez tiende a incrementarse como consecuencia del uso inadecuado de la tecnología; por ejemplo, algunas personas delegan la responsabilidad de redacción y acentuación al ordenador, sorprendente, pero real, los jóvenes toman lo que les sugiere la máquina, sin considerar si el escrito expresa lo que se quiere decir; aunado a que el corrector de la computadora se limita a la ortografía y algunos casos de gramática, pero no es constructor de textos, por lo cual existe incoherencia en el escrito.

\section{Conclusiones}

La mayor parte de los estudiantes de psicología que elaboraron el ensayo, un 93\%, tienen problemas para hacer uso de una sintaxis, puntuación y ortografía correctas; en pocas palabras, dificultad para realizar una buena redacción y en consecuencia incapacidad para elaborar investigaciones, mismas que servirían para su próxima titulación como profesionales; con esto, comparado con 
el resultado de los cuestionarios aplicados, en donde poco más de dos tercios de los entrevistados no gustan de hacer investigación, podría inferirse que los alumnos de la licenciatura de Psicología no hacen investigación por tener deficiencias en la redacción, razón por la cual podría deberse el bajo número de tesis elaboradas en la Licenciatura de Psicología del CU UAEM Zumpango, durante los periodos 2009 a 2011, que son un total de 29 como ya se había mencionado.

Es importante señalar que la experiencia de redactar una tesis, tesina o artículo científico pone en juego las capacidades de comprensión lectora, razonamiento matemático, inferencia, entre otras, que no se dan en los procesos de titulación por EGEL o aprovechamiento; sin demeritar las opciones mencionadas, en ellas las habilidades que se evalúan no desarrollan la función sustancial de toda universidad, la cual es la extensión e investigación científica.

Así, a nivel nacional se reconoce la incapacidad de generar investigación aplicada o pura a nivel licenciatura, aunque el proyecto Alfa Tuning lo exige como una competencia inherente a toda formación universitaria. Actualmente, en el nivel posgrado se titulan por aprovechamiento y estudios superiores como el Doctorado, situación que agudiza la problemática de generación de conocimiento. Como futuro generador de investigación se considera que es necesario implementar programas emergentes y reales de intervención para lograr una comprensión adecuada de lo que se lee, y no sólo aplicar estrategias remediales y paliativas, que aunque intentan trabajar de forma rápida, no se logra la adquisición y desarrollo de las habilidades, ya que éstas no se aprenden, se desarrollan como consecuencia de un proceso continuo y a largo plazo; situación que han dejado de lado los analistas educativos, y ahora los políticos.

Es cierto que la riqueza de un pueblo se encuentra en la educación, pero en una real reforma ligada a cambios pedagógicos centrados en los métodos, técnicas y estrategias que partan de situaciones reales y evalúen de forma auténtica, sin pensar, en el promedio como una meta obligatoria que condiciona a los docentes simular la adquisición de competencias indispensables para la vida como lo es leer y escribir correctamente.

\section{Referencias}

Asociación Nacional de Universidades e Instituciones de Educación Superior. (2006). Consolidación y avance de la educación superior en México. México.

Arrieta, B., Batista, O. J., Meza, C. R. \& Meza, C. D. (2006). La comprensión lectora y la relación académica como centro del currículum. Acción pedagógica, 15, 94-98.

Altbach, P. (2003). El surgimiento de las pseudouniversidades. Seminario de Educación Superior, Universidad Nacional Autónoma de México, 22, p. 4.

Benítez, M. G., Barajas, J. I. \& Hernández, I. N. (2014). Efecto de la aplicación de una estrategia de comprensión de lectura en un entorno virtual. Revista Electrónica de Investigación Educativa, 16(3), 71-87. Recuperado de http://redie.uabc. $\mathrm{mx/vol16no3/contenido-benitezbh.html}$

Bilbao, O. (2004). Descubre cómo escribir cartas de marketing directo efectivas. Madrid, España: Editorial ESIC. Recuperado de la base de datos de google books.

Carlino, P. (2002). Enseñar a escribir en la Universidad. Como lo hacen en los Estados Unidos y por qué. Organización de Estados Iberoamericanos, agosto. Recuperado de http:// www.rieoei.org/deloslectores/279carlino.pdf

Cepeda, M., Santoyo C. \& López, M. (2009). Réplica de una estrategia de análisis de textos científicos en estudiantes universitarios de primer ingreso. Consejo Mexicano de Investigación Educativa, 10, 1-13. Recuperado de http:// www.comie.org.mx/congreso/memoriaelectronica/v10/ pdf/area_tematica_01/ponencias/0351-F.pdf

Cohen, S. (2004). Redacción sin dolor: Aprenda a escribir con claridad y precisión (4ta edición). México D.F: Ed. Planeta.

Flores, R., Jiménez, J. E. \& García, E. (2015). Adolescentes pobres lectores: evaluación de procesos cognitivos básicos. Revista Electrónica de Investigación Educativa, 17(2), 34-47. Recuperado de http://redie.uabc.mx/vol17no2/ contenido-floresjimg.html

García Retana, J. Á. (2011). Modelo Educativo Basado En Competencias: Importancia y Necesidad. Revista Electrónica "Actualidades Investigativas en Educación", 11(3), 1-24. Recuperado de http://www.redalyc.org/ articulo.oa?id=44722178014

Geertz, C. (1987). La interpretación de las culturas. México: Gedisa.

Guevara, G. (1991). México: ¿Un País de Reprobados? Nexos, 162, 33-44.

Hernández, G. (2004). Gregorio Torres Quintero: Su vida y su obra. Universidad de Colima: Colima, México. Recuperado de la base de datos de google books.

Hernández, G. (18 de Abril, 2004). Deficiente política Educativa ¿Se puede leer sin escribir? La Jornada. Recuperado de: http://www.jornada.unam.mx/2004/04/18/mas-puede. html

Hernández, R., Fernández, C. \& Baptista, P. (2003). Metodología de la investigación. México: Editorial McGraw Hill.

Hernández, R., Fernández, C. \& Baptista, P. (2010). Metodología de la investigación ( $5^{\text {a }}$. ed.). México: Editorial McGraw Hill.

Le Compte, M. D. \& Goetz, J. P. (1986). "Los problemas de confiabilidad y validez de la investigación etnográfica". Revista de Investigación Educativa, 52(1), 31-60.

León, O. G. (2005). Cómo redactar textos científicos en psicología y educación. España: Netbiblo.

Organization for Economic Cooperation and Development. (2012). International student assessment (PISA). Recuperado de http://data.oecd.org/pisa/readingperformance-pisa.htm

Real Academia Española. (2010). Ortografía De La Lengua 
Española. Madrid, España: Editorial Espasa libros.

Ramírez, F. (2002). La importancia de la redacción como instrumento comunicativo (Tesis de Maestría). Universidad Pedagógica Nacional. Recuperado de la base de datos biblioteca Gregorio Quintero.

Rodríguez, I., Márquez, M. \& Estrada, Y. (2005). El desarrollo de la conciencia ortográfica desde el enfoque comunicativo funcional: Una intervención psicopedagógica (Tesis de licenciatura). Universidad Pedagógica Nacional. Recuperado de la base de datos biblioteca Gregorio Quintero.

Rodríguez, M. (2002). Habilidades de lectura y redacción de licenciatura en Pedagogía de la UPN (Tesina). Universidad Pedagógica Nacional. Recuperado de la base de datos de la Biblioteca Gregorio Quintero.

Saad, A. (1982). Redacción: desde cuestiones gramaticales hasta el informe formal extenso (1ra ed.). México D.F: Ed. Continental.

Saavedra, M. (2001). Diccionario de pedagogía: Pedagogía Dinámica. México, DF: Editorial Pax México. Recuperado de la base de datos de google books.

Secretaría de Educación Pública. (2013). Resultados Históricos Nacionales, 2006-2013. Recuperado de http://www. enlace.sep.gob.mx/content/gr/docs/2013/historico/00_ EB_2013.pdf
Secretaría de Educación Pública. (2015). Resultados Primera Aplicación 2015. Recuperado de http://planea.sep. gob.mx/content/general/docs/2015/PLANEA_MS2015_ publicacion_resultados_040815.pdf

Tuning (s.f.) Proyecto ALFA Tuning - América Latina: Innovación Educativa y Social (2011-2013). Recuperado de http:// www.tuningal.org/pt/publicaciones/doc_download/6presentacion-inaural-de-la-reunion-

Universidad Autónoma del Estado de México. (2014). Currículum de la Licenciatura en Psicología (Informe 2014). Toluca, Estado de México, México

Universidad Autónoma del Estado de México. (2016). Plan de Estudios de la Licenciatura en Psicología. Recuperado del sitio de Internet de la Universidad Autónoma de México, CU UAEM-Zumpango http://www.cuzumpango.uaemex. $\mathrm{mx} /$ ?page_id $=117$

Waldegg G. \& Block, D. (1997). Estudios en Didáctica, Enseñanza y Aprendizaje de: Ciencias Histórico-Sociales, Ciencias Naturales, Salud y Ambiente, Lengua Escrita y Matemáticas. Consejo Mexicano de Investigación Educativa: Grupo Editorial Iberoamérica. 


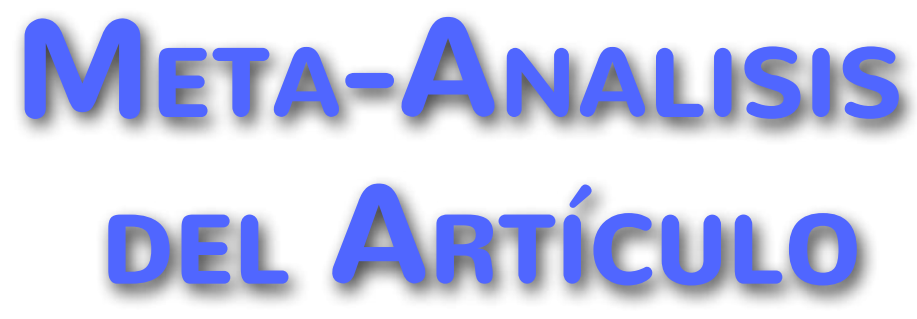




\section{Dimensión Cuantitativa}

\section{Perfil de Evaluación entre pares}
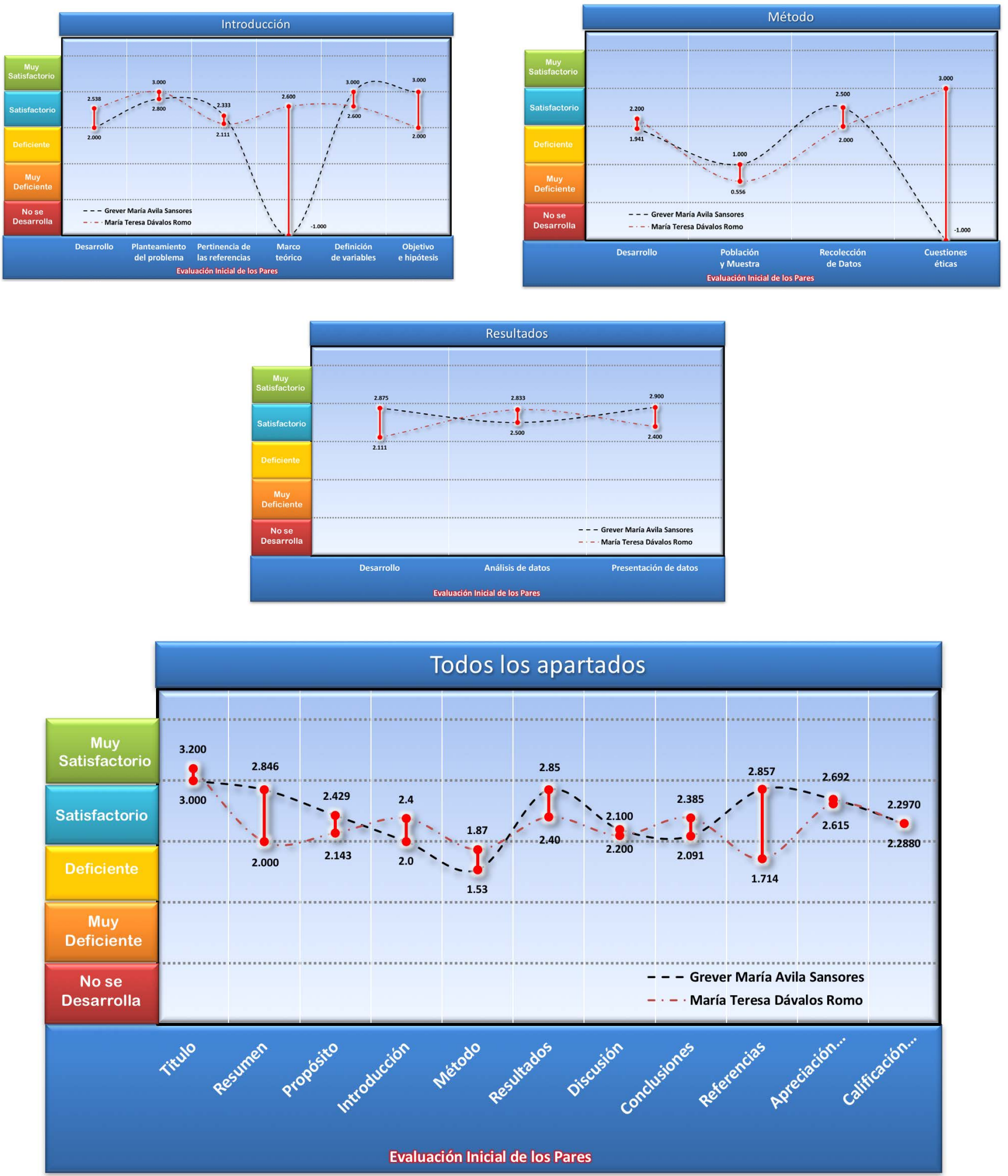


\section{Índice de Concordancia}

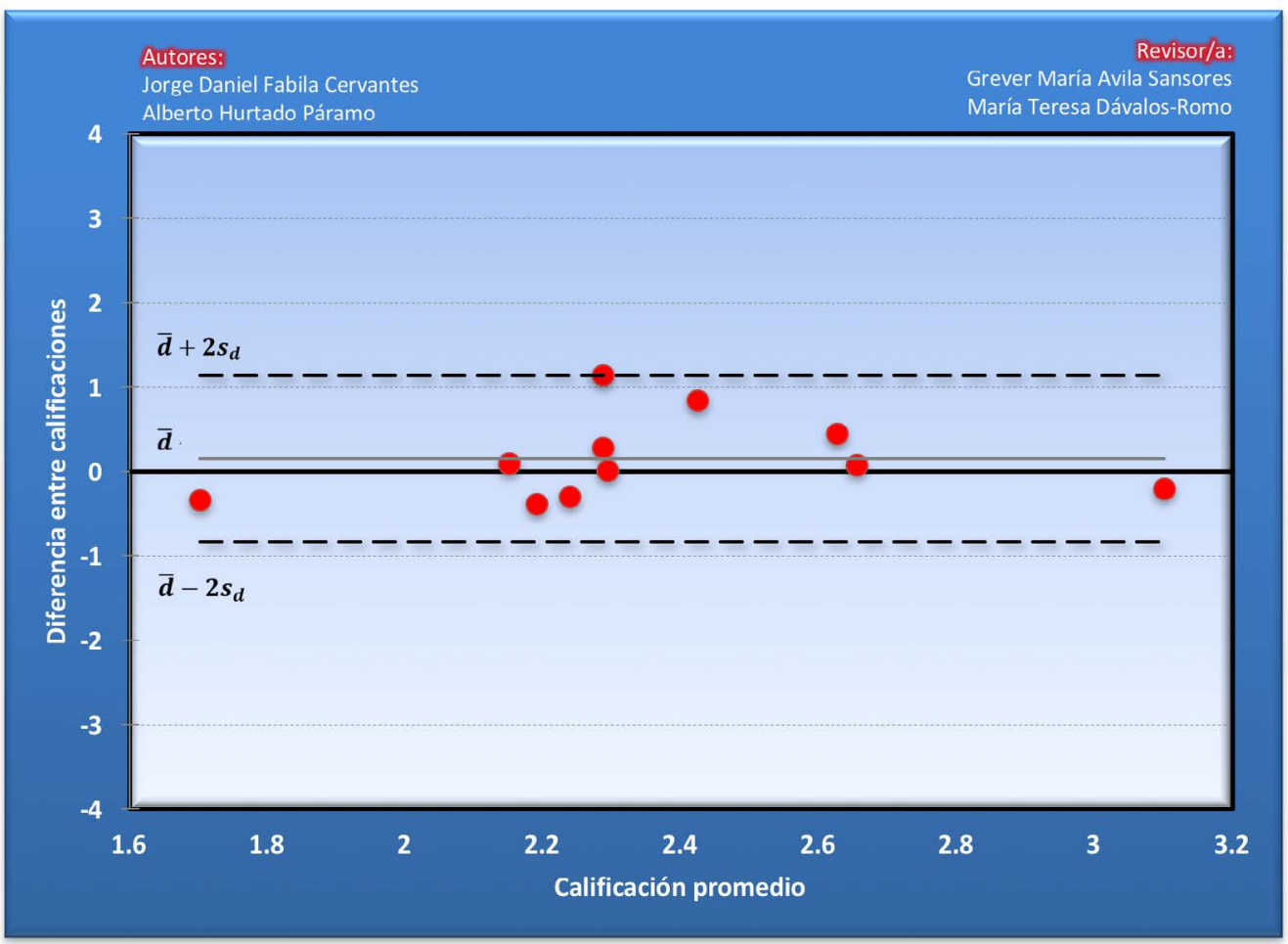

\section{Índice de Acuerdo}

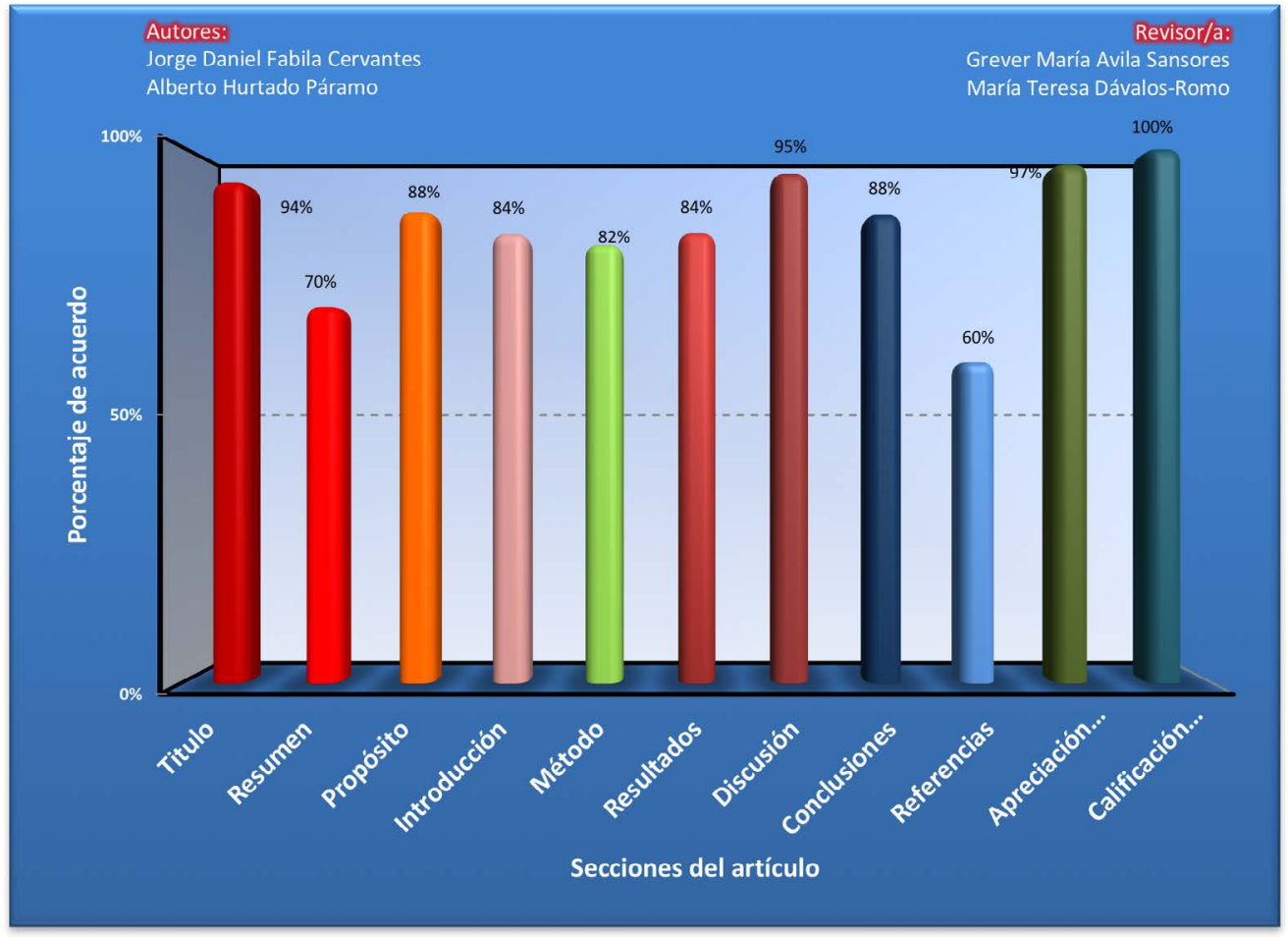

MW Aिम 


\begin{tabular}{|c|c|}
\hline ReVISOR 1 & ReVISOR 2 \\
\hline Grever María Avila Sansores & María Teresa Dávalos Romo \\
\hline \multicolumn{2}{|c|}{ TÍtulo/Autoría } \\
\hline El título es correcto & Redactar de forma que resalte más sus variables. \\
\hline \multicolumn{2}{|c|}{ Resumen } \\
\hline $\begin{array}{l}\text { Debido a que es un estudio mixto con predominan- } \\
\text { cia cualitativa, en la parte metodológica se debe } \\
\text { señalar el tipo de análisis cualitativo realizado, por } \\
\text { ejemplo análisis de contenido. No se señala la con- } \\
\text { clusión del estudio }\end{array}$ & $\begin{array}{l}\text { Es importante aclarar qué son habilidades redacto- } \\
\text { ras. No se ven las conclusiones del escrito. Revisar } \\
\text { aspectos de redacción. No son claros algunos ele- } \\
\text { mentos metodológicos de la investigación. Las pal- } \\
\text { abras claves están en ingles, en este primer apartado } \\
\text { quizás deberían estar en español. Emplea palabras } \\
\text { claves que no están en el titulo, objetivo o desarrollo } \\
\text { del documento. }\end{array}$ \\
\hline
\end{tabular}

\section{Próposito del Estudio}

El propósito del estudio es claro sin embargo al momento de abordar la metodología no se cumple con lo requerido, pues hace falta más rigor metodológico sobre el análisis cualitativo, abordaje teórico para sustentar y discutir los resultados.
Es importante revisar algunos aspectos de redacción. No se ve claro el objetivo. Algunos párrafos aportan poco al contenido de la investigación (no son claras las ideas que se intentan transmitir). Considero, desde mi punto de vista, que el propósito es relevante y aborda una problemática actual en los universitarios, solo falta aclarar un poco más el documento.

\section{INTRODUCCIÓN}

Sobre la introducción se necesita realizar más revisión bibliográfica con autores más actualizados. Cuando se aborda el problema de redacción en la elaboración de una tesis, los datos que proporciona de índices de titulación y trabajos de investigación se basan en el Plan curricular 2001, y a mi parecer deben actualizar dichos datos pues son un importante sustento para el artículo. De igual forma al abordar las tesis en el período 2009-2011 se habla de un total de 29, ¿esa cifra es la que prevalece hasta la actualidad?. Por otra parte los cuestionamientos siguientes: ¿qué tipo de estudiantes están formando las instituciones educativas?, o si no están formando estudiantes ¿qué están formando?, considero que se necesita un mayor fundamento, creo que sería mejor cuestionar sobre el funcionamiento del modelo educativo de la universidad y la efectividad de su implementación.
Revisar aspectos de redacción y ortografía. Revisar lineamientos APA (autores, años, citas de citas, citas textuales). Algunos elementos en el marco teórico no son claros, sólo se hace mención pero no se profundiza en ellos. No se ve claro el objetivo, pregunta de investigación e hipótesis 


\section{MÉtodo}

El estudio a pesar de ser mixto con predominancia cualitativa carece de la metodología cualitativa adecuada. en la sección de procedimientos se deben agregar si las entrevistas fueron audiograbadas, de cuanto tiempo fue cada una, etc. Se recomienda tener un sustento teórico para el planteamiento de preguntas de la entrevista.

\section{Poco claro}

\section{Resultados}

Es recomendable que en el apartado de resultados se agregaran algunos extractos de los ensayos representativos del análisis cualitativo que se realizó.

Son poco claros estos apartados

\section{Discusión}

: Es recomendable agregar una revisión bibliográfica más amplia y actualizada que permita la discusión de los resultados, por ejemplo se pueden mencionar otros países donde se hayan encontrado con las mismas carencias, también abordar cuáles modelos educativos se están utilizando a nivel mundial y si se refleja la misma problemática, etc.

Es poco claro este apartado. No se establece relación entre datos e investigaciones previas. Se sugiere que este apartado sea más contundente en base a las investigaciones previas y a los resultados obtenidos

\section{Conclusiones}

En la conclusión se hacen afirmaciones muy arriesgadas, como por ejemplo: "a nivel nacional se reconoce la incapacidad de generar investigación aplicada o pura a nivel licenciatura", esta situación depende de la naturaleza de la carrera, además que a partir del articulo propuesto no se puede llegar a esta conclusión. Es recomendable aterrizar las conclusiones acorde al contexto abordado y específico para esa población, así como realizar sugerencias para mejora de dicha problemática encontrada (motivación de los jóvenes a veranos de investigación, becas de investigación, etc.)

Es poco claro este apartado. No se establece relación entre datos e investigaciones previas. Se sugiere que este apartado sea más contundente en base a las investigaciones previas y a los resultados obtenidos

\section{Referencias}

Agregar mas referencias de no más de 8 años de antigüedad.

Es importante fortalecer más la cantidad y actualizar los documentos revisados. Es importante atender los criterios APA. 


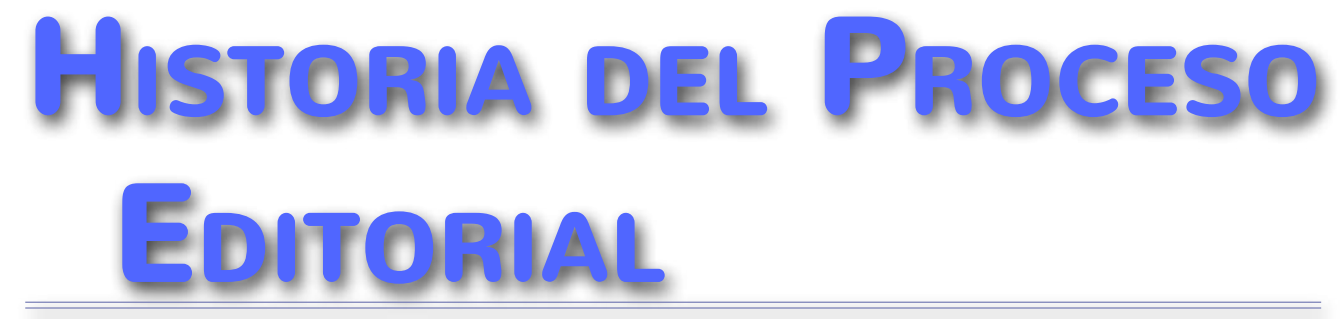


Sección

)

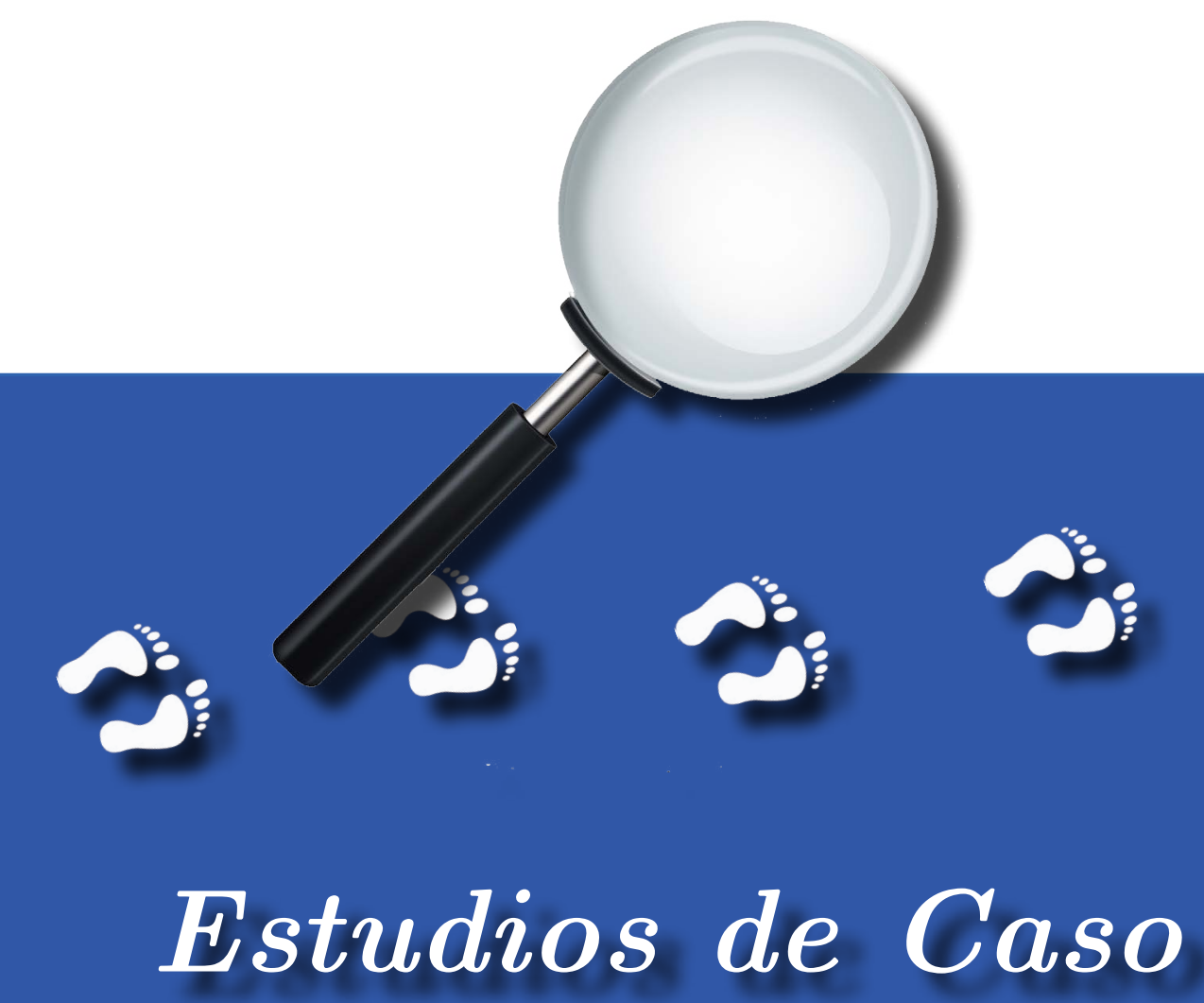




\title{
RELACIÓN ENTRE NIVEL DE ANSIEDAD Y FUNCIONAMIENTO FAMILIAR
}

\author{
Lourdes Remigio-Mondragón y Angélica Pérez-Arredondo \\ INSTITUTO FAMILIAR SISTÉMICO ACT \\ MÉXICO
}

\begin{abstract}
RESUMEN
El presente trabajo tiene como objetivo describir la relación existente entre la funcionalidad de la familia y las causas de la ansiedad en algunos de sus miembros. Se encontró que la madre ha presentado ansiedad la mayor parte de su vida de casada. Acude la familia a terapia solicitando el servicio psicológico para el hijo mayor de 20 años que presenta crisis de ansiedad y preocupación por su padre cuando éste se encuentra fuera de casa. Se trabajó con intervenciones principalmente bajo el modelo centrado en soluciones y, como herramienta complementaria, técnicas de hipnosis ericksoniana. Desde la segunda sesión fueron reportando cambios significativos en las interacciones familiares y en el autocontrol de la ansiedad que la madre presentaba y que su hijo había aprendido, ahora ella interactuaba de forma asertiva con su esposo e hijos y, en consecuencia, el hijo ya no presentaba síntomas de ansiedad.
\end{abstract}

Palabras Clave:

Ansiedad, familia, modelo centrado en soluciones, hipnosis ericksoniana.

\section{RELATIONSHIP BETWEEN THE LEVEL OF ANXIETY AND FAMILY FUNCTIONING}

\begin{abstract}
This paper aims to describe the relationship between family functioning and causes anxiety in some of its members. It was found that the mother has presented anxiety most of her married life. Family comes to seeking psychological therapy service for the eldest son of 20 years who has panic attacks and concern for his dad when he is away from home. We worked with interventions mainly in the model focused on solutions and complementary techniques as Ericksonian hypnosis tool. Since the second session were reporting significant changes in family interactions and self-anxiety that the mother had and that his son had learned, now she interacted assertively with her husband and children, and consequently, the son not had symptoms of anxiety.
\end{abstract}

Keywords:

Anxiety, family, solution-focused model, Ericksonian hypnosis.

Bitácora del Artículo:

| Recibido: 03 de octubre de 2015 | Aceptado: 06 mayo de 2016 | Publicado en línea: 15 de diciembre de 2015 | 


\title{
RELACIÓN ENTRE NIVEL DE ANSIEDAD Y FUNCIONAMIENTO FAMILIAR
}

\author{
Lourdes Remigio-Mondragón y Angélica Pérez-Arredondo
}

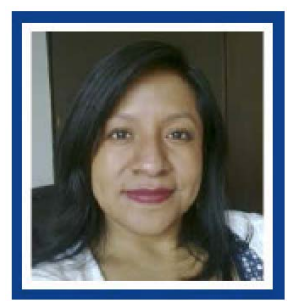

Lourdes Remigio-Mondragón Instituto Familiar Sistémico ACT

Correo: lourdesremm@gmail.com

Licenciada en Psicología por la Universidad del Valle de México y Maestra en Hipnosis y Terapia Familiar Breve Sistémica por la Universidad José Martí de Latinoamérica e INFASI ACT. Diplomada en Terapia Familiar Breve Sistémica y en Hipnosis Clínica Ericksoniana, por la Universidad Autónoma de Nuevo León.

Ver más...

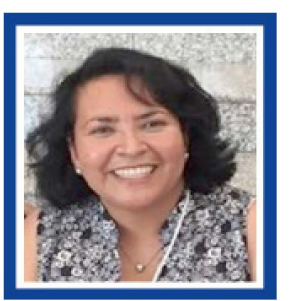

Angélica Pérez-Arredondo Instituto Familiar Sistémico ACT Correo: para_angelica@hotmail.com

Maestra en Psicología Educativa, de la Facultad de Psicología, UNAM y egresada de la licenciatura en Psicología de la ENEP Iztacala-UNAM. Diplomada en Filosofía; en Terapia Familiar Breve Sistémica, y en Hipnosis Clínica Ericksoniana.

Ver más...

\section{CONTRIBUCIÓN DE LOS AUtORAS}

La primera autora realizó el trabajo terapéutico y la segunda lo supervisó. Ambas redactaron el artículo.

\section{AgRADECIMIENTOS}

Las autoras del presente trabajo agradecen la supervisión del caso, guiada por la Mtra. Alejandra Andrade, profesora de la Maestría en Hipnosis y Terapia Familiar Breve Sistémica y Directora Administrativa de INFASI ACT.

\section{DATOS DE FILIACIÓN DE LAS AUTORAS}

Primera autora egresada de la Maestría en Hipnosis y Terapia Familiar Breve Sistémica, INFASI ACT. Segunda autora profesora del Instituto Familiar Sistémico

Copyright: (c) 2015 Remigio-Mondragón, L. \& Pérez-Arredondo, A.

Este es un artículo de acceso abierto distribuido bajo los términos de la licencia Creative Commons Reconocimiento-NoComercial 4.0 Internacional, por lo que su contenido gráfico y escrito se puede compartir, copiar y redistribuir total o parcialmente sin necesidad de permiso expreso de sus autoras con la única condición de que no se puede usar con fines directamente comerciales y los términos legales de cualquier trabajo derivado deben ser los mismos que se expresan en la presente declaración. La única condición es que se cite la fuente con referencia a la Revista Digital Internacional de Psicología y Ciencia Social y a sus autoras. 


\section{TABLA DE CONTENIDO}

INTRODUCCIÓN

266

La intervención terapéutica, 266

MÉTODO

268

Identificación del caso, 268

Análisis del motivo de la intervención, 268

Antecedentes del problema, 268

Descripción y análisis del problema, 268

Plan de InTERVEnción

Descripción del plan de intervención, 269

Establecimiento de los objetivos y las metas del plan de intervención, 269

Técnicas de evaluación del plan de intervención, 269

Aplicación del plan de intervención, 270

PRESENTACIÓN DE RESULTADOS

Análisis de los cambios que produjo el plan de intervención, 272

CONCLUSIONES

REFERENCIAS

Meta-Analisis del Artículo

Dimensión Cuantitativa, 278

Dimensión Cualitativa, 280

Historia del Proceso Editorial

283 


\section{INTRODUCCIÓN}

$\mathrm{L}$

os datos sobre la ansiedad en nuestro país han sido alarmantes desde hace más de una década, la información reportada por la Encuesta Nacional de Epidemiología Psiquiátrica (2003; citado en Fuentes, 2013) la ubica como uno de los trastornos más frecuentes en nuestro país, con una prevalencia de $14.3 \%$ alguna vez en la vida de las personas, seguidos por los trastornos por uso de sustancias $(9.2 \%)$ y los trastornos afectivos (9.1\%).

Para Goldman (2001; como se citó en Zavala, Ríos, García \& Rodríguez, 2009), la ansiedad es considerada como un estado emocional que frecuentemente se acompaña de síntomas fisiológicos que pueden conducir a la fatiga o incluso al agotamiento. Aunque más preciso es Isaacs (2000), quien la define como una res"La relación familiar
se ve influida por la
ansiedad que presenta
la madre" puesta subjetiva al estrés, como una sensación de aprensión, incertidumbre o temor, a consecuencia de una amenaza real o percibida cuyo origen se desconoce o no es reconocido.

Según Yalóm (como se citó en De Castro \& García, 2011), la ansiedad "surge a partir de la conciencia que se tiene de estos supuestos básicos, en el ser humano siempre habrá en algún grado la posibilidad de que sus valores se destruyan, que no los pueda seguir afirmando o que fracase en algún proyecto que sea valioso para sí, lo que es un generador de ansiedad en la persona" (p. 45). Y así como lo menciona Goldman (2001), la intensidad de la ansiedad puede ir variando en grados desde inquietudes menores hasta temblores notables e incluso crisis de angustia completa, con síntomas como preocupación excesiva, tensión muscular, alteraciones del sueño, sentimiento de agitación, fatiga, dificultad para concentrarse, la persona encuentra difícil controlar su preocupación, entre otros.

Es a la ansiedad y sus diversas manifestaciones a la que se puede anteponer como las causas de reprobación escolar (Rosário, Núñez, Salgado, González-Pineda, Valle, Joly \& Bernardo, 2008), del estrés y depresión (Méndez, Giraldoscar, Aguirre-Acevedo \& Lopera, 2010), de la salud en general (Soria, Ávila \& Rodríguez, 2014), la satisfacción familiar (Salazar, Veytia, Márquez \& Huitrón, 2013) o bien de la influencia del clima fami- liar y estrés del padre de familia en la salud mental de los niños (Quintana \& Sotil, 2014), entre otros.

En un viejo estudio realizado por Alchaer, Bahsas, Hernández y Salinas (1994) sobre el funcionamiento familiar y su relación con el estrés y la ansiedad, los resultados mostraron que el nivel de funcionamiento puede afectar a aquellas influencias familiares controlables por el hombre, de manera tal que éstas se reflejen positiva o negativamente en la salud de sus individuos. Además, el funcionamiento familiar puede verse alterado por cualquiera de las otras variables que configuran el ambiente social. Por ejemplo, en este estudio se observó que los adolescentes, los divorciados, los del estrato socioeconómico laboral obrero, los obesos, los alcohólicos y los que pasaban por una enfermedad psicosomática, presentaban mayores niveles de disfunción familiar que otros grupos estudiados. La desventaja de este tipo de investigaciones es que, enfocados en la predictibilidad de instrumentos como el APGAR, omitieron la consideración de la capacidad de respuesta del individuo para lograr el equilibrio emocional frente a dichas agresiones. Otro dato relevante de ese trabajo fue la inconsistencia entre lo que se reporta en una escala y lo observado, ya que a pesar de que las causas de disfunción familiar más frecuente fueron la insatisfacción de la ayuda recibida por la familia y la manera como se comparte el tiempo, el espacio, el dinero y los recursos existentes, los participantes con disfunción familiar en casi la mitad de los casos manifestaron en la encuesta de APGAR Familiar II, que tenían buenas relaciones con todos los miembros de su familia.

Retomando estos resultados, para el presente trabajo nos basamos en la hipótesis de que la relación funcional de la familia se veía influida por la ansiedad que presentaba la madre, y que posiblemente era producto de un conflicto encubierto en el holón conyugal y el síntoma era exteriorizado por los hijos. En terapia se ha encontrado que cuando la ansiedad (a veces interpretada o percibida como temor, inseguridad, celos, etc.) les sucede a los padres, tienden a sobreproteger a sus hijos, ya que ellos viven en una constante zozobra por temor a perder a sus padres o que algo malo les pudiera pasar, y viceversa.

\section{La intervención terapéutica}

Desde y en el sistema. Haley (1991) consideraba que lo importante en el trabajo terapéutico es, cuántas relaciones están en la mente del terapeuta porque de ello se de- 
riva el camino a seguir. Desde la perspectiva que se parte para el presente caso, Charles (2008) supone que el terapeuta sistémico ve al individuo en su contexto, y que el sistema que se crea y se conjunte para la solución del problema es diferente del sistema en el cual se originó el problema, ya que este nuevo sistema se conforma por todos y todo aquello que le da significado para quien tiene los problemas, y que además quiere colaborar para solucionarlo. Por tanto, en la definición del objetivo terapéutico queda implícito que habrá que comenzar por definir quién es cliente (el que está dispuesto a pagar, el que hace la primera llamada y que está dispuesto a hacer un cambio, regularmente al que le duele más, y en este momento está preocupado) y quién paciente, para así seguir identificando las interacciones que se den, así como el tipo de éstas. Se trata aquí de que la ansiedad ha sido mantenida por un sistema que parecía óptimo hasta que ya no resultó serlo para toda la familia.

La adherencia en terapia. La terapia cubre varias fases, ya que se trabaja con los miembros del sistema (estén o no presentes en el consultorio), lo que interesa es saber el nivel en el que se debe abordar la problemática, comenzando por lo obvio para los consultantes hasta deshacer los conflictos disfrazados. Puede ser que a terapia haya llegado la familia completa, pero conforme se va analizando la problemática, ésta resulte ser mantenida sólo por algunos de los miembros. Coincidiendo con el presente caso y lo señalado por Charles, ante los conflictos encubiertos por la pareja, lo primero que Ilega a terapia es trabajar con su rol de padres para un problema prioritario de un hijo, ya que la terapia de pareja será en una segunda o tercera fase del trabajo; es decir, pudiera ser que la conducta de los niños y adolescentes de alguna manera es una metáfora de la conducta de algunos de los padres, o de la relación de los padres. Será hasta la segunda etapa en la que se pueda entrar a los problemas de comunicación y conflictos de relación conyugal.

Con enfoque centrado en soluciones. Como lo señala Moreno (2013), es difícil llegar a darnos cuenta de que, tras varios intentos por solucionar una situación, ésta llega a complicarse tanto que se convierte en un problema. El aspecto que subraya De Shazer (como se citó en Moreno, 2013) es que, mientras esto sucede, la persona percibe cada vez más su problema y su incapacidad de resolverlo, pasando por alto aquellas ocasiones en las que el problema no se da, o se da con menor intensidad o duración, impidiendo entonces detectar posibles variaciones y excepciones.

Por ello es que, apoyándonos en el modelo de terapia sistémica centrado en soluciones, el trabajo para la ansiedad tiene un impacto diferente a las estrategias convencionales de autocontrol. En este sentido, el objetivo de la terapia es ayudar al consultante a encontrar un modo en que pueda percibir las excepciones como "una diferencia que marca una diferencia" y aumentarlas hasta que el problema deje de ser tal. Este modelo se centra en las posibles soluciones, conduciendo a la persona que piense qué estaría haciendo diferente si no tuviera ese problema, que se imagine sin su problema, y junto con la ayuda del terapeuta se co-crea una realidad diferente ante su problema, de menos que sea manejable; parte del enfoque es que la persona vaya realizando pequeños cambios, de estos mismos que se reportan en cada sesión el terapeuta los celebra, así mismo por medio de las preguntas preposicionales se da por hecho que los cambios ya están sucediendo, cabe mencionar que una de las tareas que se formula desde la primera sesión se les pregunta a los clientes, qué cosas positivas quiere que continúe ocurriendo. (De Shazer, 1985; como se citó en O'Hanlon \& Weiner-Davis, 2010)

En el transcurso de las sesiones cuando el paciente reporta los cambios logrados estos se profundizan de tal modo que piense minuciosamente quién de la familia se dio cuenta que está logrando, en este caso, controlar la ansiedad y qué es diferente ahora, en ésta misma línea se le pide al paciente que suponga justamente que por la noche ocurre un milagro, a la mañana siguiente el problema está resuelto, quién será el primero en darse cuenta y qué cosas han cambiado.

En forma resumida, el modelo centrado en soluciones se enfoca estratégicamente en intervenciones de comunicación terapéutica como: utilización cuidadosamente del lenguaje, trabajar con las respuestas que sus miembros vayan dando y seguir preguntando para lograr que estas respuestas resulten útiles; además, será necesario gestionar sus respuestas para generar nueva información sobre los avances ya producidos, las expectativas de futuro y los pasos siguientes a dar (Beyebach, 2013). Todo ello a través de iluminar, ampliar, anclar las soluciones o atribuir el control, promover activamente la cooperación con la familia, festejar el cambio, elogiar y el uso de tareas (Neipp, s.f.).

Hipnosis ericksoniana. Milton H. Erickson creía que las personas tienen dentro de sí las capacidades naturales necesarias para superar dificultades, resolver problemas, entrar en trance y experimentar todos los fenómenos del trance, según lo describe O'Hanlon (2001).

De acuerdo a Haley (1991), la forma en que Erickson trabajaba con sus pacientes era la siguiente: a) Concepción del ser humano como una fuente de recursos y capacidades, la mayoría de ellos inconscientes. b) Tera- 
pia estratégica en el sentido de que Erickson asumía la responsabilidad de influir directamente en las personas. c) Aliento de la resistencia en el sentido de prescribir el "síntoma". d) Ofrecimiento de una alternativa peor o "ilusión de alternativas", en donde el usuario aparentemente decide sobre dos opciones que el terapeuta le propone, pero finalmente hace lo que el terapeuta planea. e) Provocar cambios a través del uso de metáforas. f) Empleo del espacio y la posición, es lo que comúnmente se le llama escenificación en la terapia estructural. g) Énfasis en lo positivo, magnificándolo y utilizándolo. h) Utilización de lo que el paciente ofrece, incluyendo el síntoma, la postura, el lenguaje, etc. i) Consideración de las etapas del ciclo vital en las metas terapéuticas. j) Evitación de la exploración del sí mismo. I) Uso de la amnesia y el control de la información.

Respecto al caso que se presenta en este trabajo, y como lo señalan Guy y Schnur (2004), y Mendoza y Capafons (2009), la hipnosis ha demostrado ser una herramienta efectiva para el trabajo clínico en problemas físicos y emocionales, lo que incluye la ansiedad.

Es así como en el presente estudio de caso se describe la intervención terapéutica en una familia cuyo motivo de consulta era eliminar la ansiedad en su hijo mayor, pero que durante el proceso terapéutico se logró abrir el conflicto que limitaba el funcionamiento familiar, apoyándonos en el enfoque centrado en soluciones y la hipnosis ericksoniana.

\section{MÉTodo}

\section{Identificación del caso}

\section{Participantes}

Se trató de un matrimonio de clase media, en ciclo vital pertinente de hijos adultos. La familia estaba compuesta por 4 integrantes: madre, de 47 años de edad, ama de casa; el padre de 48 años de edad y comerciante de autopartes; el hijo mayor varón de 20 años de edad, estudiante del tercer semestre de publicidad, además de que trabaja con su padre, y la hija menor de 14 años que estudiaba la secundaria al tiempo que cursaba una carrera técnica en comercio.

En cuanto a la estructura familiar, inicialmente se encontraron: límites rígidos, conflicto en el holón conyugal, la triangulación y centralidad negativa recaía en el hijo, conflicto en el holón fraternal, y la jerarquía la tenía el esposo.

\section{Análisis del motivo de la intervención}

La madre Ilamó a las instalaciones de INFASI para solicitar terapia debido a que su hijo mayor presentaba crisis de ansiedad, al grado de ponerse violento, y refirió que se preocupaba mucho por su padre cuando éste se encontraba fuera o bien no regresaba temprano a casa; así que solicitaba que se le ayudara a que su hijo supiera controlar esa ansiedad.

\section{Antecedentes del problema}

Entre los antecedentes del problema importantes a señalar, mencionados durante las sesiones, la madre refirió sentimientos de celos hacia el esposo cuando salía de casa y no sabía dónde se encontraba, incluso cuando estaba embarazada de su hija sentía que le hervía la sangre por esa situación y llegaba el momento en que salía a buscarlo, pero esta situación disminuyó hasta que nació su hijo. En ese tiempo ella padeció dermatitis atópica, así que, durante los primeros tres años de su hijo, el padre se había hecho cargo del cuidado del mismo.

Otra situación más que podría resultar importante para el caso fue que cuando el hijo tenía 6 años de edad, había presenciado un intento de secuestro que iba dirigido a su padre, hubo disparos de un arma de fuego, pero no había sido requerido el apoyo psicológico. Y, finalmente, la hija padecía alopecia.

\section{Descripción y análisis del problema}

Durante la segunda sesión, cuando los padres asistieron solos a terapia, la información obtenida resultó importante para el análisis del problema ya que unos días antes de esta sesión, el hijo se había alterado al grado de ponerse agresivo incluso decía que quería golpear.

Cuando le preguntaban por qué se ponía así, él solamente respondía que era el temor a que le pasara algo a su padre, culpando además a su madre porque ella era la responsable de cuidar que el esposo regresara temprano a casa. Por su parte, el esposo mencionó que no había presenciado las crisis de su hijo, sólo se lo habían platicado. Por otro lado, se comentó también que la hija sólo se refugiaba en la computadora cuando las crisis del hermano se presentaban; sin embargo, ella presentaba una sintomatología de alopecia.

Finalmente, otro dato relevante fue que el padre había notado que cuando el hijo tenía fiesta y salía, la pre- 
ocupación no se presentaba, aunque la madre reportaba que sí. También comentaron que el hijo estaba saliendo con una joven no muy del agrado de la madre, pero que no le impedía estar con ella ni hacer planes ya que había compartido con ambos padres su deseo de irse a Europa porque la novia se iría para allá.

Después de la segunda sesión se hizo la revisión del caso, encontrando seis hipótesis:

- Posiblemente cuando la madre se recuperó de la dermatitis atópica, el padre cedió en atención a su hijo y tal vez el hijo presentó crisis de ansiedad para obtener atención o cariño de éste.

- Posiblemente la esposa sentía celos y preocupación por su esposo, y al no saber cómo expresarlo, era probable que lo estuviera comunicando por medio de sus hijos, quizá con la creencia de poder controlar a su esposo.

- Probablemente el hijo no estaba de acuerdo sobre control que tenía la madre hacia el padre y una forma de comunicar su desacuerdo era por medio de las crisis de ansiedad y preocupación.

- Probablemente la periferia del padre se debía a que él no se dejaba controlar por su esposa, de esta manera se desencadenaba un conflicto conyugal.

- Posiblemente la alopecia de la hija era una forma de mostrar su desacuerdo del control que ejercía su madre en ella; aunado a esto, cabía la posibilidad de ser una manera de comunicar atención de los padres, ya que ellos estaban enfocados en la crisis de ansiedad de su hermano.

De estas hipótesis se generó una sistémica donde se presuponía que los celos y la preocupación que la esposa sentía hacía su marido los estaba comunicando por medio de sus hijos, tal vez de esta manera ella creía que podía tener algún tipo de control sobre él.

Sin embargo, era probable también que los hijos no estuvieran de acuerdo con ella y a su vez sus síntomas (crisis de ansiedad y preocupación por parte del hijo, y alopecia por parte de la hija) eran una prueba de ello. En cuanto al esposo, quizás él prolongaba sus salidas de la casa debido a los constantes reclamos que le hacían su esposa y sus hijos.

\section{Plan de intervención}

\section{Descripción del plan de intervención}

Tras la información obtenida en la primera sesión (familiar), segunda sesión (de pareja) y tercera sesión (individual, ya que sólo asistió la madre), se optó por trabajar con el autocontrol de la ansiedad de la madre a través del modelo de intervención centrado en las soluciones y la hipnosis clínica, bajo el supuesto de que la madre tiene los recursos y fortalezas necesarios para mover el cambio del sistema familiar completo.

\section{Establecimiento de los objetivos y las metas del plan de intervención}

Objetivo: Disminuir la ansiedad como problema en el funcionamiento familiar.

\section{Metas de intervención:}

a. Identificar el ciclo que en la familia llevaba la ansiedad como síntoma y como mantenimiento del funcionamiento familiar.

b. Evidenciar el problema familiar.

c. Romper ciclo del problema.

d. Establecer estrategias en la familia para alentar el cambio.

\section{Técnicas de evaluación del plan de intervención}

\section{Instrumentos}

Se utilizó el esquema de intervención de la Maestría en Hipnosis y Terapia Familiar Breve Sistémica para la Ilamada telefónica (recuperar principalmente el motivo de consulta y formar un familiograma que permitiera generar algunas hipótesis), primera sesión (dar un encuadre al modelo de trabajo, identificar recursos positivos y lados fuertes de los clientes; establecer la meta y objetivos terapéuticos), y el seguimiento de las mismas (revisión de tareas, evaluación de objetivos).

Todas las sesiones fueron videograbadas con la finalidad de dar seguimiento y poder evaluar a la familia por medio de su discurso verbal tomando en cuenta su lenguaje analógico (Beyebach, 2006).

\section{Procedimiento del trabajo terapéutico}

Se realizó una primera llamada al cliente para recabar la información general del caso (familiograma y motivo de consulta), y concretar la fecha de la primera sesión.

Ya en la primera sesión, a los asistentes a terapia se les explicaron las condiciones en las que se llevaría a cabo la terapia, siguiendo el procedimiento de la Maestría en Hipnosis y Terapia Familiar Breve Sistémica. Se mencionó que sería un trabajo de supervisión en vivo, donde estarían presentes la familia, el terapeuta, un equipo terapéutico y un supervisor del caso. Las sesiones programadas fueron 5 (correspondientes al calendario de la maestría), la duración de cada una de ellas 
fue de aproximadamente una hora, con un espacio de 15 días.

\section{Aplicación del plan de intervención}

\section{Desarrollo de las sesiones}

\section{Primera sesión:}

Asistió la familia completa, y cuando se estaba leyendo el reglamento de usuarios y autorización para grabar la sesión, el hijo mayor comenzó a mover la cabeza negativamente, mencionando que no quería el servicio terapéutico con tanta gente, entonces el equipo terapéutico y supervisora le comentaron a la familia que se dieran la oportunidad de conocer el tipo de servicio que se ofrecía, si no era de su agrado que no los tomaran. Aceptaron entonces quedarse a una plática informativa del ciclo vital de la familia.

El mensaje final fue que, si como familia decidían tomar el proceso terapéutico, no sólo nos bridan la oportunidad de trabajar en la situación que les preocupaba a ellos sino que también se daban la oportunidad de lograr cambios como familia. Al terminar la sesión, el padre mencionó que continuarían con el proceso terapéutico. Además, se pudo obtener como meta terapéutica que el hijo mayor supiera controlar su ansiedad y preocupación por su padre. Suponíamos en esta sesión que lo que podría ayudar en esta familia era recuperar sus logros y antecedentes positivos que ellos mismos se reconocen como ser una familia unida.

\section{Segunda sesión:}

Ambos padres llegaron puntuales a la sesión, refirieron que de la plática informativa de la sesión anterior habían reflexionado sobre su etapa como familia y entonces sus hijos habían decidido acudir a terapia de forma individual. Al continuar indagando sobre antecedentes del problema, la madre hizo referencia a que ella había estado presente cuando su hijo había tenido crisis de ansiedad, la cual era desencadenada cuando el padre llegaba tarde a casa, o no se reportaba si es que tenía que salir. Mencionó que ella, por su parte, comenzaba a orar y es así como notaba que el hijo se tranquilizaba.

Ambos padres ratificaron su motivo de estar en terapia para que su hijo controlara su ansiedad, y en esta sesión se les dejó claro que sí se les podría ayudar, pero como familia tendrían que hacer cambios, como por ejemplo, cuando el hijo presentara alguna crisis de ansiedad, la madre no debía estar presente (incluso debía salirse de casa). Se les mencionó también que posiblemente también tuvieran que dejarlo ir a Europa, aunque fuera por perseguir a la novia, así tal vez regresara con otra persona, pero independiente.

Como mensaje final se les comentó lo siguiente: "una familia se mueve como un sistema, lo que sucede con alguno de sus integrantes está muy relacionado con todo lo demás. En algunos momentos el hijo no se preocupa por su padre, el que quiera irse a Europa con la novia, eso quiere decir que es posible controlar sus crisis porque no siempre las tiene. Por otro lado, ustedes son una familia sabia, que saben tomar decisiones, ya tienen velatorio y tienen un lugar preparado que de cierta forma da certeza, y tranquilidad y seguridad; y por cosas como éstas están aquí como familia que dejará que su hijo adulto tome decisiones y sea autosuficiente, así como su hija adolescente empieza a tomar sus decisiones. En todas las familias hay problemas, pero con inteligencia se resuelven. Lo que nos preguntamos ahora como terapeutas es, ustedes como padres de familia qué están dispuestos a hacer para que su familia esté mejor, porque con lo que nos han comentado y la experiencia que tenemos en el trabajo clínico, creemos que su caso no es fácil pero los podemos ayudar, es más, posiblemente tengan que romper un paradigma familiar, empezando quizá por la lealtad a situaciones que no es posible seguir manteniendo de la misma forma, de la misma forma volteen hacia sus hijos, lo que les va a costar trabajo es desprenderse de sus hijos, la independencia de sus hijos no es fácil.

Su hijo quiere controlar, es válido, es necesario, el control sobre él deriva en la capacidad de independencia. Se va ir con una mujer, sí y cómo lo va hacer, no ponerle trabas y tal vez regrese con otras habilidades, se deben unir como pareja, que retomen sus salidas, el actúa como niño, qué es lo que lo limita a estudiar, hay escuela pública, si él quiere hacer algo, que lo dejen, la señora ya no haga nada por su hijo, y que no le diga nada, les va a costar trabajo, porque la señora le dice que hacer y él no le hace caso, entonces para ella es un desgaste emocional, porque ella está acomodando...Su hijo no está loco, tiene mucha energía y una manera de sacarla es preocupándose por su padre, cuando tenga otra crisis de ansiedad, sólo sálgase, déjelo a él solo".

\section{Tercera sesión A:}

No asisten a la sesión a pesar de que la señora llamó por teléfono a la terapeuta para comentarle que asistiría su hijo. 


\section{Tercera sesión B (un mes después de la segunda se-} sión):

La señora llegó sola y mencionó que su esposo no quiso asistir. Refirió sentirse liberada de un miedo crónico, mismo que le había ayudado a controlar su preocupación. Ella comentó que el hecho de que su esposo e hijo no hubieran asistido a sesión era una forma de no hacerse responsables. También dijo que las crisis de ansiedad de su hijo ya no habían aparecido; sin embargo, su hija se había salido de casa sin permiso en dos ocasiones, la primera a una colonia cerca de su casa para irse a desayunar después de salir de la iglesia y la segunda ocasión para encontrarse con su novio, aunque los padres del novio la regresaron a su casa.

En ambas ocasiones el padre se había puesto violento con su hija, así que se le cuestionó a la madre qué hacia ella mientras observaba a su esposo en esas condiciones, y ella respondió que nada, aun cuando no estaba de acuerdo en la forma de actuar. Así que se le comentó que, si bien no era la forma más adecuada de actuar de ambos padres para que la situación se calmara y no volviera a suceder, se debería de enfocar en buscar y accionar con respeto. La energía que tienen para pelearse como esposos la tendrán que ocupar para ponerse de acuerdo, y de manera firme tendría que decirle a su esposo que no apoyaba ni estaba de acuerdo por la violencia que ejerce sobre sus hijos. Se preguntó también qué hacían como padres para superar que su hija tenía más fortaleza que su hijo mayor, y qué para que la hija obedeciera o fuera capaz de enfrentar al mundo, en ambos casos se necesitaba templanza y paciencia de ella como madre.

Finalmente, se le dijo que ella era catalizadora de todas las emociones, comprendía a su esposo, a sus hijos, pero parecía que a ella nadie la comprendía, tenía que estar tranquila para responder de forma asertiva; por tanto, se le aplicó una técnica de hipnosis "Un lugar de serenidad" (de Corydon, que consiste en llevar a la persona a un lugar especial, tranquilo y seguro, centrando su atención en su respiración, en como su cuerpo se relaja y en como su cuerpo recarga baterías de sentimientos gratificantes, de tal manera que estas sugestiones permanezcan en ella y las practique en el día) con la finalidad de que la señora centrará su atención en sus emociones, en su respiración, y en consecuencia, canalizarlas de manera favorable, y se le dejó de tarea practicarla todos los días en casa, porque su familia se le va a desmoronar si sigue pensando que ella puede, advirtiendo también que lo sucedido en la sesión de hoy no lo platicara con su familia.

\section{Cuarta sesión:}

Se trabajó de manera individual con la señora. Se habló sobre la realización de la tarea (ejercicio de hipnosis) y de los beneficios obtenidos al darse cuenta que estaba más tranquila, de encontrase consigo misma, logró concentrar su atención en las oraciones matutinas que realiza, y todo ello había ayudado a que su angustia disminuyera. Comentó que de presentarse un acontecimiento como el ocurrido con su hija hace un mes, ella tomaría el tiempo para calmarse, pensar y actuar acertadamente. Refirió que las discusiones con su esposo habían disminuido, también percibía un ambiente familiar más tranquilo, dándose cuenta que si quería un cambio tenía que empezar por ella misma como el bajar su tono de vOz cuando se percibe gritando.

Entonces se le preguntó que si no tuviera estos problemas qué pasaría, qué estaría haciendo, cuál sería la diferencia de estar relajada a estar a la expectativa, a lo que ella respondió que entendía que si quería ver a su hijo manejando la ansiedad tenía que verse ella sin ansiedad. También se cuestionó y dejó como mensaje el que pensara en lo que le tocaba hacer para que su hijo no copiara su forma de actuar y de sentir, y respondía que entonces debería estar cero alterada, tono de voz bajo, incluso eso había comenzado a notar en la última vez que su hijo tuvo crisis de ansiedad, ya que ella guardó silencio y pudo pensar.

Finalmente, se trabajó con ella la técnica de hipnosis "Orquesta de sanación" (de Roberts Dilts; que consiste en una breve inducción que guía a la persona a un estado de relajación, cuyo foco de atención es en una parte del cuerpo, que sienta o se considere sano de forma que dirija la atención en cómo se extiende por todo el cuerpo, y este sentimiento podrá evocarlo posteriormente de tal manera que la sanación se expande favorable y paulatinamente, es así como se obtiene ganancias a la sanación), para continuar reforzando en canalizar de manera funcional sus emociones y que además ella ya estaba experimentando sentirse tranquila, y se le dejó de tarea que este ejercicio de relajación lo practicara todos los días además de no mencionar nada de lo sucedido en la sesión en casa, esto porque ella tendría que saber describir cómo es estar tranquila, de esta manera no sólo podría actuar de manera acertada, sino que también podrá apoyar y ayudar a su hijo si se presentará otra crisis de ansiedad. En este sentido ella era quién pondría ejemplo de cómo tranquilizarse para que las enfermedades somáticas de su familia disminuyeran paulatinamente. 


\section{Quinta sesión:}

De acuerdo con el calendario escolar, esta era la última sesión programada, tal como se había especificado a la familia desde la primera vez que asistieron. Así que consideró trabajarla en tres momentos: revisión de tareas, trabajo con hipnosis y cierre de la terapia. Cabe mencionar que, dados los resultados reportados, no fue necesario el uso de técnicas de hipnosis. Se describe a continuación el trabajo realizado.

La señora asistió puntualmente a la cita y comentó haber realizado en un promedio de 8 ocasiones el ejercicio de relajación, dándose cuenta de que mientras más relajada se sentía la actitud hacia su esposo y hacia sus hijos en momentos de conflicto cambiaba favorablemente. Y de eso se había percatado más en una ocasión en que discutió con su hija acerca de la responsabilidad, honestidad y de que no respetaba los horarios, y su esposo había intervenido a su favor para pedirle a su hija que respetara y escuchara a su madre y no tenía porque levantar el tono de voz, en señal de respeto, cuando solicitaba algo.

En cuanto a su hijo, había presentado nuevamente una crisis de ansiedad, la había llamado del cine y sólo para preguntarle si su padre ya estaba en casa, él había pedido que ella se comunicara con el padre para saber dónde estaba, y ella le respondió que no haría tal cosa y le colgó el teléfono, en la segunda llamada trató de calmar a su hijo, él le refirió que su padre ya había apagado el celular; en la tercera Ilamada escuchó a su hijo más tranquilo, y comentaba que no había seguido el juego, con esto ella se sentía tranquila y así actuó y confió, recordando lo que se había trabajado ya en la terapia. Incluso después de esa ocasión, sus hijos ya habían comentado sobre su cambio, que la veían más tranquila y más calmada.

Algo que le preocupaba en ese momento era no tenerle confianza a su hija, incluso ya había platicado con ella acerca de la sexualidad y los embarazos no deseados. Le molestaba que no le respondiera la llamada telefónica; sin embargo, ya había reconocido que era un círculo lo que sucedía: "te cacho en la mentira - no te creo - no te dejo salir - necesito salir/conocer, pero mi madre no me deja salir (negociar) - ella no me cree, por lo tanto, miento para poder salir". Se le preguntó cómo podría ella romper el círculo ya que el sistema familiar mantenía su atención en las actividades que sus hijos hacían y que de alguna manera estaban fuera de lugar, por lo tanto el hecho de cambiar o romper esto alteraría favorablemente el patrón del sistema familiar que tanto le preocupaba y que además parecía ser una constante en la forma de comunicación, todo el sistema se movía a través de situaciones como éstas y, aunque se le dejó como tarea el pensar en esta solución, también se le comentó que la edad de su hija era complicada, y al no darle permiso a su hija, ésta no crecerá ni aprenderá así que tendría que empezar a soltar, la preocupación no la llevaría a ningún lado por lo tanto tenía que ocuparse por medio del ejercicio de relajación en encontrar un punto de equilibrio en una negociación donde ella como madre sí pudiera darle permiso de acuerdo a las costumbres de la familia y a la edad de su hija.

Se anotó también que era un buen momento para trabajar esto sola donde pusiera en práctica los recursos que la tranquilidad le ha traído, con mente más clara se puede pensar más claro y mejor, evitando llegar a que su hija agravara su alopecia o ella o cualquiera de la familia desarrollará una enfermedad somática. Para finalizar la sesión, se acordó con la señora continuar el proceso terapéutico, aunque fuera del programa académico, así que se programaron dos sesiones más a las que la señora ya no asistió. En la llamada de seguimiento mencionó que seguía tranquila, había aprendido a controlar su ansiedad y estaba aún trabajando en su cambio personal.

\section{Presentación de resultados}

En la tabla 1 se muestra en resumen el trabajo realizado por sesión, las intervenciones terapéuticas realizadas, así como los objetivos programados y la evaluación de los mismos. En cuanto a los resultados alcanzados, en la tabla se puede observar el avance que se tuvo en el trabajo de la disminución de ansiedad y ante su relación con la funcionalidad familiar.

\section{Análisis de los cambios que produjo el plan de intervención}

A partir de la descripción del caso, y como ya hacía mención Yalóm (como se citó en De Castro \& García, 2011), la ansiedad puede surgir al darse cuenta de que nuestros valores y sistemas de creencia se destruyen, y quizá nos sintamos fracasados en algún proyecto, por mínimo que sea, porque la incertidumbre viene acompañando la idea de que no todo cambio es positivo. En esta familia, la etapa del ciclo vital (con hijos adolescentes) representaba también una constante para que la independencia se permitiera, pero la manifestación de la ansiedad resaltaba más como el problema a considerar.

Con lo señalado, resultó interesante el proceso terapéutico en sí mismo, ya que la madre como cliente había solicitado apoyo para su hijo (paciente); sin em- 


\begin{tabular}{|c|c|c|c|}
\hline Sesión & INTERVENCIONES TERAPÉUTICAS & Objetivos Terapéuticos & Avances Reales \\
\hline 1 & $\begin{array}{l}\text {-Complementariedad } \\
\text {-Consejo especializado }\end{array}$ & - Concretar meta terapéutica. & $\begin{array}{l}\text { - La familia decidió quedarse a la plática informativa, y } \\
\text { se mantuvo atenta a lo que se decía. } \\
\text { - Se definió meta terapéutica. } \\
\text { - Se reconocieron como una familia unida. }\end{array}$ \\
\hline II & $\begin{array}{l}\text { - Repetición del mensaje } \\
\text { - Orientaciones para la negociación } \\
\text { - Conversación para el cambio } \\
\text { - Preguntas presuposicionales } \\
\text { - Búsqueda de excepciones. }\end{array}$ & $\begin{array}{l}\text { - Identificar el ciclo que en la familia } \\
\text { llevaba la ansiedad como síntoma y como } \\
\text { mantenimiento del funcionamiento familiar. } \\
\text { - Ampliar la excepción del problema. }\end{array}$ & $\begin{array}{l}\text { - Reflexionaron sobre su etapa como familia. } \\
\text { - Los hijos decidieron asistir a terapia de forma } \\
\text { individual. } \\
\text {-Ambos padres se confrontaron sobre las excepciones } \\
\text { en que el problema no se presentaba. }\end{array}$ \\
\hline III & $\begin{array}{l}\text {-Preguntas presuposicionales } \\
\text { - Pregunta milagro } \\
\text { - Excepciones } \\
\text { - Co-crear realidades } \\
\text { - Atribución de control } \\
\text { - Técnica de hipnosis "Un lugar de } \\
\text { serenidad" } \\
\text { - Tarea }\end{array}$ & $\begin{array}{l}\text {-Evidenciar el ciclo del problema. } \\
\text { - Romper con ciclo del problema. } \\
\text { - Establecer estrategias de cambio. }\end{array}$ & $\begin{array}{l}\text { - La madre se dio cuenta que se liberó de un miedo } \\
\text { crónico y controló su preocupación. } \\
\text { - Hijo no presentó crisis de ansiedad. } \\
\text { - En la técnica de hipnosis, se logró un trance profundo } \\
\text { lo que llevó a la señora a relajarse y comenzar la } \\
\text { necesidad de buscar opciones para mantenerse en ese } \\
\text { estado. }\end{array}$ \\
\hline IV & $\begin{array}{l}\text {-Preguntas presuposicionales } \\
\text { - Co-crear realidades } \\
\text { - Anclar las soluciones } \\
\text { - Festejar el cambio } \\
\text { - Técnica de hipnosis "Orquesta de } \\
\text { sanación" } \\
\text { - Tarea } \\
\text {-Elogiar el cambio }\end{array}$ & $\begin{array}{l}\text {-Evidenciar avances. } \\
\text {-Mantener estrategias de cambio. }\end{array}$ & $\begin{array}{l}\text { - La madre realizó la tarea de ejercicios de relajación, } \\
\text { y logró darse cuenta que estaba más tranquila, } \\
\text { encontrándose consigo misma, logró concentrar su } \\
\text { atención en sus oraciones y todo ello ayudó a que la } \\
\text { angustia disminuyera } \\
\text { - La madre mencionó que se tomaría el tiempo para } \\
\text { calmarse, para pensar y así actuaría acertadamente } \\
\text { - Las discusiones entre los cónyuges disminuyeron, } \\
\text { percibiéndose un ambiente familiar más tranquilo en } \\
\text { su casa. } \\
\text { - Se dio cuenta que el cambio debía empezar por ella, } \\
\text { como bajar su tono de voz y que la percibieran sin } \\
\text { ansiedad. }\end{array}$ \\
\hline v & $\begin{array}{l}\text { - Elogiar. } \\
\text {-Atribuir el control. } \\
\text {-Promover activamente la cooperación } \\
\text { con la familia. }\end{array}$ & $\begin{array}{l}\text {-Mantener estrategias de cambio. } \\
\text { - Reforzar recursos y fortalezas personales } \\
\text { que influyen en la funcionalidad familiar. }\end{array}$ & $\begin{array}{l}\text { - La señora continuó realizando el ejercicio de relajación } \\
\text { esto a su vez se dio cuenta que sentía una actitud de } \\
\text { cambio favorable de su esposo e hijos. } \\
\text { - El esposo validó a la esposa frente a los hijos. } \\
\text { - La familia percibe a la señora más tranquila y más } \\
\text { calmada. }\end{array}$ \\
\hline
\end{tabular}

bargo, el transcurso de las sesiones fue definiendo al paciente identificado: en la primera sesión se trabajó con la familia completa, en la segunda sesión asistieron ambos padres únicamente y a partir de la tercera sesión asistió sólo la madre, quedando ella como paciente identificado. Y es que como lo mencionó Charles (2008), ante los conflictos encubiertos por la pareja, lo primero que llega a terapia es trabajar con su rol de padres para un problema prioritario de un hijo, ya que la terapia de pareja será en una segunda o tercera fase del trabajo; es decir, pudiera ser que la conducta de los niños y adolescentes de alguna manera es una metáfora de la conducta de algunos de los padres; o de la relación de los padres.
Será hasta la segunda etapa en la que se pueda entrar a los problemas de comunicación y conflictos de relación conyugal. Además, a partir del trabajo realizado en la segunda sesión, y de acuerdo a la información que proporcionaron los padres, se pudieron generar hipótesis que sirvieron de eje base para el proceso terapéutico (que era desaparecer las crisis de ansiedad en el hijo); sin embargo, también éstas se fueron modificando de acuerdo al avance de las sesiones logrando cumplir el objetivo terapéutico de disminuir la ansiedad del hijo, sólo cuando la madre se dio cuenta que podía autocontrolar la ansiedad y como resultado (y paulatinamente) desaparecerla, canalizando sus emociones de forma 
asertiva y por tanto el funcionamiento familiar también tenía cambios.

En el momento en que a ambos padres se les mencionó que sí se les podría ayudar (primera sesión), pero tendrían que hacer cambios dentro del sistema familiar para lograr control de la ansiedad de su hijo, hubo un cambio importante, ya que también habría repercusiones en la independencia de sus hijos. Como padres deberían respetar las decisiones que tomaran sus hijos, aunque ellos no estuvieran de acuerdo, de esta manera también se fortalecería la relación de pareja. Y esto sucedió porque la esposa de alguna manera insistía en que sus hijos se preocupaban tanto por su padre, al grado de que ella notaba como reprimían sus emociones, y así ella parecía forzar a que su esposo se diera cuenta del daño; sin embargo, asumimos la hipótesis de que dicha preocupación era de ella, de su sistema de creencias y valores, y no de los hijos.

Específicamente sobre las sesiones se identificaron los siguientes resultados: En la primera sesión, como un

"La ansiedad se
convierte en un ciclo
de comunicación y en
un estilo de vida"
consejo especializado, el tema central fue el ciclo vital de la familia; en este sentido se logró alianza terapéutica con la familia donde sólo se habló de las diferentes etapas y responsabilidades de cada holón individual, es así como la familia pudo darse cuenta que las interacciones y dinámica de la misma deben encaminarse a la funcionalidad.

Para la segunda sesión, donde asistieron sólo los padres, el proceso terapéutico se enfocó indagando sobre las premisas de la terapia centrada en soluciones; la idea de que posiblemente los celos y preocupación por el esposo, al no saber cómo expresarlo, es probable que lo esté comunicando por medio de sus hijos, tal vez de esta manera ella cree que puede controlar a su esposo. En este sentido, los esposos se dieron cuenta que deberían ponerse de acuerdo y retomar su relación de pareja, con la intención de que la comunicación entre ambos era vital para el funcionamiento familiar de acuerdo a la etapa en la que estaba viviendo entre cambios e incertidumbres.

En la tercera sesión, la hipnosis ericksoniana fue de gran apoyo ya que se normalizó una situación problemática que parecía de deserción del esposo a la terapia, y se brindó una oportunidad para que la madre-esposa-mujer aprendiera y reaprendiera a tomar decisiones de manera tranquila en su familia, si ella lograba eso, la familia cambiaría también. Ante este trabajo, los cambios reportados por la señora sobre el miedo controlado y la tranquilidad que se siente al soltar lo que no le pertenece se hicieron evidentes.

Para la cuarta sesión, los recursos personales y la fortaleza de la señora se volvían visibles para todos, ya que podía concentrar su atención en sus oraciones, mencionó sentirse más tranquila y darse cuenta que durante el ejercicio de hipnosis podía estar consigo misma, refirió también que los cambios que estaba logrando le ayudarían en la toma de decisiones acertadas como pensar y actuar de manera tranquila ante las crisis de ansiedad del hijo y las de ella misma.

En la quinta sesión la señora reportó cambios claros, dándose cuenta de que su cuerpo estaba tranquilo porque se sabía más calmada, más relajada, más confiada, hacia conciencia antes de actuar y prueba de ello fue cuando su hijo tuvo una crisis de ansiedad y ella le colgó el teléfono rompiendo con el patrón de elevar el nivel de ansiedad, en este sentido ella no se conectaba con la ansiedad de él, de esta manera ella se daba cuenta que su hijo también estaba logrando dismi-

nuir su ansiedad y preocupación por su padre.

Finalmente, si bien el funcionamiento familiar podría tener más cambios hablando terapéuticamente, en la llamada de seguimiento, la señora reportaba el mantenerse tranquila y su familia también tomando ya decisiones con sus hijos adolescentes. Lo cual implicó que, con las intervenciones trabajadas, se logró poner a flote los recursos personales y familiares.

\section{CONCLUSIONES}

En este estudio de caso sobre la ansiedad y su relación con el funcionamiento familiar, se manifiesta la idea de que las personas ya disponen de habilidades y recursos que pueden usar para resolver sus problemas, y que con herramientas como intervenciones desde el modelo centrado en soluciones y de hipnosis clínica, el trabajo individual, que a su vez gira en torno a un cambio pequeño, sólo se moviliza a los clientes a encontrar o buscar sus propias soluciones de manera más efectiva.

En el trabajo se destacó pensar que la ansiedad es parte de la cotidianidad, siempre que sea en nivel moderado y que permita ser funcional en las actividades al individuo y a la familia; sin embargo, en ocasiones parece indicar que ésta fue aprendida y que funciona como un ciclo en la comunicación, es más, puede ser ya un estilo de vida y que llega un momento en que no a todo el sistema le conviene mantenerse en este patrón y busca 
salirse, provocando incluso quiebre en otros miembros del sistema y por lo tanto un cambio.

En el caso, la familia se había percatado que la ansiedad del hijo no estaba siendo canalizada de la mejor manera posible, al grado de causar incomodidad sobre todo en la interacción familiar, es así como decidieron acudir a terapia psicológica, pero enfocando la atención en el hijo mayor; sin embargo, el trabajo terapéutico se centró en la madre y en las interacciones familiares, cuya característica fundamental fue el enfoque que se le dio a las conversaciones donde el contenido varió dependiendo de los acontecimientos de la paciente, aunado a ello se fueron ampliando los cambios que reportó, y que en muchas ocasiones no se había percatado que sucedieron, por eso es que hubo la necesidad de enfatizar a que continuara realizando aquello que la hacía sentir bien.

Resultan interesantes los cambios que fueron reportados por la señora, ya que al inicio del proceso la familia rechazó el servicio terapéutico, en este sentido ella se dio la oportunidad de crecer para su bienestar, sin duda alguna que asistió puntualmente a las sesiones pensando en beneficio de su familia, los cambios que reportó fueron su herramienta para comunicarle a su familia que era posible controlar y reducir la ansiedad.

Cabe mencionar que el modelo centrado en soluciones y la hipnosis ericksoniana, usados como estrategias de intervención, dieron la pauta para negociar un problema resoluble y en este sentido, los pacientes se tranquilizan ya que tienen la certeza que abordarán sus problemas de una manera eficiente fortalecidos en sus recursos y potencialidades personales. Es por ello entonces que se recomienda ampliamente ambas formas de trabajo, por su nobleza en profundizar en cualidades e ideas positivas de solución que trae el paciente a consulta.

\section{Referencias}

Alchaer, J. R.; Bahsas, F.; Hernández, N. \& Salinas, P. J. (1994). Relación entre el funcionalismo familiar, el estrés y la ansiedad. Med-ULA, Revista de la Facultad de Medicina, Universidad de Los Andes, 3(3-4), 81-88. Recuperado de erevistas.saber.ula.ve/index.php/medula/article/ view/5611

Beyebach, M. (2006). 24 ideas para una psicoterapia breve. Barcelona: Herder.

Beyebach, M. (2013). La terapia familiar breve centrada en soluciones. Manuscrito del 2013, no publicado. El texto aparecerá en (Alicia Moreno, ed.), Modelos de Terapia Familiar. Universidad Pontificia de Comillas. Recuperado de http://psyciencia.psyciencia.netdna-cdn.com/wpcontent/uploads/2013/12/El-modelo-de-la-TerapiaFamiliar-Centrada-en-Soluciones-.pdf
Charles, R. (2008). Terapia breve sistémica en soluciones para parejas y padres. Esquemas, guías y ejemplos para una práctica exitosa. México: CREE-SER.

De Castro, A. \& García, G. (2011). Psicología Clínica. Fundamentos Existenciales. Ediciones Uninorte.

Fuentes, M.L. (16 de julio de 2013). Salud mental: una agenda invisible. Periódico Excélsior. Recuperado de http://www. excelsior.com.mx/nacional/2013/07/16/909049

Goldman, H. (2001). Psiquiatría general. México: Manual Moderno.

Guy, Montgomery. \& Schnur, J. (2004). Eficacia y aplicación de la hipnosis clínica. Papeles del Psicólogo, 89. Recuperado de http://www.papelesdelpsicologo.es/vernumero. asp?id=1180

Haley, J. (1991). Terapia no convencional. Buenos Aires: Amorrortu.

Isaacs, A. (2000). Enfermería de salud mental y psiquiátrica (2a ed.). Madrid: McGraw-Hill/Interamericana de España.

Méndez, L.; Giraldo, O.; Aguirre-Acevedo, D. \& Lopera, F. (2010). Relación entre ansiedad, depresión, estrés y sobrecarga en cuidadores familiares de personas con demencia tipo alzheimer por mutación e280a en presenilina 1. Revista Chilena de Neuropsicología, 5(2), 137-145. Recuperado de www.redalyc.org/articulo.oa?id=179314915007

Mendoza, M. E. \& Capafons, A. (2009). Eficacia de la hipnosis clínica: resumen de su evidencia empírica. Papeles del psicólogo, 30(2), 98-116. Recuperado de http://dialnet. unirioja.es/servlet/articulo?codigo $=3002275$

Moreno, A. (2013).). Modelos de Terapia Familiar. Manuscrito no publicado. El texto aparecerá en Alicia Moreno (Ed.). Universidad Pontificia de Comillas. Recuperado de http:// psyciencia.psyciencia.netdna-cdn.com/wp-content/ uploads/2013/12/El-modelo-de-la-Terapia-FamiliarCentrada-en-Soluciones-.pdf

Neipp, M. C. (s.f.). Introducción a la terapia breve centrada en soluciones. Presentación. Recuperada de http://umh1365. edu.umh.es/wp-content/uploads/sites/95/2013/02/ TCSFinal2013.pdf

O'Hanlon, B. (2001). Desarrollar Posibilidades, un itinerario por la obra de uno de los fundadores de la terapia breve. España: Paidós.

O ' Hanlon, W. \& Weiner-Davis, M. (2010). En busca de soluciones, un nuevo enfoque de psicoterapia. España: Paidós.

Quintana, A. \& Sotil, A. (2014). Influencia del clima familiar y estrés del padre de familia en la salud mental de los niños. Revista de Investigación en Psicología, Norteamérica, 3(2). Recuperado de <http://revistasinvestigacion.unmsm.edu. pe/index.php/psico/article/view/4990/4054>

Rosário, P; Núñez, J. C.; Salgado, A.; González-Pineda, J. A.; Valle, A; Joly, C. \& Bernardo, A. (2008). Ansiedad ante los exámenes: relación con variables personales y familiares. Psicothema, 20(4), 563-570. Recuperado de http://www. psicothema.com/pdf/3523.pdf

Salazar, Y.; Veytia, M.; Márquez, O. \& Huitrón, G. (2013). Relación entre satisfacción con el ambiente familiar y depresión en adolescentes. Psicología y Salud, 23(1), 141 148. Recuperado de http://revistas.uv.mx/index.php/ psicysalud/article/view/524

Soria, R.; Ávila, E. \& Rodríguez, N. (2014). Efectos del trabajo 
académico en la salud y en las relaciones familiares de hombres y mujeres estudiantes universitarios. Revista Electrónica de Psicología Iztacala, 17(1), 150-164. Recuperado de http://www.iztacala.unam.mx/carreras/ psicologia/psiclin/vol17num1/Vol17No1Art8.pdf
Zavala, M. R.; Ríos, M. C.; García, G. \& Rodríguez, C. P. (2009). Funcionalidad familiar y ansiedad en pacientes adultos con enfermedad crónica. Chía, Colombia, 9(3), 257-270. Recuperado de www.redalyc.org/pdf/741/74112147006. pdf 


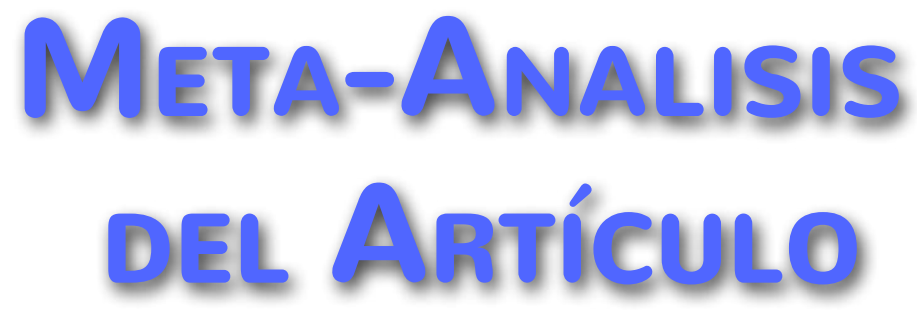




\section{Dimensión Cuantitativa}

\section{Perfil de Evaluación entre pares}
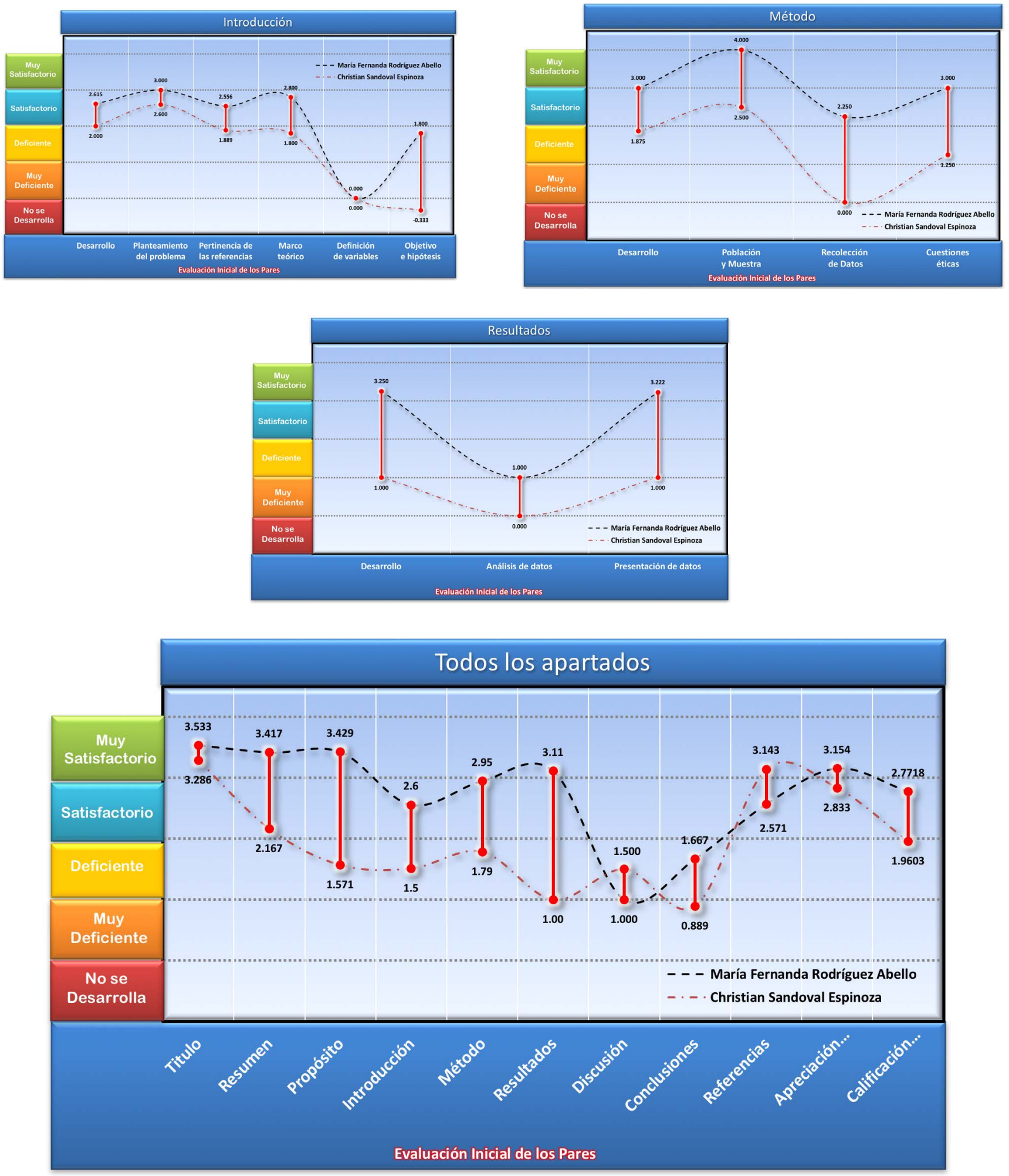

$\min \rightarrow \infty$ 


\section{Índice de Concordancia}

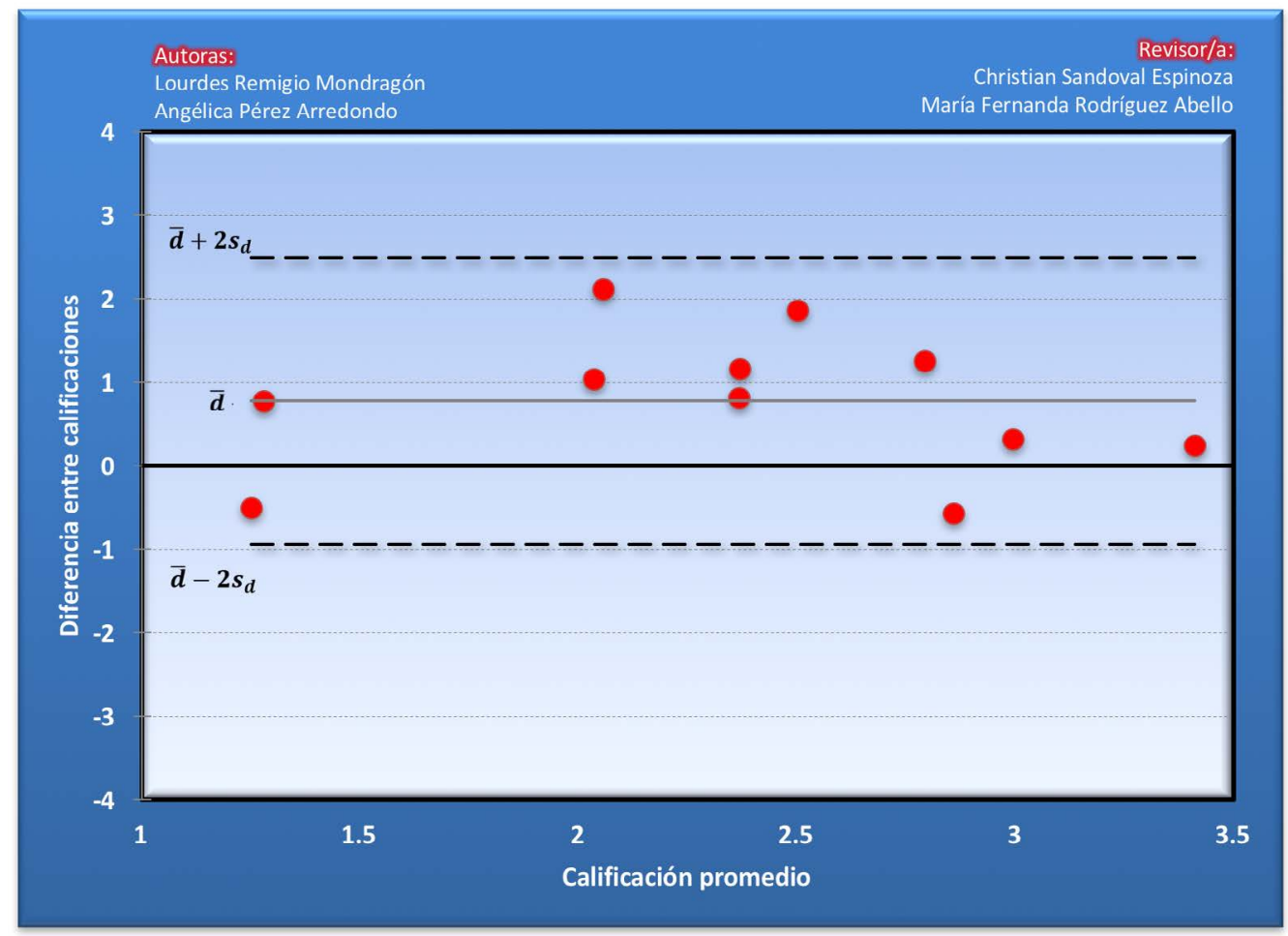

\section{Índice de Acuerdo}

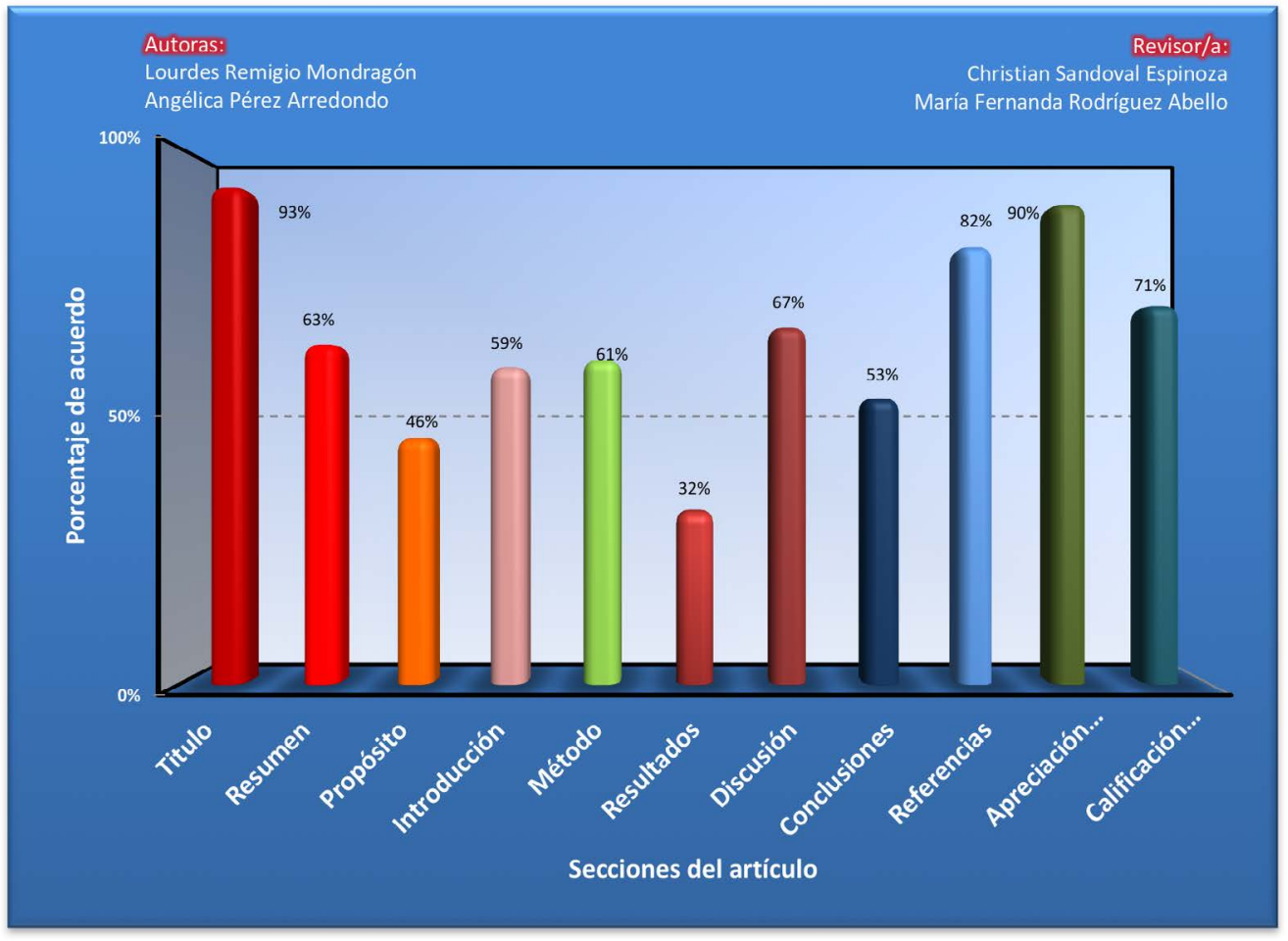

MUNAD 


\begin{tabular}{|c|c|}
\hline ReVISOR 1 & ReVISOR 2 \\
\hline Christian Sandoval Espinosa & María Fernanda Rodríguez Abello \\
\hline \multicolumn{2}{|c|}{ Título/Autoría } \\
\hline $\begin{array}{l}\text { No posee el formato que marca el APA respecto a la } \\
\text { presentación del artículo }\end{array}$ & $\begin{array}{l}\text { El artículo tiene como objetivo revisar el impacto } \\
\text { de la terapia sobre los niveles de ansiedad que ex- } \\
\text { perimenta una familia, por lo que el título no es el } \\
\text { coherente, no van a revisar la relación entre funcio- } \\
\text { namiento familiar y ansiedad }\end{array}$ \\
\hline
\end{tabular}

\section{Resumen}

Es necesario revisar la redacción general del resu-

El resumen contiene muchos problemas de mecanografía y/u ortografía men y reemplazar palabras como mamá y papá por madre y padre. La traducción a inglés es muy deficiente

\section{Próposito del Estudio}

El propósito carece de rigurosidad y congruencia con el método y sobre todo con el tipo de hipótesis planteadas
Definen varios propósitos en el artículo ya que según el título se va a revisar la relación entre funcionamiento familiar y ansiedad, en el resumen el objetivo es ver de qué manera la terapia ayuda a disminuir los niveles de ansiedad en una familia y en el marco teórico dicen qu la hipótesis de la que parten es que la ansiedad es heredada

\section{INTRODUCCIÓN}

En el marco teórico no se trabaja el modelo de hipnosis eriksoniana, el cual se empleó en casi el 50\% del caso y el tipo de hipótesis son epitemológicamente incompatibles con la visión sistémica, dado que son lineales y no recursivas o circulare
Revisar el uso de las normas APA para las citas textuales. Cuando se usan siglas como APGAR la primera vez debe escribirse el nombre completo y luego entre paréntesis la sigla. Mencionar de otra manera "los del estrato socioeconómico laboral obrero, los obesos". Revisar la redacción general, sobre todo en el título "intervención terapéutica" esa sección está desconectada del artículo ya que habla de la terapia por desde diferentes enfoques, habría que enfocarla a soluciones e hipnosis y conectarla con el tema de ansiedad, además de buscar investigaciones al respecto 


\section{MÉTOdo}

El mismo artículo posee rubros adicionales que no fueron desarrollados, se ha referencia a técnicas que nunca se explican o describen, y se cometió una falta de ética importante, se dio de "alta" el caso porque terminó el semestre, lo cual denota poco interés por el cliente y su proceso, lo que consideraron fue el tiempo cronológico
Revisar la redacción, utilizar iniciales hace la lectura complicada, es mejor usar seudónimos o nombres falsos y hacer la aclaración de que los nombres fueron cambiados. Se explica sesión a sesión lo que sucede con la familia, es importante hace énfasis, más que en la información que se obtuvo (eso va en los resultados) en la manera en que se intervino, cuales fueron los métodos utilizados, aunque para definir esto es importante definir primero la orientación del artículo, cual es el objetivo del mismo. Menciona que las sesiones fueron videograbadas lo que es un dato importante para la recolección de información, pero no menciona si este fue el instrumento que se utilizó o fue otro y luego que procedimiento se utilizó para organizar la información (se transcribieron las sesiones, se tomaron notas de ellas...)

\section{Resultados}

Se introdujo mucho la subjetividad de la terapeuta, no se citaron los resultados obtenidos a partir de las preguntas de escala y los demás miembros de la familia (esposo y hijos) tampoco reportaron mejoría, dado como resultado conclusiones dudosas. Además, no se recuperan las hipótesis como parte del cierre
Teóricamente hablando es importante tener cuidado con varias cosas: hay varias hipótesis enunciadas las cuales están desconectadas una de la otra, según mencionan en el artículo que fueron las que se elaboraron la primera sesión y para efectos del artículo es mejor mencionar cual de ellas fue la que orientó el caso o elaborar una hipótesis sistémica que conecte todos los puntos; la tabla que presentan resulta útil para resumir cada sesión, sin embargo hay cosas importantes para señalar: en objetivos de la sesión 1 aparecen "lados fuertes" lo cual es una técnica, no puede ser el objetivo utilizar una técnica en esa sesión, mas bien la técnica tiene un objetivo, la misma situación se presenta para preguntas presuposicionales, pregunta del milagro, por lo que es necesario revisarlo. Lo interesante para presentar como resultado podría ser presentar el efecto que tuvo el uso de cierta técnica, de cierta intervención en los consultantes, por lo que habría que encontrar la conexión, pero, insisto, es necesario antes definir cual es el objetivo del artículo. Revisar APA para la presentación de figuras y tablas 


\section{Dimensión Cualitativa}

\section{Discusión}

La discusión es muy breve, tanto que no da pie para la reflexión o un meta discurso basado en lo reportado en cada cédula de sesión
No hay un análisis de resultados ni una relación de estos con la teoría o con otros artículos escritos referentes al tema

\section{Conclusiones}

Las conclusiones están disgregadas del marco teórico y el desarrollo o método.
Es importante mencionar posibles campos de investigación futuras en las conclusiones y también tener cuidado con el uso de palabras como "comprobar" ya que en este caso resultan antiparadigmáticasdos

\section{RefERENCIAS}

Agregar mas referencias de no más de 8 años de antigüedad.
Es importante fortalecer más la cantidad y actualizar los documentos revisados. Es importante atender los criterios APA. 


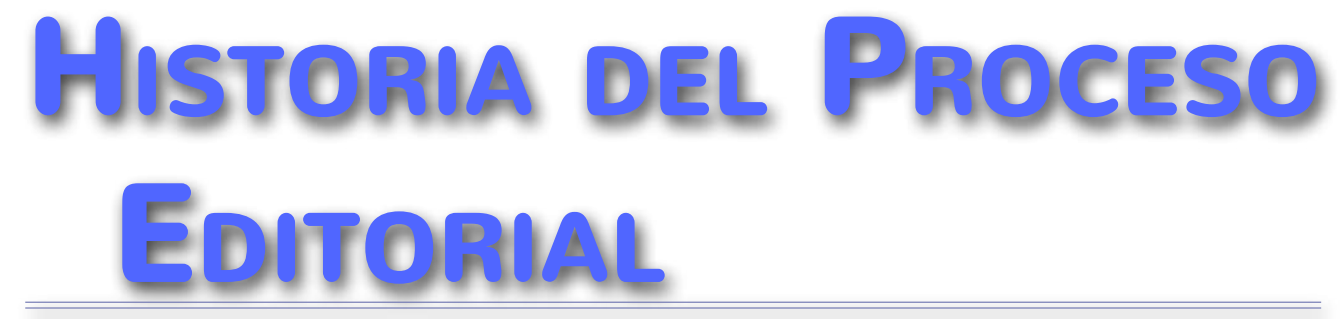


Sección

\section{Reseña de Libros}




\section{Reseña del Libro}

http://dx.doi.org/10.22402/j.rdipycs.unam.1.2.2015.25.285-290

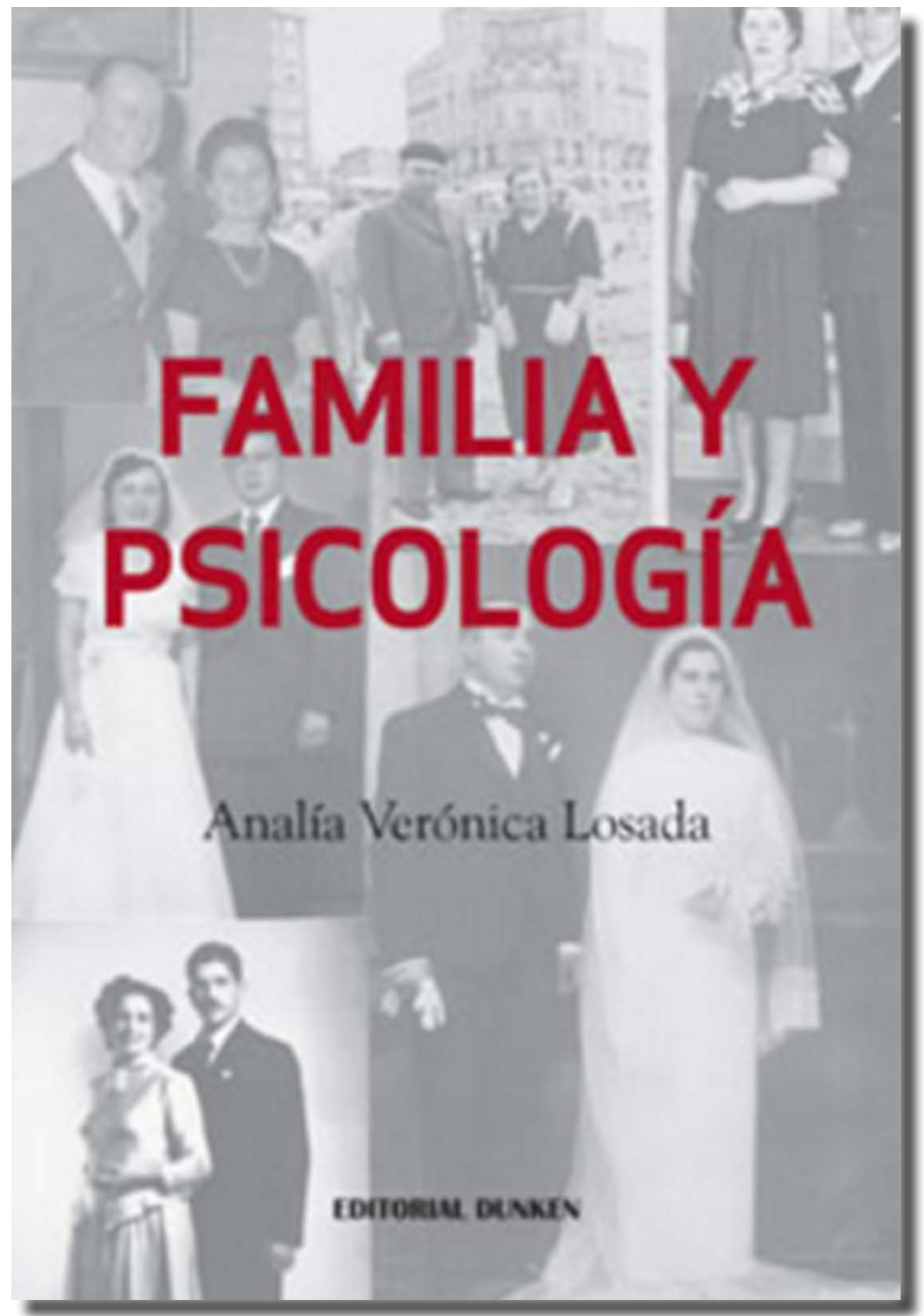

MWAM 


\section{Analía Verónica losada}
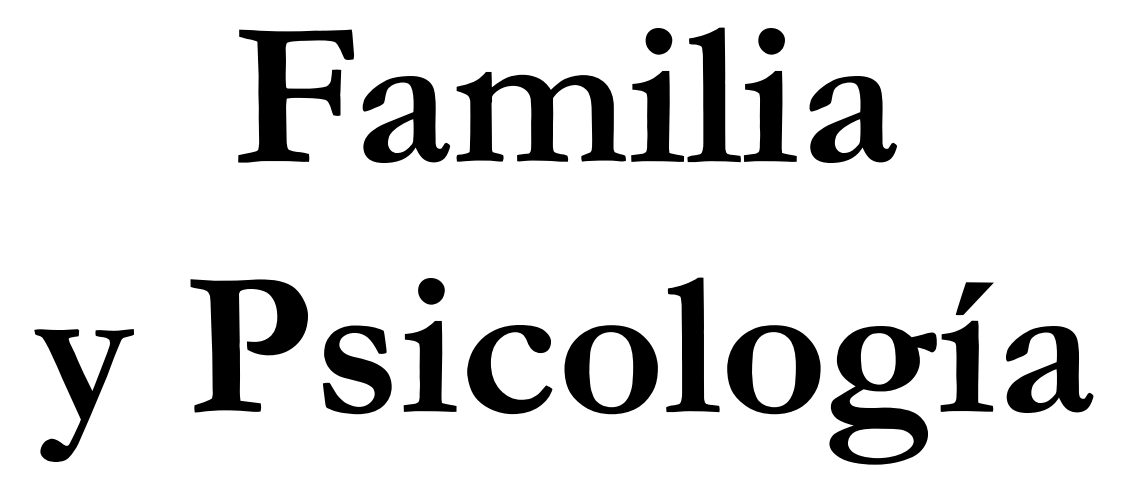

Hecho el depósito que prevé la ley 11.723

Impreso en la Argentina

(C) 2015 Analía Verónica Losada

e-mail: analia_losada@yahoo.com.ar

ISBN 978-987-02-8162-7

\section{EDITORIAL DUNKEN}

Buenos Aires

2015

MUNलDA 


\section{Reseña del libro por}

\section{Nélida Padilla-Gámez}

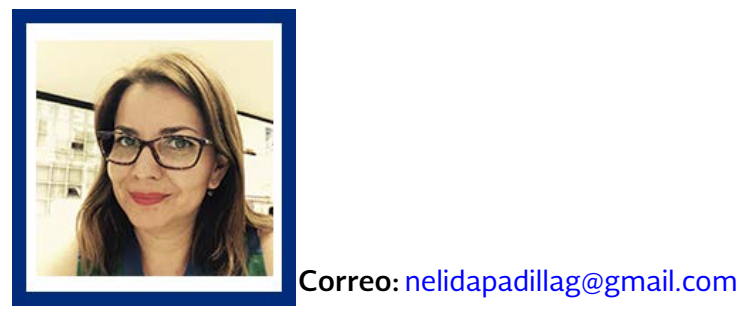

Estudió la Licenciatura y el Doctorado en Psicología en la Facultad de Psicología de la UNAM. Realizó sus estudios de maestría en la Facultad de Estudios Superiores Iztacala donde se tituló de Maestra en Psicología en la Residencia de Terapia Familiar Sistémica.

Ver más... 
$\mathrm{E}$ presente libro está estructurado en catorce capítulos que versan sobre las diferentes problemáticas que atañen a las familias, principalmente enmarcados en el contexto de la sociedad argentina, no obstante, dificultades que atraviesan a las familias en todo el mundo.

La autora hace una amplia reflexión de las distintas problemáticas desde diferentes ángulos con un agudo punto de vista que profundiza la diversidad de entramados familiares desde una mirada sistémica.

Este libro está conformado por diferentes temáticas que abordan. Los dos primeros capítulos versan sobre la importancia de la familia en la psicología de hoy, así como las diversas configuraciones, problemáticas y situaciones que experimentan hoy en día las familias, en estos capítulos el lector podrá encontrar un breve, pero no por ello superficial esbozo de varias definiciones de autores clásicos y contemporáneos que refieren a la complejidad de este entramado interaccional, en sus diversas problemáticas actuales, sociales, culturales, etc.

Nos invita a reflexionar sobre los cambios culturales y las nuevas formas de organización familiar: dinámicos, constantes, analógicamente como un reloj: en donde unos cambios se dan lentos como la manecilla que marca la hora, y otros en cambio se dan al ritmo del segundero.

Por su parte, la autora retoma un aspecto a tomar en cuenta que es la organización familiar, esta se describe en el tercer capítulo titulado: "Estructura y proceso. Sistemas y Subsistemas".

Desde el prefacio, la autora aborda las diversas configuraciones afectivas que hoy conocemos como familia, tocando sensiblemente el tema de las familias reconstruidas, familias homoparentales, las conformadas por dos miembros o las que tienen una mamá o un papá. Losada parte de la definición que propone Minuchin (1983) en donde distingue a "la familia normal" de la anormal, acotando que no se puede hablar de normalidad por la ausencia de problemas, pues estos justo hablan de la oportunidad que tienen los sistemas familiares al cambio y adaptación a las necesidades de sus miembros, de tal forma que el tema de lo saludable se convierte en adaptabilidad a los cambios y a cómo las familias abordan y resuelven sus problemáticas.
En un intento por definir a la complejidad de la familia, la autora hace una revisión de algunas descripciones de la familia; vista como un grupo social primario, en donde se pueden conjugar varias generaciones en lazos de parentesco y una experiencia de intimidad que se hace profunda y significativa a través del tiempo (Gimeneo, 2003). Por su parte, Brandam y Sandro (2010) conciben a la familia como un sistema abierto conformado por un grupo complejo de sujetos en permanente evolución, que comprende miembros en distintas fases de crecimiento, mismos que desempeñan ciertos roles y funciones que buscan contribuir con el logro progresivo de la identidad, sentido de valía personal y profesional, cuidado, organización y desarrollo de sus integrantes. Este apartado concluye en la heterogeneidad y plasticidad familiar como constructos en desarrollo ante la premura de consentir y consolidar familias de hoy, no de ayer, ni de mañana.

Posteriormente, citando a Minuchin (1983) quien propone entender la dinámica familiar como una estructura que se conforma de relaciones familiares que organizan y determinan los modos de interacción entre los diferentes miembros de las familias; describe en qué consiste cada subsistema en la estructura familiar, no obstante realiza una detallada explicación del subsistema fraterno, tema que poco se menciona en el trabajo con familias; en este sentido, la autora describe las interrelaciones y los efectos de éstas en los vínculos entre hermanos, tan importantes como el primer laboratorio social en donde los niños se relacionan con iguales, en un intercambio de mutuo aprendizaje, en el cual los hermanos se apoyan, aprenden a lograr amigos y aliados, a negociar, cooperar, compartir, y a lograr reconocimientos por sus habilidades. Las acciones de los padres, determinarán en gran medida como se establecerán las vinculaciones fraternas. Es un apartado digno de revisar con detenimiento, pues se analizan los efectos del orden, cercanía o lejanía respecto a los padres, así también cuando son hermanos gemelos o cuates, o embarazos múltiples, en este caso, si se promueve el proceso de diferenciación o no, individuación o comparación entre ellos.

La autora representa estas configuraciones a través de un cuadro comparativo en donde explica, los grados de identificación, sus procesos así como el tipo de relación resultante, es un excelente apoyo para entender las dinámicas familiares, además de los posibles efectos tanto en la conformación de la identidad, así como en sus relaciones interpersonales. Destaca la importancia de la lealtad en las relaciones fraternas pues de esta identificación y sentimientos entre hermanos, se generarán las subsecuentes relaciones sociales. La autora sugiere 
que lo saludable en este subsistema es la cooperación mutua y las construcciones de sentimientos relativos a compartir.

A su vez, se plantea clara y contundentemente el acontecer actual respecto al auge de los embarazos "múltiples" o gemelares, dados los avances científicos en este rubro. Describe los procesos biológicos así como los que se gestan a nivel emocional y de vinculación.

Por otra parte, dentro de las dinámicas familiares observamos que un ingrediente substancial para el desarrollo y supervivencia es la comunicación, para explicar esto la autora hace una revisión general de la Teoría de la Comunicación Humana que formularon Watzlawick, Beavin y Jackson (2002) a través de cinco axiomas: la imposibilidad de no comunicar, los niveles de contenido y relación de la comunicación, la puntuación de la secuencia de hechos, la comunicación analógica y digital y las interacciones simétricas y complementarias. En este sentido se torna muy importante analizar los postulados de dicha teoría en el trabajo con las familias, puesto que la comunicación es la pauta que conecta todas las interacciones del entramado familiar, tanto en la comunicación analógica, como en la comunicación digital, es decir lo que se dice, y cómo se dice, así como lo que no se dice y por qué no se dice. A pesar de ser una teoría compleja de analizar, la revisión que hace la autora nos traduce de una manera clara y sencilla dichos postulados.

Más adelante, en un capitulo breve describe los mitos, ritos y mandatos familiares, es decir las narrativas dominantes en la dinámica y funcionamiento familiar. La importancia de este capítulo radica en la identificación de dichas narrativas, a través de mitos que toman forma en temas como: la alimentación, la separación, la pérdida, el abandono, las problemáticas no resueltas, y la privación, que dibujan las siluetas de las familias y sus integrantes, determinando así, en formas de mandatos o premisas familiares las dinámicas de interacción de sus miembros, sus obstáculos, recursos, su funcionalidad, o su rigidez hacia el cambio; el cuestionamiento y trabajo a través del discurso narrativo de estas premisas permite a las familias y sus integrantes incorporar nuevas formas de pensarse, de contarse historias de sí mismos así como de flexibilizarse hacia el cambio.

El cambio es uno de los temas cruciales en las familias y parejas, el cual se verá reflejado a través de ciclos de vida, tanto a nivel individual, como en etapas que viven las parejas y las familias, por diversas circunstancias como la edad, tiempos de relación, llegada de los hijos, etc. El curso de la vida en general. En este libro también se retoma la importante tarea de reconocer los ciclos vitales en la familia, describiendo desde la mirada estratégica de Haley (1989) las etapas y los retos correspondientes a cada una, desde el inicio de la vida en pareja hasta el cierre del ciclo vital familiar. Qué sucede cuando la pareja decide iniciar un proyecto de vida en común, cuando llegan los hijos, cuando crecen y son adolescentes, cuando se casan y se van o cuando alguno de los cónyuges muere; la descripción va en torno de lo esperado en cada etapa, con un ritmo y una secuencia determinada; sin embargo, los problemas surgen cuando alguna de estas etapas se superpone a la otra, o se conjuga con otra situación del contexto, aquí es cuando el estudioso de la familia, debe ser sensible al analizar el todo y cada una de las partes en la danza familiar.

Con base en lo anterior, se plantea el siguiente capítulo que va muy de la mano con los retos y el cambio en las familias titulado: familia y crisis. Las crisis definidas como peligro y oportunidad, promueven una postura menos catastrófica del término, pues se concibe como una forma distinta de transitar en el camino del crecimiento y desarrollo de la familia.

Se sostiene que no debe evitársele, sin las crisis es difícil cambiar, como así también el cambiar puede acompañarse de una crisis. Estas son los indicadores de que algo en la familia no anda del todo bien, son las alarmas del malestar, y sin malestar nada cambia, se permanece inmóvil; la identificación específica de la tensión es un requisito sine qua non para la resolución de las crisis familiares. En resumen, sin crisis no hay desarrollo, el desarrollo mismo requiere de crisis. Muy atinadamente, la autora hace una descripción de las diversas formas de crisis, entre ellas menciona: las accidentales, denominadas por Pittman (1990) como aquellas desgracias inesperadas; las crisis vitales, derivadas del desarrollo correspondientes a la transición de una etapa a otra; las crisis estructurales que tienen que ver con la estructura familiar, el orden, las jerarquías, los límites, etc.; finalmente las crisis de cuidado, que refieren a aquéllas crisis derivadas de la necesidad de asistencia y cuidado de algún integrante de la familia. La descripción de estas crisis se describe claramente en un cuadro comparativo entre tipos de tensión y las crisis producidas.

De tal forma, salvaguardar estas crisis es a través de las funciones protectoras de la familia, que es el siguiente capítulo de este libro, definidas como: aquéllas características personales, elementos del ambiente o la calidad del vínculo del apego, que posibilitan mitigar el riesgo de consecuencias adversas en situaciones desfavorables (Di Bartolo, 2003). Es la capa protectora que permite reducir y disminuir determinados daños, e incluso evitarlos, entre ellos se mencionan: la competencia, asertividad y habilidad. 
Desafortunadamente las crisis son inevitables en el contexto familiar y de pareja, como ya se ha mencionado son la oportunidad para el cambio y la adaptación del sistema, no obstante una de las crisis que más dolores, conflictos, decepciones, y confusiones crea a los miembros de la familia es la separación y el divorcio. En este capítulo se abordan los efectos del divorcio tanto en los hijos como en la pareja, ejemplificando con un caso atendido en el consultorio y cómo se fue destrabando la complejidad del evento, en donde un hijo es triangulado por el padre y su amante, en coalición con la madre. Las presiones que se ejercen desde el exterior las instituciones, la familia extensa; hasta lo interno, la desestructuración en los afectos de los hijos adentrándolos en un conflicto de lealtades. Este capítulo describe a profundidad los efectos de lo que Linares (2011) ha definido como las Prácticas Alienadoras Familiares, así como el papel crucial del terapeuta en desentramar estas complejas dinámicas en las que se enredan las parejas en los procesos de separación.

Por otra parte, en este libro se retoma la teoría de Bowlby (1951) en donde se plantea la importancia de la cercanía, el afecto, la protección y el contacto físico de los cuidadores primarios en el sano desarrollo de los niños. Se describen los estilos parentales que tienen la función de educar, influir, y orientar a sus hijos para que puedan constituirse en relaciones sociales, en este sentido, cita los estilos parentales propuestos por Baumrind (1973) como los estilos y estrategias que utilizan los padres en la crianza de sus hijos, entre ellos se encuentran: el estilo autoritario, el democrático, el permisivo, terminando con el estilo negligente o indiferente. De lo anterior se concluye la importancia del estilo parental en el funcionamiento familiar así como en la calidad del mismo.
En contraparte con los factores protectores y de resiliencia, se encuentra un tema por desgracia frecuente en muchas familias, la violencia. En este apartado hace una reflexión profunda y extensa sobre las características, curso y evolución en los sistemas familiares, es necesario detenerse a reflexionar lo vertido en este capítulo en conjunto con el final en donde rescata que a pesar de las multiproblemáticas que pueden presentar algunas familias, siempre se encontrarán factores autoprotectores también conocidos como resiliencia.

Como puede observarse, en este breve recorrido a través de Familia y Psicología la familia tiene un papel crucial en el desarrollo, evolución y adaptación de sus miembros, tanto al interior como al exterior, dentro de un contexto social inmediato e interpersonal. En términos generales el libro aborda las problemáticas y temas centrales que todo estudioso de la psicología de la familia debe tener en sus acervos, con una lectura fluida, sencilla, tersa, Losada nos va adentrando en las dinámicas familiares, profundizando en ciertas temáticas trascendentales que se presentan a lo largo del ciclo vital de las familias, como la oportunidad de adaptación y evolución de la misma.

Es un libro que puede recomendarse a estudiantes de licenciatura, sin embargo es una excelente herramienta para los inicios de los posgrados en terapia familiar así como en los posgrados sobre estudios de la familia, evidentemente también puede formar parte de la bibliografía básica para académicos así como para terapeutas o profesionistas de la salud familiar.

Ir a Google Books para revisar la tabla de contenido del libro 


\section{Reseña del Libro}

http://dx.doi.org/10.22402/j.rdipycs.unam.1.2.2015.26.291-295

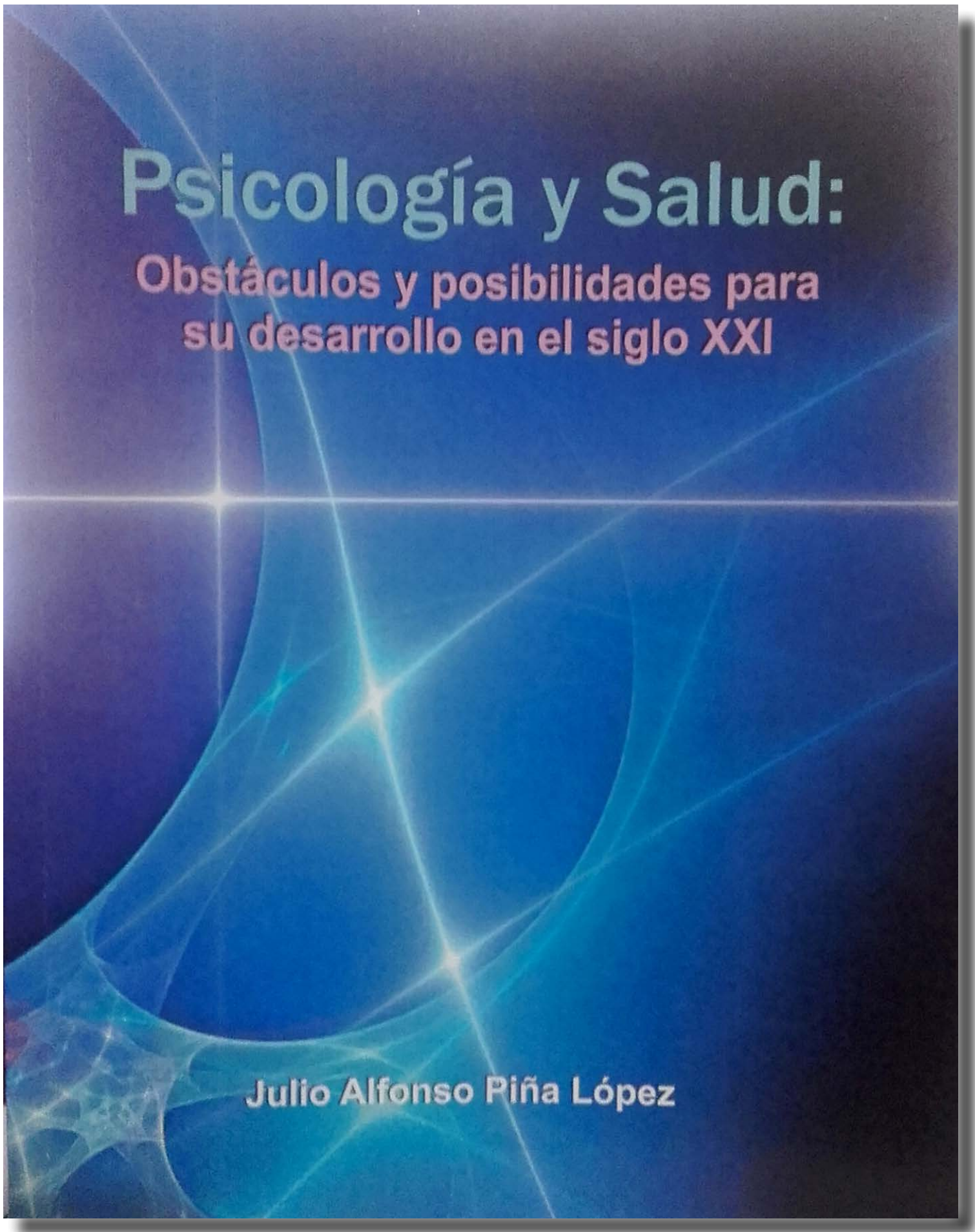




\section{Julio Alfonso Piña López}

Psicología y Salud 


\section{Reseña del libro por}

\section{Sandra Ivonne Muñoz Maldonado}

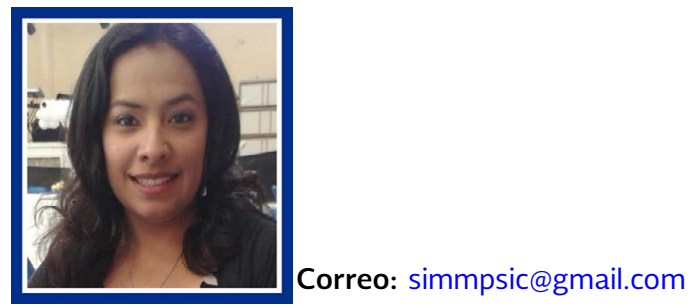

Doctora en Psicología en el área de la Salud por la UNAM, 2016. Licenciada en Psicología por la Facultad de Psicología de la UNAM; miembro del Grupo de Investigación en Procesos Psicológicos y Sociales en la UNAM FES Iztacala.

Ver más... 
E n un país como el nuestro, donde en el sistema de salud ha predominado una visión patologista, que se centra en la cura de enfermedades y no en la prevención de las mismas, es difícil que un psicólogo se inserte y además se reconozca la contribución que puede hacer para la promoción de la salud y la prevención de las enfermedades. Aún cuando la Ley General de Salud de México, publicada en 2007, determina que la investigación en salud debe identificar los procesos tanto biológicos como psicológicos relacionados con la salud, no se establece el rol del psicólogo en la investigación de los mismos. Los psicólogos que se han insertado en el campo tienen dentro de sus actividades las referentes a la evaluación y diagnóstico de trastornos psicológicos, funciones propias de un psicólogo clínico, de manera que el propio sistema de salud no contempla que el psicólogo es capaz de aportar en este ámbito para explicar por qué la persona enferma, predecir qué conductas se pueden modificar para prevenir que enferme, y llevar a cabo intervenciones preventivas y acciones de promoción de la salud.

Es necesario resaltar que el contexto de salud en México está definido por un aumento en enfermedades crónicas no transmisibles, asimismo que los costos que estas enfermedades causan a las instituciones de salud pública están mermando los recursos económicos e impactan en el desarrollo del país, dando como resultado mayor ausentismo laboral y pobre desarrollo personal debido a complicaciones cardiovasculares, hipertensión, diabetes, etc. De seguir con este panorama llegará un momento en que el sistema de salud no pueda atender a todas aquellas personas con una enfermedad crónica, degenerativa; por ello es importante redirigir los esfuerzos no sólo al tratamiento o control de las enfermedades, sino más bien enfocarse a la prevención de dichas enfermedades y promover conductas que hagan permanente el estado de salud del individuo, por lo que el libro que se presenta a continuación aborda y expone la relación de la psicología y la salud, y los factores a considerar para su consolidación en México.

El libro Psicología y salud: obstáculos y posibilidades para su desarrollo en el siglo XXI, es una obra realizada por el M. en C. Alfonso Piña; ésta fue publicada en el año 2015 por la Universidad de Sonora. El objetivo principal del libro es hacer una reflexión y una crítica sustentada en evidencias sobre aspectos relacionados con la psicología y la salud, que de forma general el autor delinea en tres puntos: el primero se refiere a la diferenciación de la psicología clínica y la psicología en el campo de la salud; el segundo alude al origen y características de los modelos teóricos utilizados en la psicología de la salud, y el tercero se enfoca en las competencias profesionales que debe desempeñar un psicólogo en esta área, centrándose en la prevención de la enfermedad y la promoción de la salud.

Esta obra está estructurada en cuatro capítulos que retoman los aspectos mencionados; en el primer capítulo se hace un recorrido por los antecedentes que se han marcado de forma tradicional como los principales ejes o hechos para el surgimiento de la psicología de la salud, se examinan la superposición de la psicología clínica y de la salud en términos de sus funciones, y se propone la diferenciación de ambas demandando tener claridad respecto a lo que la psicología aporta con relación a la salud, y no caer en el eclecticismo teórico que permea las definiciones actuales.

En el segundo capítulo se definen diversos conceptos como "modelo teórico", "paradigma" y "teoría" para dar paso a la definición de "psicológico" desde la visión del autor, y cómo es que lo psicológico se relaciona con los fenómenos de salud y enfermedad; apela a una propuesta teórica articulada en lo conceptual que posibilite la predicción de las conductas que favorecen la salud o que previenen que las personas adquieran enfermedades. En la segunda parte del capítulo se examinan modelos teóricos que se emplean en el campo de la salud, como el de creencias en salud (Rosentock,1974), la acción razonada (Azjen y Fishbein, 1980), biopsicosocial (Engel, 1977), integrado de cambio conductual (Fishbein, 2000); cada uno es analizado, desde la definición de sus variables, su congruencia conceptual y en la evidencia empírica que aporta a través de diversos estudios empíricos.

En el tercer capítulo se insiste en la importancia de lo psicológico en relación con la salud; este último concepto lo revisa y analiza desde diversos puntos de vista, para finalmente aportar una definición propia de la salud basada en la psicología interconductual, lo que permite abordar el modelo de salud biológica (Ribes, 1990), que se revisa de forma crítica y reflexiva desde sus supuestos teóricos, aplicaciones y limitaciones. Una vez establecido el modelo, se delimitan las funciones del psicólogo en la promoción, prevención y rehabilitación. 
El capítulo final retoma aspectos revisados en los tres anteriores para identificar cuáles serían las competencias que debemos formar en los nuevos profesionales en psicología; la propuesta contempla competencias teóricas y metodológicas que se enfocan a planear, evaluar e investigar, para promover, prevenir y rehabilitar en el campo de la salud. Esta empresa — afirma el autor- es un compromiso que se debe cumplir en aras de poder avanzar en la consolidación de este campo de actuación.

A manera de conclusión, este volumen se dirige a población que ya tenga conocimientos acerca del área; no es recomendable para lectores que empiezan a conocer el campo, debido a que es necesario conocer los antecedentes de la psicología de la salud, conocer y manejar los modelos teóricos que relacionan la psicología y la salud; asimismo, debe tener bagaje empírico y teórico que le permita seguir al autor en las disertaciones, reflexiones y propuestas que plantea acerca de los modelos teóricos revisados, para al final Ilevar a cabo una reflexión crítica de lo expuesto en los diferentes niveles de conocimiento, ya sea teórico, metodológico y prácti- co, de forma que el público estaría más bien en los profesionales que ya están insertos en el campo de acción o a los profesores que se encuentran formando profesionales en esta área, para hacer una reflexión de lo que el autor propone y clarificar las metas que se deben alcanzar en la formación de competencias en los jóvenes que están ingresando a las instituciones de educación superior con un programa de psicología que tiene una vertiente en salud.

\section{Referencias}

Azjen, I., \& Fishbein, M. (1980). Understanding attitudes and predicting social behavior. New York, Prentice Hall.

Fishbein, M. (2000). The role of theory in HIV prevention. AIDS Care, 12, 273-278.

Ribes, E. (1990). Psicología y salud: un análisis conceptual. Barcelona, Martínez Roca.

Rosenstock, I. (1974). Historical Origins of the Health Belief Model. Health Education Monographs, 2(4), 328-335.

Ir a Google Books para revisar la tabla de contenido del libro 
La edición en formato electrónico fue realizada en la Editorial LEED del Laboratorio de Evaluación y Educación Digital

Diciembre, 2015

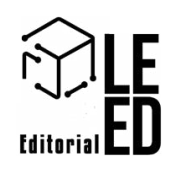




\section{(c) (i) (5) \\ BY NC}

Copyright: @ 2015 Revista Digital Internacional de Psicología y Ciencia Social

Esta es una revista de acceso abierto distribuida bajo los términos de la licencia

, por lo que su contenido gráfico y escrito se puede compartir, copiar y redistribuir total o parcialmente sin necesidad de permiso expreso de sus creadores con la única condición de que no se puede usar con fines directamente comerciales y los términos legales de cualquier trabajo derivado deben ser los mismos que se expresan en la presente declaración. La única condición es que se cite la fuente con referencia a la y a sus creadores.

2015, es una una publicación semestral editada por la Universidad Nacional Autónoma de México, tercer piso del edificio B de la of. admin. ext. de la Zona Cultural, Ciudad Universitaria, Coyoacán, C.P. 04510, Distrito Federal, Tel. (55) 5623-1333, Ext. \#39707,

.Editor Responsable: Arturo Silva Rodríguez. Reserva de Derechos al Uso Exclusivo No. 04-2016-012514394300-203, ISSN: (en trámite), ambos otorgados por el Instituto Nacional del Derecho de Autor. Responsable de la última actualización de este número, Laboratorio de Evaluación y Educación Digital de la Universidad Nacional Autónoma de México (UNAM), Facultad de Estudios Superiores Iztacala, Lic. José Manuel Sánchez Sordo, Av. de los Barrios \#1, Los Reyes Iztacala, Tlalnepantla Edo. de México. C.P. 54090, fecha de última modificación, 25 de enero de 2016. La difusión y soporte digital a cargo del Laboratorio de Evaluación y Educación Digital de la Universidad Nacional Autónoma de México (UNAM), Facultad de Estudios Superiores Iztacala. Las opiniones expresadas por los autores no necesariamentereflejan la postura del editor de la publicación. 